\title{
90 Day Trial Periods in New Zealand - The Impact on Young Unskilled Workers
}

\author{
by
}

Anthea Finlay

\author{
Submitted to the Victoria University of Wellington \\ in fulfillment of the \\ requirements for the degree of \\ Master of Commerce and Administration \\ in Human Resource Management and Industrial Relations
}

Victoria University of Wellington

2014 


\begin{abstract}
This thesis examines the early work experiences of low skilled youth against the background of the recently introduced 90 day trial periods legislation. A mixed method research approach was employed to survey young people's experiences of their early work careers, along with interviews with key stakeholders in the field of youth employment. From a sample of 100 self administered surveys from young people, the research finds that 90 day trial periods are not widely used for 15 to 19 year olds. Low incidence of use can be explained by majority of respondents being in part time or casual work. Where respondents were in full time employment trial periods are widely used, and they are more likely to be applied in a formal and long term manner by employers within the construction industry. The research concludes that while 90 day trial periods are one mechanism for increasing youth employment, they may not be the most effective as youth unemployment is a complex issue with systemic causes. The factors that contribute to youth unemployment are widespread and could be addressed by increased career advice in schools, a more comprehensive youth transition between school and employment and addressing the skills mismatch with employers needs in the workplace. Addressing these issues may have greater impact on youth unemployment than 90 day trial periods.
\end{abstract}




\section{Contents}

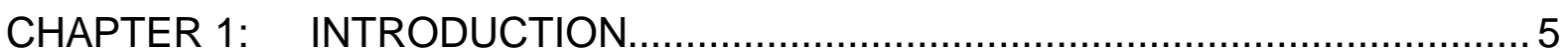

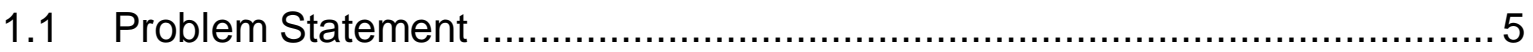

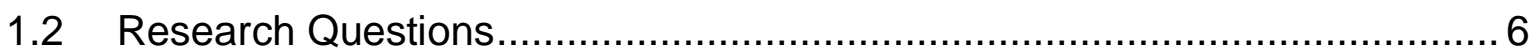

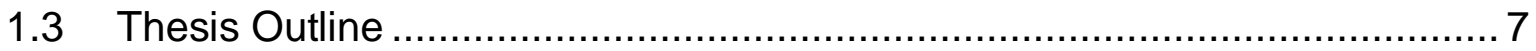

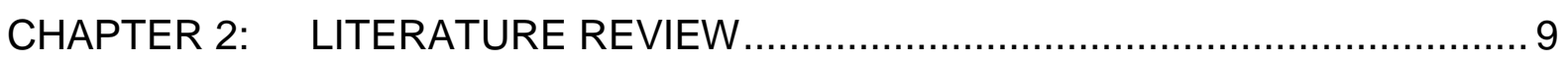

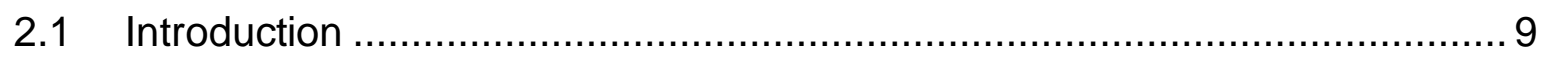

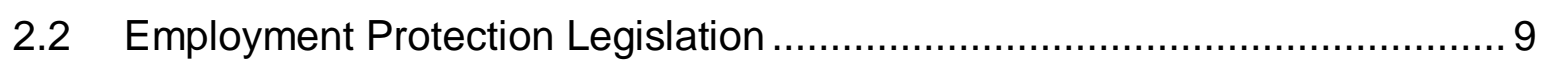

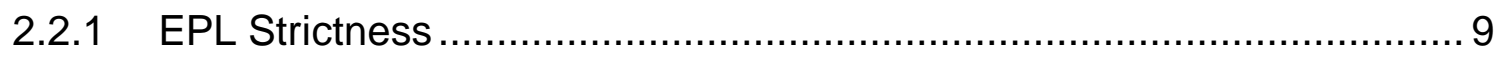

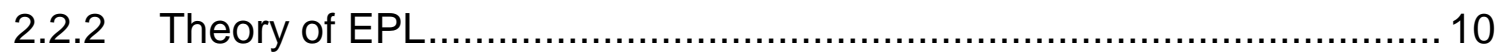

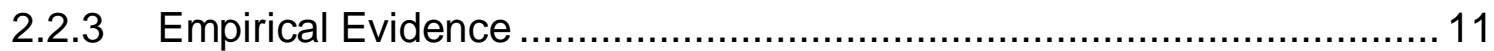

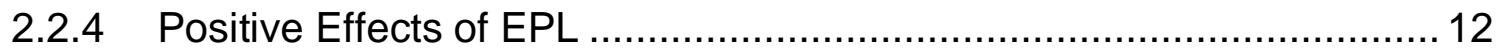

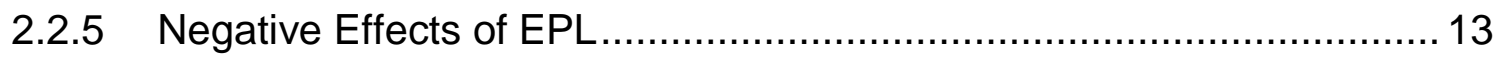

2.2.6 Active Labour Market Policies ..................................................... 14

2.3 The New Zealand Youth Labour Market................................................. 15

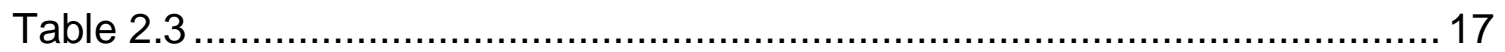

Unemployment and Employment Rates by Age ......................................... 17

Figure 2.3: Unemployment rate increases, youth and adults ${ }^{\mathrm{a}}$........................ 18

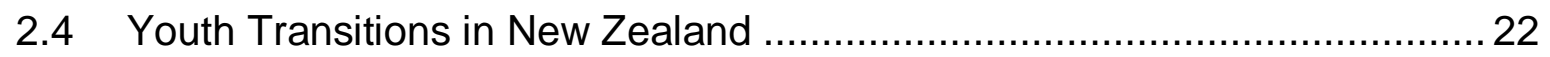

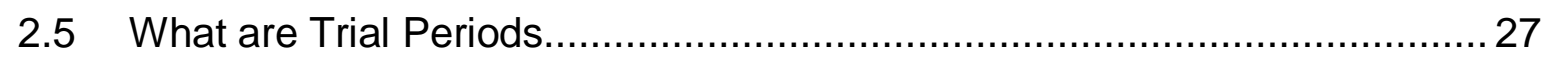

2.6 Why Introduce Trial Periods in New Zealand? .......................................... 30

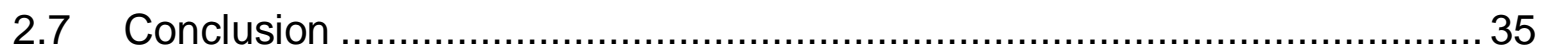

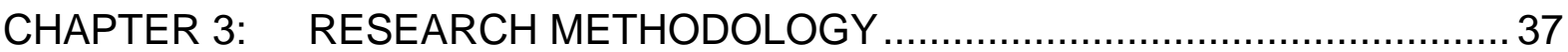

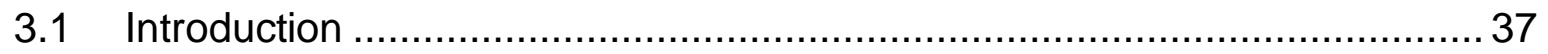

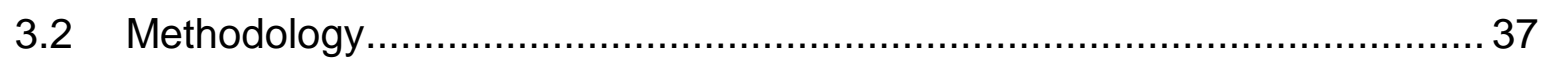

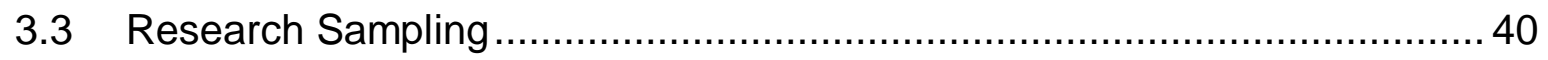

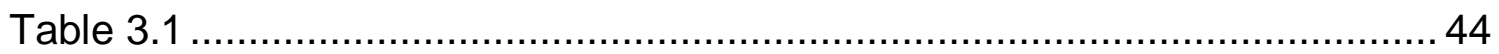

Employment and Unemployment Rates of People in Porirua City, Lower Hutt City and New Zealand in 2006 ................................................................... 44

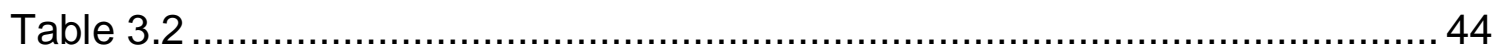

Employment and Unemployment Rates of People in Porirua City, Lower Hutt

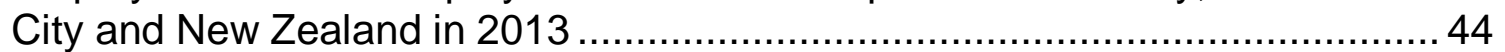

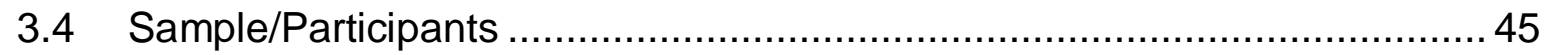

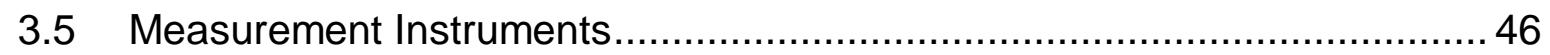

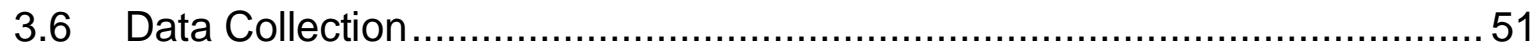

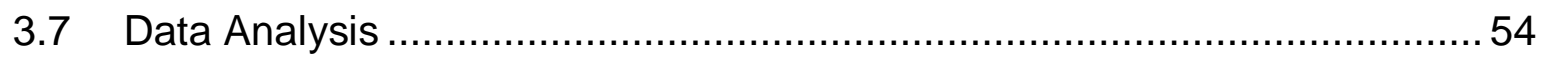




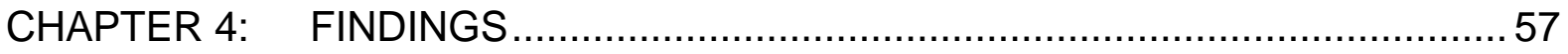

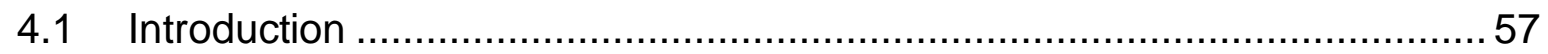

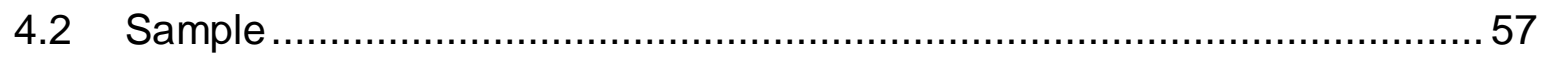

Table 4.1:

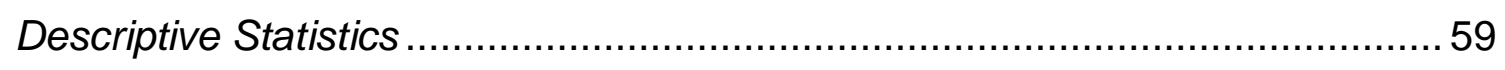

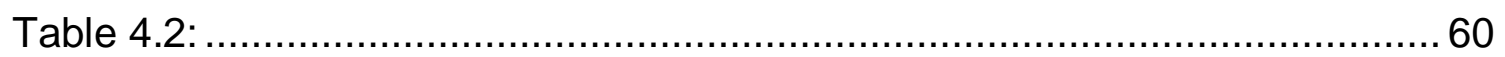

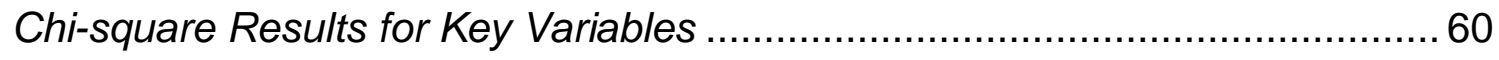

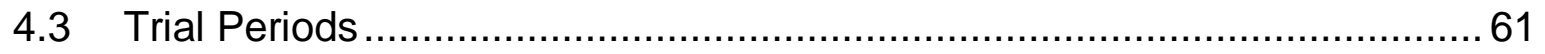

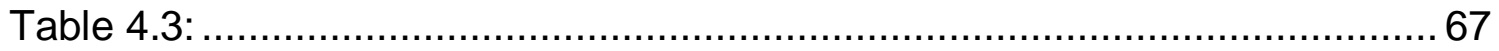

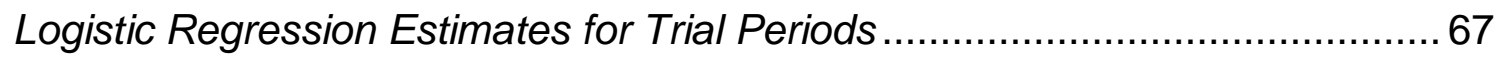

4.4 Characteristics of Employment........................................................... 70

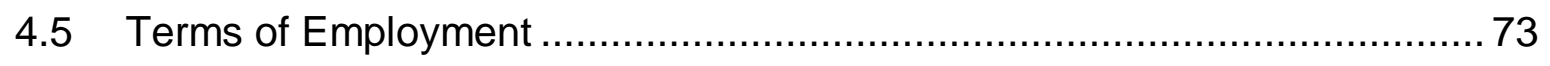

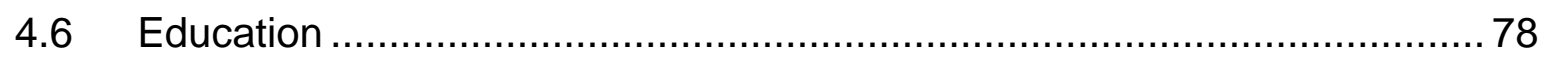

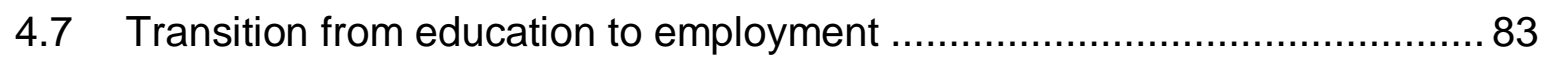

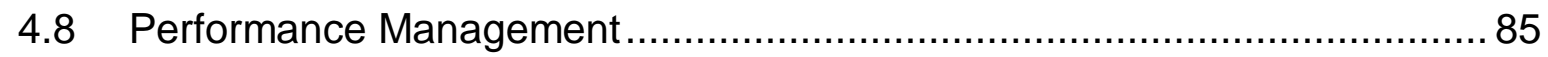

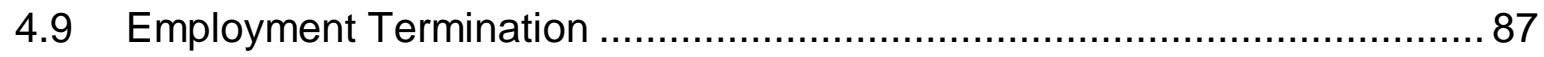

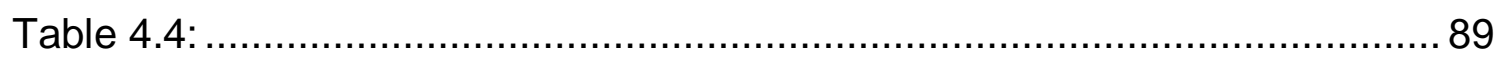

Logistic Regression Estimates for Termination of Employment …................... 89

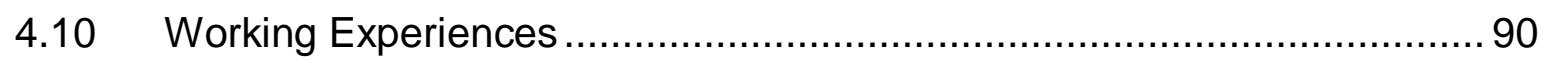

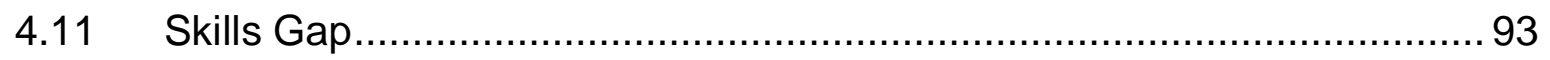

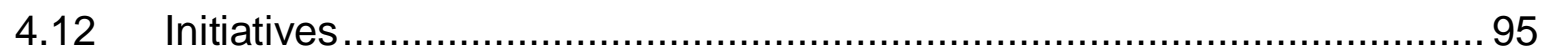

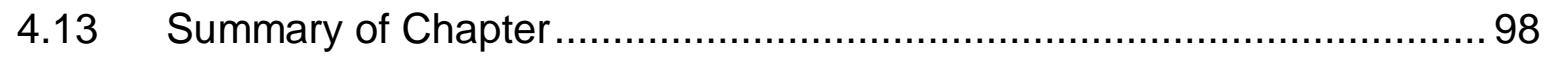

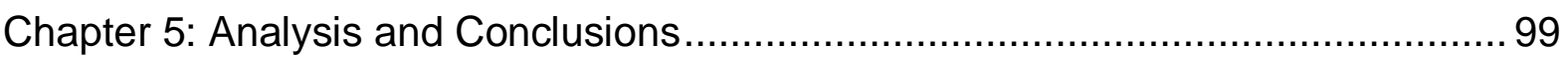

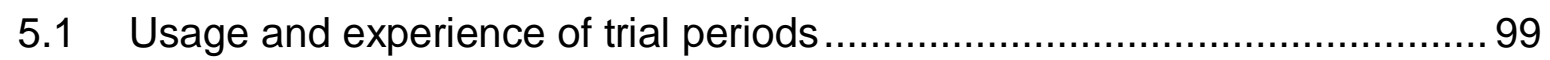

5.2 Young people's early labour market experiences................................... 102

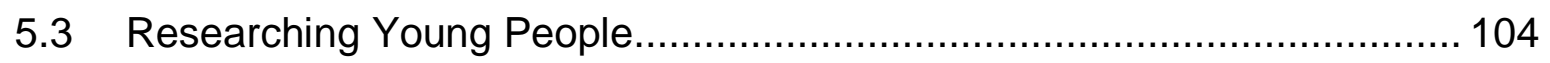

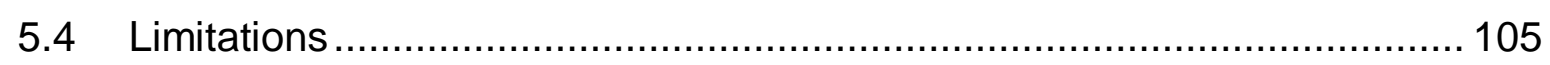

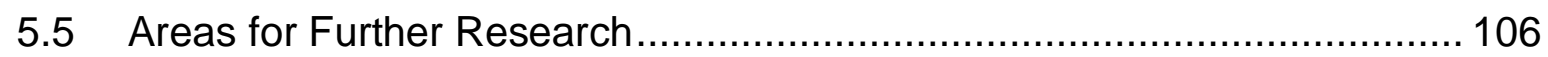

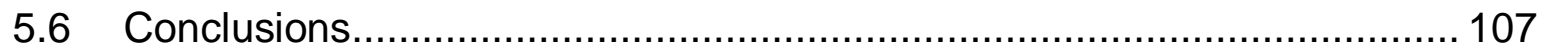

APPENDIX A: Strictness of Employment Protection Overall ............................... 109

APPENDIX B: Self Administered Questionnaire.............................................. 110

APPENDIX C: Stakeholder Interview Questions ……...................................... 125

APPENDIX D: Analysis of Trial Period Regression Estimates........................... 126

APPENDIX E: Analysis of Employment Termination Regression Estimates ....... 127

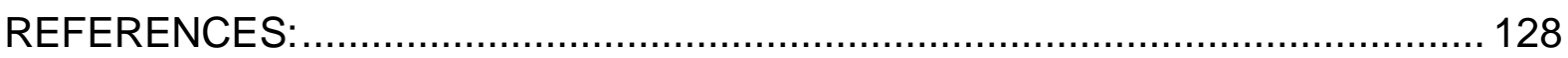




\section{CHAPTER 1: INTRODUCTION}

\subsection{Problem Statement}

Youth unemployment in New Zealand and globally is at previously unseen high levels (OECD, 2010). Young people, especially those aged 15 to 19 years, are vulnerable members of the labour force with few skills who are engaged in largely casual or part time employment (Department of Labour, 2009).

Various measures have been implemented to improve the employment opportunities for young people, and in New Zealand 90 day trial periods were introduced with the objective of reducing risks for employers in taking on unproven employees from vulnerable groups such as young people (Mapp, 2008; 2025 Taskforce, 2009).

Trial periods are a form of employment protection for employees and there are a range of views in the literature that strict employment protection legislation, such as strong dismissal laws, can restrict employers hiring new staff and therefore can have negative productivity effects (Autor, Kerr, \& Kugler 2007). However, relaxing employment protection legislation, while providing employers with more workforce flexibility and less risk in dismissals, can affect the composition of the labour force with a negative effect on vulnerable groups such as youth (Skedinger, 2010).

Early indications are that the introduction of 90 day trial periods in New Zealand has had a positive effect with employers increasing hiring as a result (Department of Labour 2010; Department of Labour 2012; Kaye-Blake, 2011). However, this research has been conducted from the employer perspective. There is a need for further research on 90 day trial periods from an employee point of view in order to understand the usage, process and outcomes of trial periods as a means of improving employment opportunities. In particular, a focus on young people in employment is important as they form a vulnerable group of people experiencing high unemployment levels and relatively poor transitions from education to employment (Boven, 2011). 
The purpose of this research is to determine the usage, characteristics and outcomes of employment for young people aged 15 to 19 years where they are employed under 90 day trial periods, and then to build a more comprehensive picture of early work experiences of this demographic group.

\subsection{Research Questions}

The research questions are: what is the usage and experience of trial periods in the employment of young people? And what are the challenges and experiences encountered by young people in their early labour market experiences?

These questions respond to an empirical gap in research on trial periods from an employee perspective as previous research has been concentrated on employer views and usage. Further to this, the questions recognise the current vulnerability of young people within the labour force, where they lack skills, experience and knowledge to allow them to successfully enter a competitive job market.

Trial periods form a subset of wider early youth employment experiences i.e. not all youth will experience the 90 day trial period. By examining both of these research questions the findings for trial period usage and outcomes can be contrasted against the more general experiences of young people entering employment.

This research will collate and analyse specific information on the usage and experience of trial periods and employment for those aged 15 to 19 years from their perspectives as youth employees. This research will also gather the views of stakeholders in the areas of youth employment, education and transitions to employment. 


\subsection{Thesis Outline}

In addressing the research questions the thesis is structured as follows:

Chapter 2 critically reviews the literature available and empirical evidence on the use and effect of employment protection legislation, characteristics of the youth labour market and the use and effects of trial periods. Use of this literature will build an understanding of youth transitions from education to employment. This in turn will identify variables for use in the self administered survey and inform questions for stakeholder semi-structured interviews.

Chapter 3 provides an overview of the methodological approach employed in this research. The focus of the research was on gathering statistical information from young people aged 15 to 19 years who are currently in employment or have been in employment recently. This information was gathered using a self administered survey. One hundred completed surveys were collected and this data provided a basis for a range of statistical analysis to determine details of significant variables, which are provided in Chapter 4 of the thesis. To qualify and provide context to the self administered survey five semi-structured interviews were conducted with selected key stakeholders in the field of youth employment. Both statistical data and qualitative data have identified key issues and themes in the area of youth employment, trial periods in particular, and have highlighted opportunities for further research in this field.

Chapter 4 presents the findings from the self administered survey analysed across key variables of age, gender, qualifications, ethnicity and hours worked, with more detailed statistical analysis of trial periods and termination of employment.

Chapter 5 combines findings from the self administered survey and stakeholder interviews to develop conclusions. Research findings are critically examined using the theoretical concepts and empirical evidence identified in Chapter 2. This chapter then examines the specific challenges encountered when conducting research with young people. It also outlines the limitations of the research and identifies areas for 
new research. The chapter discusses the relevance of the research findings and contribution that this research makes to the issue of trial periods and youth employment. 


\section{CHAPTER 2: LITERATURE REVIEW}

\subsection{Introduction}

In examining the concept and application of trial periods it is necessary to consider two significant areas of literature: the purpose and effect of employment protection legislation; and the characteristics of the youth labour market including the transition from school to work. At the intersection of these two areas is the under researched area of trial periods and the experiences of young low skilled workers of working in a trial period.

\subsection{Employment Protection Legislation}

Employment protection legislation (EPL) refers to any regulation that relates to the hiring and the dismissal of an employee. This is a broad range of legislation governing unfair dismissals, termination of employment due to redundancy, payment on separation, consultation requirements with employee representatives and minimum notice periods. (Autor, 2007; Cazes, 2003; Lazear, 1990; OECD, 2004; Skedinger, 2010).

The issue of how much employment protection to apply to the labour market, and the subsequent effect of doing so, is the subject of a large body of literature. The objective of employment protection legislation was originally a means of enhancing an employee's employment conditions and welfare, but it also represents a cost for business. Therefore the challenge for government is to achieve a balance between an employer's need to change and adapt to market and economic conditions, and an employee's need for employment protection and the subsequent level of involvement of the state.

\subsubsection{EPL Strictness}

The strictness of employment protection varies greatly between countries and over time. Variation between countries is calculated and presented by the Organisation for Economic Cooperation and Development (OECD) (2008) to show countries with 
a higher score representing increased EPL strictness (Appendix A). New Zealand has a low score on this table in terms of EPL strictness with only Canada, US and UK displaying less strict EPL.

Within the last decade there has been an increase in international competition and rapid technological change. As a result business needs to be able to adapt quickly to these changing conditions and therefore the balance of employment protection legislation is currently an important issue (OECD, 2013). In addition, high unemployment levels due to the economic recession means vulnerable groups, such as young people, are becoming excluded from the labour market. As a result a general global trend can be seen in the loosening up of EPL to allow speedier and less costly changes to businesses to meet these global influences and to create employment opportunities for vulnerable groups of the labour force (Skedinger, 2010).

Employment protection legislation in New Zealand is among the least strict within the OECD. Historically very low levels of EPL were reached following the introduction of the Employment Contracts Act in 1991, which removed the blanket coverage and monopoly bargaining right of unions, and introduced freedom of association into workplaces (OECD 2008). EPL strictness in New Zealand increased slightly with the introduction of the Employment Relations Act in 2000. This Act reverted to promoting collective bargaining, requiring good faith in all bargaining, promoting mediation to resolve employment disputes and limiting the use of fixed term agreements by requiring a valid reason for their use.

\subsubsection{Theory of EPL}

The theoretical assumptions underpinning EPL show that an employee has less chance of losing their job in a strict EPL environment. Overall this means an increase in employment through fewer dismissals. However, this also means that employers will take more care and consideration in the decision to hire new employees and therefore will restrict future hiring. Theoretical assumptions also indicate that those who are vulnerable, such as new entrants and immigrants, feel the negative effect of EPL as employers are more selective in their employment 
decisions and choose not to hire them (Skedinger, 2010). In contrast, EPL can increase the duration of employment for employees who are in permanent roles, and can increase periods of unemployment for others who may be employed on a temporary basis or with irregular hours (Skedinger, 2010). Autor (2007) predicts that EPL will reduce productivity by limiting business choices in the means of production; if employers face high dismissal costs they will maintain hiring levels at a level below optimum efficiency and will be forced to retain unproductive employees. Funk (2003) makes a case for less restrictive EPL creating additional employment as employers have less cost and risk in employing new staff. This report finds that in a labour market where economic shocks such as a recession occur the effect of strict EPL is increased. This is due to small and/or new businesses reluctance to hire in an uncertain environment coupled with higher dismissal costs. Bentolila, Dolado and Jimeno (2012) follow this line of thinking in examining Spain's extremely high unemployment rate. Chronic labour market problems were attributed in part to a dual labour market made up of those covered by rigid collective bargaining systems and large numbers in temporary, less protected employment. Efforts to loosen EPL resulted in little change in unemployment rates, with the suggestion that a lack of significant change in active labour market policies failed to support transitions back into the labour force.

There are two models commonly applied to EPL, the "competitive model" theory assumes the existence of self interested parties who will seek to maximize profits and therefore encourages competition, and the "equilibrium model" which assumes there is a set of circumstances that will result in equilibrium over interacting variables. (Autor, 2007; Lazear, 1990; Leonardi \& Pica, 2007). The ongoing intervention and balancing of EPL against economic circumstances seen throughout the supporting literature strongly supports the quest for an equilibrium approach, although empirical research is needed to test this theory as outcomes are difficult to predict with numerous variables present (Skedinger, 2010).

\subsubsection{Empirical Evidence}

These theoretical assumptions are tested well within the literature in a variety of settings, economic conditions and methodologies. Addressed are outcomes 
associated with introducing employment protection (Brugemann, 2006; Lazear, 1990) and descriptive analysis of the effects of the dramatic removal of EPL on the vulnerable members of the workforce (Elton, 2007). Brugemann (2006) considered the actions of employers faced with the pending introduction of stricter EPL. This quantitative analysis of both United States (US) and United Kingdom (UK) employers examined whether employers acted to take advantage of the opportunity to lay off employees before EPL made it difficult and costly to do so. Brugemann (2006) found evidence of this behavior and that through this reaction the effect of the introduction of EPL could be to reduce employment. Similarly, Lazear (1990) considered the issue of the effect of state intervention in the labour market across 22 developed countries. Lazear (1990) found that employment population did reduce as a result of EPL and that the effect was largely the result of the transformation of full time into part time jobs. This occurred as part times roles retained an exemption from severance protection, although this effect was seen inconsistently over the 22 developed countries examined.

The empirical evidence suggests that employers will act to avoid strict EPL, or to maximize the advantages presented by a loosening of EPL, in order to maximize benefit for their organisation.

\subsubsection{Positive Effects of EPL}

Further empirical evidence (Autor, 2007; Cazes, 2003; Harding, 2002; OECD, 2004; Skedinger, 2010) identifies the benefits of EPL in dampening employment fluctuations and creating a more stable labour market. Additionally making internal changes is more cost effective in a strict EPL environment than making costly structural changes to the labour force, therefore strict EPL can result in a deepening of business investment in capital and in current employee skills, with resulting increases in organisation productivity. On a macro level EPL can provide a labour market stabilizing effect and can protect and mitigate discrimination against vulnerable workers.

And as Cazes (2003) notes: 
Stricter EPL ensuring higher job stability should enhance aggregate productivity through better enterprise adaptation, technological progress and a constant training of workers while simultaneously ensuring higher income equality and fighting against discrimination. The overall effect is expected to be improved economic performance and living standards of the population (p.3).

\subsubsection{Negative Effects of EPL}

A significant negative of strict EPL is the creation of duality in the labour market where 'insiders' are secure in their employment, but 'outsiders' have difficulty breaking into, or staying in the labour market, as there is more likelihood of temporary or casual employment. These outsiders are commonly those who are vulnerable and include the unemployed, immigrants, young people and those with disabilities. The review of levels of strictness of EPL in Cazes (2003) found evidence over a number of countries that the stricter the EPL the more likely there was to be duality and inequality in the labour market. With strict EPL, markets become more rigid and more inequality is evident (Harding, 2002; Kugler \& Saint-Paul, 2000; OECD, 2004).

Thus, the overall effect of EPL is largely ambiguous, with no clear link to productivity or employment rates, however there is evidence to suggest that it does tend to stabilize labour market fluctuations (Cazes, 2003; Lazear, 1990; Skedinger, 2010). It is clear that EPL does have an effect on the composition of the workforce (Garibaldi, 2002; OECD, 2004; Skedinger, 2010). Stricter EPL will favour those who are established in the labour force and will have a disproportionate effect on those who have a weaker link to the labour market, such as middle aged women and youth who will encounter more entry problems to employment. Therefore the demographic mix of the labour force will reflect this. A focus on youth through rebalancing employment protection to create opportunities for them and to reduce duality in the market can theoretically be achieved through relaxing employment protection laws surrounding dismissals (OECD, 2004).

The empirical evidence shows that it is not a simple matter to apply EPL to a labour market and obtain the correct balance of employee security and business flexibility and this is where the concept of flexicurity is useful. Flexicurity began as a 
European concept to address the pressures of globalisation within Europe. What is notable is the development of new technology requiring adaptive and innovative businesses combined with the demographic aging of the European workforce, high levels of long-term unemployment and increasingly segmented labour markets with "insiders" being secure and well protected and "outsiders" made up of vulnerable groups of youth, women and older workers having difficulty entering and remaining in the labour market. These factors combine to increase the need to address labour market pressures for flexibility for employers and employment security for employees. The concept of flexicurity was well defined in Wilthagen and Tros, 2004:

Flexicurity is (1) a degree of job, employment, income and 'combination' security that facilitates the labour market careers and biographies of workers with a relatively weak position and allows for enduring and high quality labour market participation and social inclusion, while at the same time providing (2) a degree of numerical (both external and internal), functional and wage flexibility that allows for labour markets'(and individual companies') timely and adequate adjustment to changing conditions in order to enhance competitiveness and productivity (p.170).

Evidence shows that in a situation of strictness of EPL varying based on the size of organisations, smaller businesses are reluctant to grow and maintain their staffing levels at the legislated threshold. Garibaldi, Pacelli, Borgarello (2003) provide evidence of this in Italy where the primary remedy for wrongful dismissal is monetary compensation for the ex-employee in businesses with up to fourteen employees, but once the threshold of fifteen employees is reached the primary remedy is reinstatement of employment. Interestingly the size of firms was also examined in Harding (2002) where stricter EPL was introduced to small to medium sized organisations. In this case it was found that the extra protections and processes afforded by EPL had resulted in employers developing more thorough recruitment and staff management processes which had increased transparency and fairness to employees. However, the downside was that more temporary employment arrangements were used, and lengthier probation periods were applied.

\subsubsection{Active Labour Market Policies}

The effects of EPL can be made more or less effective with the concurrent use of active labour market policies (OECD, 2004). Active labour market policies (ALMP) 
facilitate the transition from unemployment to employment through the use of a range of interventions such as job search assistance, vocational training, job creation schemes, employment subsidies and job placement schemes. These policies are designed to improve the employability of those who have a weak link to the labour market. ALMP and EPL can be designed as complementary policy tools but the relationship between the two may not always be clear. For example strict EPL limits employers hiring, and ALMP facilitates individual transitions into work - therefore EPL reduces the effectiveness of ALMP (OECD, 2004). Therefore, with ALMP in the labour force it may be difficult to see the effectiveness or otherwise of EPL.

Theory and empirical evidence indicate that loosening EPL can benefit vulnerable groups with a weak connection to the labour market and this is the approach taken in New Zealand with the introduction of 90 day trial periods. However, the overall evidence of EPL is that the effect on employment levels is ambiguous, and is also affected by other variables in the labour market such as ALMPs and economic trends affecting industry. It is therefore unclear how much effect 90 day trial periods will have on increasing employment opportunities for young people in particular.

In conclusion the literature relating to EPL shows that although the overall effect on productivity and employment levels is ambiguous, it appears clear that increasing or decreasing EPL will have an effect on the composition of the workforce. Levels of ELP tend to have a more significant impact on small and medium sized organisations as strict EPL represents higher business costs, therefore loosening of EPL may provide more benefit for small and medium sized organisations. Overall the effectiveness of EPL is influenced by the existing nature of labour markets, including ALMPs which may work in a complementary manner or to undermine EPL changes.

\subsection{The New Zealand Youth Labour Market}

The youth labour market has distinct characteristics from the rest of the labour market. There are particular youth employment trends that can be seen in New 
Zealand, as well as internationally, such as: industries where youth are more prevalent, patterns of employment, increased migration to pursue employment and educational opportunities and increasing multi-culturalism (Department of Labour, 2009; Dupuis \& McLaren, 2006; Fenton \& Dermott, 2006; Marks, 2006; OECD, 2010; Zhou 2009/10).

Youth are defined internationally and within New Zealand as those aged between 15 and 24 years. However within this age range there are significant differences, for example most 15 year olds will be living at home and still in education, whereas most 24 year olds will be living independently and will be in the workforce on a more full time basis (Department of Labour, 2009).

The focus of this literature review is on the lower range of youth, which is from 15-19 years of age. The rationale behind this is that this group are unique in many ways. Across OECD countries youth aged 20 to 24 years tend to have similar rates of employment and similar trends in their transition to full time careers. By contrast, youth aged 15 to 19 years in New Zealand fare worse than their counterparts in other OECD countries in terms of unemployment rates. In comparison with their peers in other OECD countries, youth within the age group 15-19 years in New Zealand tend to leave school at an earlier age and then make a relatively poor transition into employment (Boven, Harland \& Grace, 2011).

The profile of this age group is also unique in that they have a lower labour force employment rate than other age groups as many of them will continue to participate in further education (Household Labour Force Survey, March 2008). This age group have a high unemployment rate compared to the whole working age population, and have an increased vulnerability in the labour force (OECD, 2010). Overall those aged 15 to 19, compared to other age groups, have a higher unemployment rate and a correspondingly low labour force employment rate as seen in Table 2.3. This shows that those in the 15-19 age group have a labour force employment rate of $43.6 \%$ which is significantly lower than all other age groups, with the exception of those 65 and older. Table 2.3 also shows that 15 to 19 year olds have a corresponding high unemployment rate of $25.6 \%$ which is significantly higher than all other age groups. 


\begin{tabular}{|c|c|c|c|c|c|}
\hline Unem & ployment & and Employn & nent Rates by Age & & \\
\hline$\underline{\text { Age }}$ & Employed & $\underline{\text { Unemployed }}$ & Labour force Employment rate & Employment Rate & $\underline{\text { Unemployment rate }}$ \\
\hline & $(000)$ & $(000)$ & $\%$ & $\%$ & $\%$ \\
\hline $15-10$ & 99.2 & 34.2 & 43.6 & 32.4 & 25.6 \\
\hline $20-24$ & 219.1 & 26.7 & 74.7 & 66.6 & 10.9 \\
\hline $25-29$ & 225.7 & 17.2 & 81.7 & 75.9 & 7.1 \\
\hline $30-34$ & 214.0 & 12.8 & 81.6 & 77.0 & 5.7 \\
\hline $35-39$ & 218.7 & 11.8 & 83.4 & 79.1 & 5.1 \\
\hline $40-44$ & 252.3 & 11.6 & 84.9 & 81.1 & 4.4 \\
\hline $45-49$ & 255.6 & 12.7 & 86.3 & 82.3 & 4.7 \\
\hline $50-54$ & 253.9 & 11.5 & 86.8 & 83.0 & 4.3 \\
\hline $55-59$ & 209.4 & 8.8 & 82.5 & 79.2 & 4.0 \\
\hline $60-64$ & 159.9 & 7.2 & 70.6 & 67.6 & 4.3 \\
\hline $65+$ & 115.1 & 2.0 & 20.1 & 19.7 & 1.7 \\
\hline
\end{tabular}

Source: Household Labour Force Survey, March 2013

This higher unemployment rate can be largely attributed to remaining in education for longer, the nature of the occupations they are employed in (sales, service and retail), and to the fact they commonly have less skills and experience than other members of the labour force. The effect of these factors combined means youth employment levels are vulnerable to economic downturn.

In 2008 New Zealand rated well in regard to youth employment compared to other OECD countries with less than $10 \%$ of young people aged 15 to 24 unemployed in New Zealand, compared to over $14 \%$ over all OECD countries (OECD, 2008). At this time New Zealand was regarded as having a very flexible labour market which helped to lift overall employment rates, including those for young people (OECD, 2008). OECD (2010) identified a significant change in the labour market with employment rates for youth falling more than for other groups of employees both internationally and within New Zealand. The review demonstrated that in most OECD countries youth unemployment had increased more than the adult rate, but New Zealand was among six countries where the youth unemployment rate was triple the adult rate as seen in Figure 2.3. This shows that in New Zealand the unemployment rate for those 25 to 54 years of age increased by $2.5 \%$ between 2008 and 2010 . In 
contrast the unemployment rate for those aged 15 to 24 years increased by over $7.5 \%$ over the same time period.

Figure 2.3: Unemployment rate increases, youth and adults ${ }^{a}$

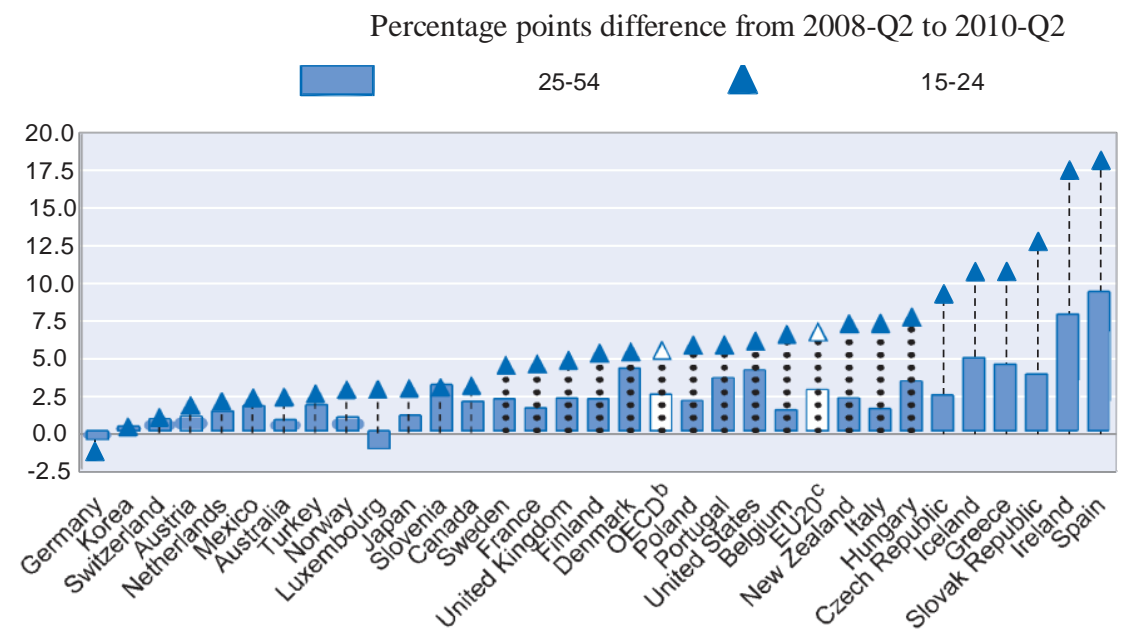

a) Non-seasonally adjusted data. Data for Switzerland refer to the second quarter 2009 and 2007.

b) Unweighted average of countries shown.

c) Unweighted average of the 20 OECD and EU member countries.

Source: OECD 2010 National labour force surveys.

However, the review commented that although youth unemployment numbers were high compared to other OECD countries, New Zealand has a dynamic youth labour market with a very low incidence of long term unemployment (OECD, 2010). Overall the economic recession has hit New Zealand youth hard, the industries they are commonly employed in have suffered and employers have reacted by limiting future employment, therefore young people are missing out on opportunities to enter the labour market.

There are distinct characteristics of the youth labour force in New Zealand in regard to the type of industries and occupations they are employed in. Working youth are over represented in low skilled industries, such as sales, service and retail. These are easy occupations to gain entry to as there are generally no educational qualifications or technical skills required, and jobs are often part time or casual, which allows work and ongoing education to be balanced. Youth tend to be clustered in the retail trade or hospitality industries, and at December $200839 \%$ of employed 15 to 19 year olds worked in retail, and $13 \%$ worked in hospitality 
(Department of Labour, 2009). Employment in the construction industry for youth grew by $40 \%$ from 2003 to 2008 and this was the fastest growing area, followed by communication services at $27 \%$ and retail at $21 \%$ (Department of Labour, 2009).

The way in which young people are employed also makes them vulnerable to economic downturn. Department of Labour (2009) shows that in New Zealand youth are more likely to work on a part time or casual basis to enable education or training, with $66 \%$ and $46 \%$ of employed young females and young males, respectively, holding part time jobs. The differences due to gender tend to be because more females are involved in ongoing education. Tenure for young employees is generally shorter than for other groups, with the length of employment being a matter of months rather than years (Department of Labour, 2009).

A particularly vulnerable sub-group within youth are those at school and working on a part time basis. The rates of employment of this sub-group are estimated to be between $31 \%$ and $50 \%$ of school aged people who work part time during the school term (Caritas, 2003; Gasson, Linsell, Gasson, Mundy-McPherson, 2003; Meyer, McClure, Weir, Walkey, McKenzie, 2009). The rate of employment for these students increases as they age, with the highest rates of employment being for those 13 years and older (Gasson, 2003). This group of working students tend to be from high decile schools and are mostly NZ Europeans (Gasson, 2003). The majority of these young people work less than 6 hours per week, with $21 \%$ working 12 or more hours per week (Gasson, 2003). The tasks they are engaged in tend to be low level with most employed in cleaning, child care, gardening and paper delivery; as these young people get older they tend to move more into the retail and hospitality industries (Caritas, 2003; Department of Labour, School Children in Paid Employment, 2010a). In particular it was found that this group of employees experienced poor and sometimes hazardous working conditions (Anderson, 2010), with high rates of workplace injuries (Caritas, 2003) and a lack of knowledge, training and supervision in safety and health (Department of Labour, 2010a).

The New Zealand statistics echo the youth labour market internationally with a marked trend to non-standard work, defined by Dupuis (2006) and Marks (2006) as any deviation from the standard arrangement of 40 hours per week for the same 
employer with an expectation of ongoing employment. The youth labour market is typified by part time, casual and temporary work arrangements. The question is whether these working patterns are detrimental to employment prospects, or provide opportunities to enter a tight labour market.

Evidence exists that youth transitions into employment are less linear now than in the past, they are also more complex and individualistic (Dupuis, 2006; Fenton, 2006; Zhou 2009). Zhou (2009) provides evidence that this change and fragmentation is a negative for youth, that it leads to ongoing non-permanent employment and employees reluctant to enter the labour force. In addition, the literature suggests that many young employees would prefer to be in full time and permanent employment and non-standard forms of employment are "a labour market adaptation, rather than a destination of choice" (Dupuis, 2006). It is also argued that these fragmented employment patterns among young people highlight genderrelated and socio-economic disadvantage (Fenton, 2006) as employment fragmentation is seen more frequently among young people with low qualification levels and in poorly paying jobs. Supporting these findings Holzer \& LaLonde, (1994) present evidence that frequent job changes are not often beneficial, and in fact for low skilled young people these transitions are more likely to be from a job to unemployment, rather than from one job to another. These frequent transitions were found to have a negative effect on young people through significant losses in earnings over time as experience in the labour market is reduced.

However, these negative findings are in the minority in the literature reviewed, with several pieces of research based on longitudinal studies showing that non-standard employment can provide satisfactory outcomes for youth (Higgens, 2002; Marks, 2006; Rea \& Callister, 2009). While working non-standard hours youth display a higher commitment to education and to finding work; they are extremely proactive and have a high level of consciousness of the choices they make (Higgens, 2002). Perceptions that youth within the labour market are "milling and churning", not pursuing further education, continually moving from one low paid job to another, are overly pessimistic and not the complete view (Marks, 2006). A positive by product is that young people are remaining in education for longer and although they are 
postponing their entry into the labour market, they are better positioned to do well when they enter it (Rea, 2009).

Increased part time or temporary work can provide a stepping- stone to permanent full time work and higher wages and a movement from a series of temporary jobs to more long term employment can be associated with large wage gains through making multiple transitions. This research provides evidence that job mobility has an important role in career development for young people (Topel \& Ward, 1992):

Our evidence is that the process of job changing among young workers, while apparently haphazard, is a critical phase in workers' movement towards the long-term, stable employment relations that characterize mature careers ( $p$. 443).

This phenomenon of 'job sampling' is a recognised part of youth transition into the labour market and may be interspersed with periods of unemployment, casual or temporary work (Rea, 2009). Rather than being an ongoing trap, part time work plays an important part in up-skilling young employees and increasing their employability, therefore often leading to more permanent and full time work opportunities. This literature also provides evidence that it is preferable to be in part time employment than be unemployed as lengthy periods of unemployment decrease future opportunities in the labour force (Gregg \& Tominey, 2005). However, full time work is shown to provide better outcomes for employees than part time work. Full time employees are more likely to have higher earnings, higher levels of satisfaction, hold higher levels of skills, and be in professional or managerial roles (Marks, 2006).

The benefits of temporary jobs in providing steps for a transition to stable employment were outlined by the OECD (2010), with temporary jobs being seen in a positive light for young workers in some situations. It was noted that transitioning from temporary to permanent employment in this way was more likely for those with tertiary qualifications. A positive correlation was evidenced in transitioning from temporary employment to permanent employment, with particular reference to Belgium and Australia where it was found that those holding temporary employment had an increased likelihood of securing permanent employment at a later stage. 
Further to this, little evidence of young people being trapped in a cycle of temporary work was found in the New Zealand youth labour market (OECD, 2008).

Overall it seems that non-standard employment does not inhibit the future prospects or ambitions of young people as described in Dupuis (2006):

Rather, non-standard work was incorporated into the lives of these workers as a way of dealing with the changing and increasingly dynamic nature of New Zealand's labour market and the equally dynamic changes in the lives of young people as they negotiated employment pathways and the expectations of adult life that are very different from the linearity which characterised the employment and life expectations of their parents' generations (p.34).

Correspondingly the OECD report (2008) found that:

Temporary work is increasingly common among youth for their first job but, in contrast to the situation in other OECD countries, conversion rates into permanent work are high. It also seems that most youth appreciate the flexibility afforded by casual work arrangements (p.18).

Youth employment in New Zealand is typified by non-standard hours and low skilled jobs within the retail and hospitality industries. These employment characteristics mean they are vulnerable to economic downturn and exploitation.

\subsection{Youth Transitions in New Zealand}

Youth transitions from education to employment have changed over time, largely due to economic conditions. In New Zealand's post war years the education system channeled youth into apprenticeships, or into specific occupations depending on gender and socio-economic background. Only an elite few went on to university. At this time there was full employment in New Zealand and consequently there were ample opportunities for school leavers, and they tended to enter the labour force at an early age. This was a linear and narrow process with a limited range of options for school leavers. At this time apprenticeships were a numerous and popular option as they provided on the job training, and an entry into the labour force without facing competition from older, more experienced job seekers. Transition policies were a powerful sorting mechanism, and the associated infrastructure established avenues 
for youth to access opportunities shaped by employment focused on farming and manufacturing (Higgens, 2002).

But by the mid 1970s economic conditions changed and these transition policies were not equipped to deal with rising unemployment. Efforts were made to change transition policies to aid a return to full employment through private sector wage subsidy schemes and public sector job creation. At this time young people still faced a linear transition from education to employment

During the 1980s and 1990s a change in focus was made to a model of transition, which would establish a well functioning education system and labour market, therefore policies were directed at creating a competitive environment in both these areas. There was a focus on skills deficits in industry, subsequently education initiatives were planned with the objective of building up skills in the labour force. From this point transitions became more complex with a less linear pathway for young people, and a focus on balancing ongoing education with employment (Higgens, 2002). This trend has continued and shaped the current transition policy in New Zealand which involves multiple transitions and more complex decision making. Transition support into employment is provided for young people in the form of Modern Apprenticeships, the Gateway programme and youth transition services. These programmes and support channels facilitate young people into trade occupations, provide workplace experience to school students and provide one to one, or group transition support (OECD, 2008).

These programmes recognise that youth no longer experience a linear transition into the workplace, but that they now face a more complex and fragmented education and labour market experience. For example, in the past apprenticeships provided a channel for large numbers of youth to train, earn a wage and gain a qualification. The choices were narrow, there were low wages and a slow transition and this was a more predictable transition from school to work (Higgens, 2002; Vickerstaff 2003). Currently, youth experience more individualistic and flexible pathways with greater variability in outcomes (Higgens, 2002; OECD, 2008). 
It is clear how important the transition is from leaving school into early labour market experiences and the process of transition is covered by a range of literature. The way youth make this transition has changed over time as outlined in Rea (2009):

Compared to more recent cohorts, young people born from the mid 1950s to the late 1960s spent less time in education, moved into full time employment at younger ages, had higher personal incomes when aged 15-24, were less exposed to unemployment, were less mobile, and were more likely to marry and have children at younger ages (p. 29).

The state of the labour market at the time of making the transition into employment is a key influencer of these differences. For example, poor labour market opportunities for youth in the early 1990s led to an increase in unemployment levels, higher benefit receipt rates and reduced incomes over time.

The transition from school into the labour market is a challenging time for youth, it is seen that they function best when they have support in navigating employment and training options (Hodkinson, 1996). This may be from a training provider, career guidance counselor, agencies or family members. For example, case study research showed youth performing well under supported and formal trial periods, however when this support was removed the employees demonstrated a change in attitude with resulting difficulties in work relationships and communications (Hodkinson, 1996).

The research also indicates that another important factor in determining outcomes in employment is the home or educational environment. Positive experiences and support at the transition from school to work have a positive bearing on outcomes, such as employment stability and labour market performance overall, and can increase the attachment of less skilled youth to the labour market at an early stage (Holzer, 1994). Demonstrated success factors in youth transitions were the ability to utilise their family networks to enable resources and create work opportunities. This family support is a form of cultural capital and this support can also assist with channeling decision making; some options are ruled out and others are encouraged (Higgens, 2002). Familial knowledge and resources can be more valuable than financial resources and transitions can be supported and influenced by them (Ball, 
Maguire, \& McRae, 2000). There was strong evidence of resilience among the youth sampled who had received support, they received many knock backs in their early employment and unpredictable changes occurred which changed their plans. However, they displayed resilience and were able to identify and move on to other opportunities over time by drawing on the support of those around them and by altering their career aspirations - often to an occupation more suited to their personal interests or skills (Hodkinson, 1996). They were also able to demonstrate high levels of ongoing commitment to their training and employment plans, perhaps because the emphasis was on them managing the transition process more actively than other generations have (Higgens, 2002; Hodkinson, 1996).

A further strong theme within the literature is that young people often have only vague career plans at the time of leaving school and do not feel well prepared for entering the labour market. There is a difference seen in career choice maturity between young people, and one of the key influences on this is family and their affluence level (Ferry, 2006). This research found that in the more affluent schools surveyed young people had defined career goals and a plan of how to achieve them, whereas in the less affluent schools a lack of career decision was the norm. Those in this situation responded positively to transition programmes designed to allow them to sample a variety of different occupations. Generally this group displayed unrealistic career goals and needed to gain a better understanding of the working world to then allow them to make more informed decisions. Overall it seems that amongst many young people their career choice tends to be based on 'whim and opportunity' rather than on any clear career objective (Hodkinson, 1996) and it may be unrealistic to expect that all young people should have clear career goals by the end of secondary schooling (Super, Savicks \& Super, 1996).

The role of the education system is clearly important in preparation of students for the workforce, by providing career counseling, teaching useful skills, shaping realistic career goals and by providing support through the early stages of a transition to the workforce. Boven (2011) finds the New Zealand education system lacking in supporting this transition to the workplace and concludes that this is a contributor to the high rate of youth unemployment in New Zealand. The differences in rigour between schools in career counseling are marked and youth tend to commence 
courses or employment they are not suited to and do not achieve a successful outcome.

Literature on the skills mismatch between young people entering the workforce and employers' needs show that young people often: lack the knowledge to present for an interview well; experience limited means of access into organisations; have a scattergun approach to seeking employment which shows a lack of aspirations and career direction; and have low levels of confidence in the employment process (Rudiger, 2013). The view is that this skills mismatch is a significant cause of youth unemployment and there is a need for more comprehensive transition support. In addition, there is a need for employers to recognise there is a business case to invest in young people as employees by thinking more strategically about future workforce planning. Anticipating demographic changes is an important factor for employers. An expected reduction in the population of young people and increased numbers of aging, and therefore retiring employees, will create an urgent need to increase investment in training and developing young people in the labour force (Rudiger, 2012).

The reviewed literature strongly supports the view that young people's early work experiences are valuable in terms of future employment prospects. In particular early work experience results in a greater sense of responsibility, an increased understanding of work requirements, the enhanced use of initiative and more effective interaction with colleagues and customers (Education and Employers Taskforce, 2012; Smith and Green, 2004). These experiences produce a more work ready employee, with knowledge and experience providing advantages beyond qualifications alone. Additionally early work experience was shown to result in more informed decisions about future training and career direction (Smith, 2011; Taylor, 2004).

Today young people in New Zealand and globally face a situation of low wages and precarious employment after leaving school. Therefore the area of youth transition to employment has received intervention in terms of training programmes and work initiatives - differing depending on the view of the day, and the economic circumstances (Deakin, 1996). 


\subsection{What are Trial Periods}

A trial period is a fixed term monitoring period of employment imposed on a (typically) new employee. The objective is primarily to gather more information on that employee's ability and therefore productivity, as defined in Loh (1994 b) in order to encourage employers to take on employees, to reduce employment relationship problems and to provide opportunities for those who might suffer disadvantage in the labour market (Department of Labour, 2012). These include: women, youth, first time workers, Maori and Pasifika, people returning to work after a period of unemployment or child rearing, people with disabilities or mental illness, migrants and people with overseas qualifications as outlined in Loh (1994a):

First, probation allows firms to obtain information that is unavailable before hiring and that serves as a check on the quality of the match between workers and jobs. If the match is found to be poor, the workers may be fired before firms have invested heavily in them (p.471).

A trial period provides an advantage to an employer in hiring, and they may be more likely to take a chance on an unknown employee as there is a lengthy opportunity to gather information about that employee's skills and characteristics (Loh, 1994a). However, the employer does make a significant investment in terms of time and money in the trial employee, and they have an interest in the trial employee performing successfully in the role.

The process of obtaining the job initially is important and covered well by Miller \& Rosenbaum, (1997). Economic theory and employers blame youth labour market problems on the lack of skills and work ethic of young people. It is suggested that hiring employers will utilise all the information available to them to make the best hiring decision possible. However, Miller (1997) shows that employers do not use the available and relevant information in making an appointment decision. For example, there is information available from schools that can give a valuable insight into the young applicant's numeracy and literacy skills, as well as their personal characteristics of attitude, perseverance and dependability. However, employers tend to disregard this information because it is not from a trusted source, and 
alternatively choose to rely on their impressions gained through an interview. This research considered how information could be potentially tainted by conflicts of interest, and found that employers of young people especially do mistrust most of the sources of information regarding young applicants.

The importance of monitoring performance and giving feedback to the employee during the trial period is outlined by Folger \& Greenberg, (1985), who examined the concept of procedural justice as the process through which organisational decisions are made. This research is relevant to trial periods as it considered appraisals of employee performance and the factors which contribute to employee acceptance and satisfaction levels. This research identifies that the more inclusive the process of appraisal the more readily it is accepted by the employee, even if the final outcome is not desired. The opportunity to express opinions and reflect on past performance and critical incidents has a high value for employees. Critical factors to consider when examining the effectiveness of a performance assessment are: how often performance is assessed; if the employee has input and in what form this input is obtained, and whether records are kept and referred to. The existence of accurate records can provide a common reference point to assess the employee on, and may also ensure that all employees are being assessed along the same standards. Feelings of fairness are also connected to how familiar the rater is with the content of the actual job, and if the employee is encouraged to have input into the process. The more input from the employee the more satisfaction there is with the final outcome, with the probable underlying reason that this gives the employee a chance to make sure the rater has all the relevant job information. The final important factor identified is the style of the rater in the appraisal or feedback meeting. Therefore if the underlying objective of a trial period is to support and improve individual performance then a more problem solving feedback approach that the employee participates in will be more effective.

The presence of a probation employment period has been seen to act as a sorting mechanism for employers, with the theory that only those who are confident they will be successful in the role apply. This is a form of self-selection which works to the advantage of hiring employers; they are more certain that applicants who apply are willing and able to perform the role well (Loh, 1994a). The view that applying a 
probation period causes self-selection by applicants, therefore probation as a sorting mechanism is supported by empirical evidence.

An appropriate or optimum length of probation period is examined in Loh (1994b) and finds that:

The optimal probation length is that which equates the cost and benefits to the "lazy" workers of mimicking "hard-working" workers, provided that the firm's monitoring cost during probation is less than the cost incurred by hiring lazy workers (p.388).

An OECD (2010) report was less critical regarding the abilities of new employees and more specific on the optimum length of time. The report observed that the length of the trial period will affect youth hiring opportunities. With young people in particular an employer requires a lengthy period to observe the trial period employee. A shorter trial period will discourage the hiring of young people as it is difficult to anticipate their productivity in a very limited period of time. OECD (2008) data shows that the average length of a trial period used in all OECD countries was four months. At that stage New Zealand had no trial period and the longest trial periods between 10 and 12 months which were seen in Ireland, Denmark and the UK.

In this report the OECD (2010) commented that labour market duality needed to be reduced. They stated that:

There should be a rebalancing of employment protection to promote the mobility of young people (as well as other workers with limited work experience) from entry jobs, which are very often atypical, to career employment (p.19).

In short, overly strict employment protection may limit labour market dynamics, mobility and hiring opportunities for new entrants such as youth. In particular, very short trial periods are likely to discourage the hiring of young people whose productivity is difficult to judge ex ante (p.121). 


\subsection{Why Introduce Trial Periods in New Zealand?}

The global economic recession has had an effect on New Zealand, with an impact on small to medium business, the labour market overall and young employees aged 15 to 19 years in particular (OECD, 2010). The various stakeholders in the labour market have different views on the best solutions for the labour market, and specifically for young people. These views are based on differing philosophical beliefs such as those reflecting the social charter approach of Europe, which is backed by employees and trade unions, and those of a more competitive model such as Business New Zealand and the current National government (Bertola, 2004 \& Botero, 2004).

Despite international reports that New Zealand employment rates were tracking well (OECD, 2008), the National led government promoted the benefits of trial periods. The Government's position was that deregulation or loosening of employment protection would result in job opportunities and business growth. While still providing protection for employees there were ways to expand job opportunities for those who have trouble getting work, such as new immigrants and young people with few skills. The Government communicated a principle of building "a globally competitive economy, building opportunity for all, encouraging ambition" (National Party Policy, 2008). A core mechanism to allow flexibility and create employment opportunities was the introduction of the 90 day trial period. This allowed either party to terminate the employment relationship for performance reasons without personal grievance procedures being available. Good faith provisions still applied, as did minimum legislative entitlements covered by a range of Acts, the rules of natural justice and human rights legislation (Department of Labour, 2011).

Originally the trial period bill (Employment Relations Amendment Bill) was introduced under the premise that other OECD countries have these arrangements (for example Scandinavian countries) and they are not seen as harsh employers, rather they are seen as forward thinking and supportive of employee rights. The introduction of a 90 day trial period in New Zealand would be conservative in length compared to other countries such as Ireland, Canada and the UK, and would provide opportunities for those who are vulnerable in the labour market. For example, new immigrants may 
have high levels of skill and knowledge but need to be given the opportunity to show this to New Zealand employers with minimal risk and cost to the employer. In addition to this Wayne Mapp commented in 2008 (Employment Relations Amendment Bill, Second Reading) that:

The other group who will particularly benefit, I think, are people starting their first job. They are the ones who, again, say they have a lot of skills and are really keen and enthusiastic, and want employers to just give them a go. They want to prove themselves to employers through the way they work. Some employers, particularly smaller employers, find it difficult to make the decision to hire someone (p.1).

At this time the main impetus for the bill was outlined by Wayne Mapp (2008):

I tell members opposite to look at the practice of the other modern democracies that we always compare ourselves with. If it is good enough for them, with all of them doing far better than New Zealand in terms of growth and prosperity, then surely we need to match it. This is a sensible, reasonable, and appropriate proposition to help New Zealand get going (p.1).

There is a strong and well supported view in New Zealand that there should be efforts to close the income gap with Australia. This objective was the focus of the 2025 Taskforce (2009), which was established by the government and comprised submissions from employer and employer representative groups. This taskforce concluded that the income gap with Australia could be closed by creating more freedom in labour law, which in turn would enable businesses to become more innovative, creative, adapt to quickly changing demands and ultimately become more competitive in the global market. To enable this more flexible workforce the Taskforce recommended that introducing trial periods and restoring the youth minimum wage would create jobs for youth as well as for others who needed to gain entry into the workforce:

The real benefit of these provisions is to help enable new entrants to the workforce or those with a chequered track record to find employers willing to take the risk of hiring them in the first place. As above, the best protection workers have is a strong and highly competitive labour market, in which that have credible alternative employment options (p.125). 
Supporting this view were comments from the OECD (2010) that New Zealand may need to rebalance employment protection to assist youth to enter and remain in the labour market, and to reduce labour market duality. This was a stronger view than that expressed previously by the OECD (2008) which indicated that potential demand side barriers for youth should be monitored. The change in emphasis was due primarily to the developing tougher economic conditions.

Employee groups and representatives have strongly opposed 90 day trial periods, in particular the Council of Trade Unions (CTU) that maintain that New Zealand is already rated as an easy place to do business, where it is relatively easy to hire and fire (Rosenberg, 2010). The CTU maintain there is already provision for probationary periods in the Employment Relations Act (2000), this allows a lower procedural and substantive threshold for a dismissal and this should provide ample opportunity for an employer to take on a new employee with reduced risk if a dismissal situation occurs. This combined with a view that trial period terminations lack natural justice means the CTU can find no justification for introducing trial periods. This view is supported by OECD (2008) table of strictness of EPL where New Zealand ranked low down on the scale of EPL strictness, with only US, UK and Canada providing a less strict EPL environment (Appendix A). As an alternative and more effective way to improve employment levels they promote initiatives to increase the skill level of vulnerable employees, rather than the removal of employment protection.

Since the introduction of trial periods the CTU has remained critical of the outcomes resulting from the provision and have not found evidence for trial periods increasing the employment rates of vulnerable employees (Rosenberg, 2010). Further to this, the CTU claims employers are not using the provisions of the legislation well, in particular there is not always a written agreement between the parties, there is little opportunity for negotiation in setting terms of employment, and there is minimal monitoring and feedback of the employee during the trial period. The CTU claims that the existence of a 90 day trial period takes the need away from employers to have sound recruitment practices and is contributing to building a low skill and low wage economy. 
These concerns were echoed by the Human Rights Commission (2011) in their 'National Conversation about Work' report. In regard to the employment of young people the report found that there is insufficient provision of school based careers advice, the ability to enter apprenticeships or other means of entering the workforce. Dr Judy McGregor, Equal Opportunities Commissioner commented on the introduction of trial periods in the context of the 2011 report (Elder, 2011):

If they are ill-prepared for the work place in the first place and then they face a probationary period, they are at a double disadvantage.......

I think it means that there's less obligation on employers to actually invest in people during that 90 days and I think that will be a tragedy for young people. Employers may just become slacker about recruitment, instead of trying to hire the best person for the job (p.1).

The support for trial periods seems to be based on the theories of employment protection of Lazear (1990) and Skedinger (2010) and comparisons with other OECD countries (Mapp, 2008) rather than on empirical information. In contrast the opposition for trial periods seems based on anecdotal evidence and anticipated unfair application of the legislation.

Trial periods were introduced in New Zealand effective from 1 March 2009 by way of an amendment to the Employment Relations Act 2000. The amendment gave small employers, with less than 20 employees, the option of hiring new employees on a 90 day trial period, as set out in this extract from the Act:

\section{A When employment agreement may contain provision for trial period for 90 days or less}

- (1) An employment agreement containing a trial provision, as defined in subsection (2), may be entered into by an employee, as defined in subsection (3), and an employer.

(2) Trial provision means a written provision in an employment agreement that states, or is to the effect, that-

- (a) for a specified period (not exceeding 90 days), starting at the beginning of the employee's employment, the employee is to serve a trial period; and

- (b) during that period the employer may dismiss the employee; and

- (c) if the employer does so, the employee is not entitled to bring a personal grievance or other legal proceedings in respect of the dismissal. 
(3) Employee means an employee who has not been previously employed by the employer.

(4) [Repealed]

(5) To avoid doubt, a trial provision may be included in an employment agreement under-

- (a) section 61(1)(a), but subject to section 61(1)(b):

- (b) section 63(2)(b).

Section 67A: inserted, on 1 March 2009, by section 7 of the Employment Relations Amendment Act 2008

From 1 April 2011 this was extended to cover all employers. Despite the inability of an employee to bring a personal grievance or other legal proceedings in respect of a dismissal they do still have the right to challenge the employer's actions on the basis of other matters such as breaches of human rights and unjustifiable disadvantage. Employees on trial periods remain covered by the principle of good faith and they are still able to access mediation to resolve any of these issues.

The actual opportunities created by trial periods for young people in particular, and the workings and outcomes of these trial periods have been investigated in New Zealand largely from employer perspectives.

There have been two reviews carried out on different perspectives of trial periods. The first review (Department of Labour, 2012) reported that there had been a good uptake of trial periods with just over half the employers surveyed using them, with no observed difference in usage between large or small/medium sized organisations. Employers also reported that trial periods had increased their willingness to employ youth and the long-term unemployed. This was due to the reduction in perceived risk in taking on these employees who had a limited work history. Of those employers who used trial periods a large proportion (80\%) reported that employees had been retained after the 90 day trial period. It was noted that this was not an exhaustive evaluation, with particular reference to the lack of employee views. A further evaluation was carried out in 2012 (Department of Labour) to assess employer and employee knowledge about trial periods, the impacts on employers and employees and the employers cost versus benefit views. It was found that employer awareness of trial periods was high however there was a lack of detailed knowledge. Employers were found to have no costs in the implementation of trial periods, and also experienced cost savings due to the simplified and less time 
consuming dismissal process. Employees however were found to have poor knowledge of trial periods and reported feelings of vulnerability in their employment on trial periods. Further research indicated trial periods were having a small but positive effect, with employers increasing hiring as a result (NZIER, 2011).

There is a gap evident in the empirical research in fully considering the employees perspective of trial periods, and examining how trial periods are used in terms of employment processes and performance management. There is also a gap in examining further the effect of trial periods on the specific groups they were implemented to benefit, in particular young people entering the workforce.

\subsection{Conclusion}

It is possible that trial periods are a reasonable tool to create flexibility in a labour market by giving employers the confidence to take on less skilled and experienced young people, and therefore increasing work experience opportunities for young people. Alternatively trial periods may not be fully utilised by employers due to other factors in the labour market.

The presence of legislative provisions for trial periods increases work opportunities for vulnerable groups of employees, whereas strict EPL will mean that employers are hesitant to take a chance on someone unproven. Young employees represent a large risk to employers - they have little or no work experience to judge them on, and there is a lack of real information that can be drawn on to make a good recruitment decision. Trial periods remove the prohibitive dismissal procedures and costs for employers.

In a recession there is a trade off between creating a stable labour market through strict EPL, or opening up opportunities for new entrants - thereby reducing duality in the labour market. The environment of escalating youth unemployment in New Zealand means some action needed to be taken to create job opportunities. The question is whether the trial period legislation is being utilised by employers to create 
these opportunities. If so, is it for permanent roles with a genuine trial period, or is this just a convenient way to take on a low cost employee for a short period of time.

Trial periods have been introduced to create employment opportunities for young people, however this is against high, and rapidly increasing, unemployment rates for young people aged 15 to 19 years, inconsistent career guidance in schools, early drop-out rates from education, investment in training that is not suited to an individual and an overall lack of preparedness for work. With all of these issues in mind introducing trial periods to create work opportunities for young people seems to be the 'ambulance at the bottom of the cliff' and there could be many other more effective solutions.

To explore these issues further this research will investigate the usage and experience of trial periods in the employment of young people, and the challenges and experiences encountered by young people in their early labour market experiences. 


\section{CHAPTER 3: $\quad$ RESEARCH METHODOLOGY}

\subsection{Introduction}

This chapter provides an overview of the methodological approaches and research design selected for this research, along with the process used to collect and analyse the data. To reiterate, the research questions orientating this research are firstly, what are the challenges and experiences encountered by young people in their early labour market experiences and secondly, what is the usage and experience of trial periods in the employment of young people?

\subsection{Methodology}

This research utilises a mixed method approach, which encompasses "Studies that are products of the pragmatist paradigm and that combine the qualitative and quantitative approaches within different phases of the research process. (Tashakkori \& Teddlie, 2008: 22).

The mixed method approach is informed by the pragmatic and transformativeemancipatory theoretical positions. As this research focuses on a possible solution to the issue of high youth unemployment the pragmatic approach appropriately looks to "solving practical problems in the "real world" (Feilzer, 2010: 8). In addition, the transformative-emancipator paradigm places "central importance on the lives and experiences of marginalized groups..." (Mertens, 2003: 139-140) and as the research focuses on an under-represented group of young people on trial periods, this is a complementary position.

A mixed method approach is therefore considered to be methodologically appropriate to answer the research questions in order to analyse practical labour market problems experienced by young people. Further to this there has been little research carried out on trial periods and how they work, and none evident that is from an employee perspective. In addition, the topic of youth unemployment and trial periods in particular has polarized stakeholders, therefore meaningful research 
should be transparent with high levels of data reliability and rich explanations (Cavana, Delahaye \& Sekaran, 2001).

Empirical evidence reviewed within Chapter 2 utilised a combination of qualitative and quantitative methods and this enabled a comprehensive analysis of the research area. The methodology employed in this research is informed by the most relevant existing research.

Research by Fenton \& Dermott (2006) is relevant as it explored an area where little prior research had been conducted, and to build a comprehensive picture of the issues to be researched a quantitative approach was first utilised, subsequently gaps in understanding of the data were filled by qualitative data. This research was on the extent to which young people experienced fragmented employment careers due to moving between jobs either voluntarily for career advancement, or through forced changes as a result of dismissals or redundancies. The research consisted of gathering a large number of surveys, and conducting follow up interviews with a portion of the respondents to provide narrative information to further explain quantitative findings. The research found that employment fragmentation was limited to a specific demographic group only and was not as widespread as had been anticipated.

Research by Harding (2002) provides another useful reference point, indicating that a conservative and transparent methodology was effective, and using quantitative data to ensure statistically valid inferences are drawn resulted in a more robust piece of research. This research considered the cost and hiring practice effect of changes to unfair dismissal laws. Data in previous research had been criticized as leading with too many open ended questions, therefore this research used closed ended questions to conduct a telephone survey of small and medium sized businesses resulting in factual data as well as recording opinions and different perspectives, all within a quantitative survey. The findings showed that unfair dismissal laws had adverse efficiency effects for businesses, although fairer practices for dealing with employee performance problems had become the norm. Due to the quantitative and closed question approach the findings were seen as valid. 
Finally, research by Vickerstaff (2003) included interview extracts that were easily read and provided a more personal and interesting view than statistical information alone. This research sought to compare youth transitions in the past with modern day youth transitions to determine if recent youth transitions are more extended than in the past. Qualitative data was gathered via loosely structured interviews with a self-selecting sample of youth who had been employed as apprentices. The resulting data was full of rich narratives which built a picture of the apprenticeship experience. The research concluded that apprenticeships in the past were not easy or always positive however they did provide a more supported entrance into the workforce than young people experience now.

A mixed method approach to the research is appropriate as this allows the collection of statistically valid data and rich narrative to provide context and greater understanding. As a research target group, young people are difficult to access and are little surveyed. The survey used in this research will provide broad demographic information about a sample population.

Within this methodology a descriptive approach will be taken in analysing collected data to answer the research questions. This is a suitable approach as the aim of descriptive research is to gather information on an existing situation and to explore questions in order to understand the situation more fully (Creswell, 1994). This approach is also flexible enough to allow further investigation of unexpected issues that may arise during the research. A descriptive research approach is appropriate for describing the early work experiences and the trial period experiences of young people in New Zealand, for systematically identifying the factors which influence the outcome of the trial period, and for capturing the characteristics of employees and organisations who utilise trial periods.

The descriptive method utilises a combination of quantitative data through a self administered survey and qualitative data through semi-structured stakeholder interviews to ensure statistically verifiable data is gathered, as well as rich narratives to capture personal perspectives. Quantitative data collection achieves validity and reliability in the data analysis, and prevents bias in data collection and data analysis. 
In applying a mixed method approach this research sought to answer the research questions through firstly gathering quantitative data via a survey of young people. As Phase 1 of the data collection, this survey focused on establishing the extent to which trial periods are used for this age group, and their experiences of gaining and retaining employment. Appendix B contains the self-administered questionnaire. This quantitative data was analysed using descriptive statistics for the most part, with inferential statistical analysis used for the trial period data in particular.

Secondly, semi-structured interviews were used to collect data from stakeholders in the areas of youth employment, education and transitions to employment. The objective of this data collection was to provide overall insight into young people's initial labour market experiences, the challenges they face and any opportunities provided. Appendix $\mathrm{C}$ contains the questions used in semi-structured interviews. As Phase 2 of the data collection, the narrative data was transcribed, coded and categorized into themes related to the research questions. This qualitative data collection was designed to place an emphasis on understanding the situation through the particular words and descriptions rather than through a numerical approach. While qualitative data can add richness to research it is also vulnerable to researcher bias and values transfer. In this case the mixed method approach helps to manage that risk (Cavana et al, 2001).

The methodological design for this research is informed by previous relevant research. This research utilises a mixed method approach in order to gather large amounts of data and identify trends through quantitative means, and then to allow the opportunity to explore the identified themes more fully through qualitative methods.

\subsection{Research Sampling}

A focused strategy was needed to answer research questions of what are the challenges and experiences encountered by young people in their early labour market experiences and the usage and experience of trial periods in the employment of young people. 
The sample was initially identified as those aged 15 to 19 years. As stated earlier while most literature categorises youth as 15 to 24 years old, those aged 15 to 19 in New Zealand face more challenges in the labour market than those in the higher age bracket. They do not fare as well as their counterparts in other OECD countries in terms of employment rates (OECD, 2010) and they tend to leave school at an earlier stage and make a less successful transition from school to the workplace (Boven, 2011). Young people aged 15 to 19 years in New Zealand are vulnerable to economic downturn and experience challenges or barriers to both entering and remaining in the workforce. The specific barriers identified for this group of young people were a lack of qualifications and living in areas of high unemployment (OECD, 2010). The sampling strategy developed needed to explore these barriers more fully within specific geographical areas which had higher levels of youth unemployment and to locate those young people who had left school prior to completion or with a low level of qualifications.

It was anticipated that this group of young people could be employed, unemployed, at secondary school or in post school education or training. A broad sampling strategy was needed to identify where and to what extent trial periods were being used. Limiting sampling to a particular group of young people would not provide a complete picture of early labour market experiences. To provide meaningful information about work experiences young people were required to either be currently or very recently employed.

The population of interest for this research can be specifically defined as youth aged 15 to 19 years who are likely to have left school early, have few qualifications and live in an area where youth unemployment levels are reasonably high. A sampling frame was needed to identify and target this population of interest within a large and very fragmented group.

This research needed an adaptive sampling strategy and to be cognisant of the difficulty in conducting research involving young people, especially where they do not have a strong affiliation with any organisation (Simmons, 2007), and where they tend to view surveys negatively or have trouble reading and completing them (Tisdall, Davis \& Gallagher, 2009). As an initial step the organisations these young people 
were likely to have links to were identified with the purpose of establishing connections with young people through organisation gatekeepers. It was identified that these young people were likely to be linked to education providers, youth transition agencies, other support organisations providing training or work experience programmes and employers. Potential issues with gatekeepers were identified in Tisdall (2009) with constraints on their time resulting in a low priority being assigned to survey completion. The absence of the researcher explaining the purpose and content of the survey was identified as another factor that could result in a poor survey response (Tisdall, 2009). Employing a flexible approach to surveying young people was considered a priority in Bennett, Cieslik \& Miles (2003) with the suggestion that a non-threatening and more effect approach to data gathering is to have this done by someone who is a peer of the survey group. The benefits in this approach were also seen in Jardine \& James (2012), who state that using youth to research youth provides benefits to the response rate as participants were more comfortable talking to peers rather than an unknown researcher.

In terms of a geographical sampling frame, Porirua and Lower Hutt were targeted for data collection within the Wellington region. The rationale for this geographical target was that these two areas have similar demographics which provide a sufficient pool of responses, and they are geographical areas where youth unemployment is higher than average rates across New Zealand (Department of Labour, 2008).

Porirua is a small city with a total population of 48,546 (Census, 2006) making up only $1.3 \%$ of the total population of New Zealand. It is a multi-cultural city with a large population of Pacific Island people. The demographic make-up of the city in the 2006 census was 54\% European, 25\% Pacific Island and 20\% Maori, with the remainder made up of Asian and other ethnic groups. As a result Samoan is the second most common language spoken, after English. At the time of the 2006 Census nearly one third of the population were aged below 15 years. It is a characteristic of the city that a large young workforce will be retained over the following 20 years.

Lower Hutt City has a total population of 97,701 (Census, 2006), which comprises $2.4 \%$ of New Zealand's population. The demographic profile of Lower Hutt in the 
2006 Census was 64.9\% European, 10.5\% Pacific Island and 17.1\% Maori with the remainder made up of Asian, middle eastern and other ethnic groups. Although the percentage of Pacific Island people in Lower Hutt is lower than in Porirua the 2006 Census reports that Samoan is also the second most common language spoken, after English. At the time of the 2006 Census nearly 23\% of the population was aged less than 15 years. This is higher than the national figure of $21.5 \%$ and although not as significant as seen in Porirua, the Hutt Valley will also retain a large young workforce in the foreseeable future.

Both Porirua and Lower Hutt have seen major changes in industry over the last 10 to 15 years with the demise of manufacturing and industrial type work. These organisations had traditionally provided good entry level roles for school leavers, which would lead to ongoing employment and skill development.

An area of ongoing concern in Porirua is the low level of formal qualifications held by school leavers and therefore by the general population of the city. Over $43 \%$ of those aged 15 and over in Porirua in the 2006 Census had no formal qualifications, compared with a figure of $19.8 \%$ in the Wellington region overall. In Lower Hutt this figure was less significant with $24.8 \%$ of people aged 15 and over holding no formal qualifications. However this was still over the Wellington regional figure of $19.8 \%$.

There are therefore many challenges to youth within Porirua city. As a result of this the unemployment figures for the city tend to track higher than that for New Zealand as a whole with $7 \%$ unemployed in Porirua compared to 5.1 percent unemployed over all of New Zealand (Table 3.1). This table also shows that Porirua provides less part time opportunities than the rest of New Zealand (19.6\% are part time in Porirua, compared with $21.7 \%$ part time over all of New Zealand). Part time employment opportunities provide an opportunity for young people to enter the labour force while remaining in education and can provide valuable early employment opportunities to develop skills and an increased understanding of the employment experience.

The Lower Hutt area has an unemployment rate lower than Porirua (5.7\%) however this is higher than the overall New Zealand rate of $5.1 \%$. Therefore similar challenges apply for young people seeking their initial employment as seen in Table 
3.1 from the 2006 Census, and Lower Hutt City also provides less part time opportunities than the rest of New Zealand (19.7\% are part time in Lower Hutt, compared with $21.7 \%$ part time over all New Zealand).

\section{Table 3.1}

Employment and Unemployment Rates of People in Porirua City, Lower Hutt City and New Zealand in 2006

$\begin{array}{lccc}\text { Status } & \text { Porirua } & \text { Lower Hutt } & \text { New Zealand } \\ \text { Employed full time } & 73.4 \% & 74.6 \% & 73.2 \% \\ \text { Employed part time } & 19.6 \% & 19.7 \% & 21.7 \% \\ \text { Unemployed } & 7.0 \% & 5.7 \% & 5.1 \%\end{array}$

Source: NZ Census, 2006

\section{Table 3.2}

Employment and Unemployment Rates of People in Porirua City, Lower Hutt City and New Zealand in 2013

\begin{tabular}{lccc}
\hline Status & Porirua & Lower Hutt & New Zealand \\
Employed full time & $79.3 \%$ & $75.8 \%$ & $73.7 \%$ \\
Employed part time & $13.4 \%$ & $17.7 \%$ & $20.2 \%$ \\
Unemployed & $8.6 \%$ & $6.5 \%$ & $6.5 \%$
\end{tabular}

Source: Household Labour Force Survey, March 2013

Table 3.2 provides 2013 data to compare Porirua City and Lower Hutt City employment and unemployment levels from 2006 to 2013 and takes into account the effects of the recession. It is clear that Lower Hutt City started from a stronger point of less unemployed, and has tracked fairly similar to the rest of New Zealand in overall unemployment rates by early 2013. However, Porirua City is worse off with a high unemployment rate of $8.6 \%$ in March 2013, much higher than the rest of New Zealand overall. While in both cities the percentage of people employed on a full time basis have increased, and the number of people employed on a part time basis has decreased. This was most significant for Porirua with a decrease in those working part time from $19.6 \%$ in 2006 to $13.4 \%$ in 2013 . This change suggests 
Porirua City has felt more of the effect of the recession, with employers choosing to shed part time roles in the face of difficult financial times.

\subsection{Sample/Participants}

\section{Sampling}

The sampling procedure used for Phase 1 (self administered surveys) and Phase 2 (stakeholder semi structured interviews) was purposive sampling as individuals were selected who met relevant criteria.

In Phase 1 survey participants were restricted to those who could be accessed through a provider of support, education or training for young people either while at school or after leaving school. This pragmatic approach was taken as those aged 15 to 19 years were anticipated to be difficult to find and therefore linking into organisations where these young people were, enabled as many respondents to be identified and included as possible in a timely manner. Participants in the survey included 63 people accessed through Youth Transition Agencies and 37 people accessed through Education/Training Providers, the young people targeted through these organisations met the age and work experience criteria. The responses gathered met the minimum required 100 valid surveys, which was a sufficient number to form meaningful conclusions from the data. The response rate overall was poor with just over 600 surveys distributed to achieve 100 completed and returned.

The Phase 2 stakeholder semi structured interview participants were restricted to those who were working in key roles within the field of youth education, employment, transition from school to work and business. Interview participants included a business representative, a youth transition agency representative, a school based vocational guidance representative, a union representative and a champion of a regional youth employment initiative. A total of five stakeholder interviews took place. 


\section{Participants}

Phase 1 Survey participants were required to be aged from 15 to 19 years of age, and to either be currently or recently employed. They were from a range of ethnic backgrounds, which was in alignment with ethnicity profiles from their geographic areas. Survey participants were representative of the range of employment status options of those still at school, those in training, the employed and unemployed. A range of qualification levels was also represented from participants with no qualifications through to those who had completed NCEA Level 2. A deliberate targeting of participants who left school at an early stage and/or were struggling in the labour market was an important part of this research.

Phase 2 Interview participants were identified by the researcher as representing sectors with an involvement in youth employment, knowledge of employment practices concerning those people and holding unique perspectives on the issues facing youth employment, for example union and business representatives.

\subsection{Measurement Instruments}

The research questions in this study are broad, and some may be seen as subjective, therefore it is essential to operationalise these as fully as possible into measurable variables.

At the core of the research is respondent demographic information which provided the first step in data collection and was central to the analysis of variables. Therefore demographic data regarding respondent age, gender, ethnicity and qualification level formed the basis of the first part of the survey, and to enable ease of comparison with relevant literature demographic variables were defined in a manner consistent with the New Zealand census data (NZ Census, 2006).

To provide further means of analysis it was necessary to establish the respondents' current employment status. Due to the age of respondents (15 to 19 years) it was clear that a proportion would probably remain in secondary education and therefore the first category of "still at school" status became evident. Those respondents who 
had left secondary school then needed to be categorised into employment status and these fell into categories of employed, unemployed or engaged in further study through tertiary education providers, this approach was consistent with relevant literature (Department of Labour, 2009; Department of Statistics, 2012; Higgens, 2002; Marks, 2006). Therefore four categories of employment status were established, and for those who had left secondary education there was a need to establish the circumstances of their exit from school in order to provide a basis for further comparison between groups. Accordingly this need was operationalised through the variables of the year of leaving school, the stage of leaving school and the reason for leaving school with reference to the research of Marks (2001).

The first research question to be asked focused on young people's early labour market challenges and experiences. This was broken down and operationalised into variables to be contained in survey questions. The initial area to be included aimed to capture the issue of frequency of job changes with reference to relevant literature (Dupuis, 2006; Fenton, 2006; Holzer, 1994; Marks, 2006) and this was operationalised by including questions to ascertain the length of time a respondent had remained in their current employment, and the number of jobs they had held within their employment history. Further operationalising of the concept was through legal requirements for employment and translating these into questions relating to the employment process in order to illustrate the legality of the employment relationship. The Employment Relations Act 2000 sets out minimum standards for employment and survey questions were developed from the requirements that every employee must have a written agreement (Section 63A 2), that employers are required to retain a signed copy of the employment agreement (Section 64) and that an employer must inform the employee of their right to join a union (Section 622 ). In addition the Employment Relations Act 2000 provides the opportunity for an employee to negotiate changes to their employment agreement (Section 63A 2) and to seek independent advice on the agreement prior to signing (Section 63A 2). These legal rights were operationalised into survey questions which indicated if these opportunities were given by the employer and acted on by the employee. The Minimum Wage Act 1983 provides minimum hourly rates and gathering data on respondent rates of pay was also included as a survey question to show if minimum rates were being paid, but also to observe differences in rates of pay within different 
categories of respondents. A further indicator of early work experiences was the hours of work and this was operationalised with reference to relevant literature (Dupuis, 2006; Marks 2006) to include a question on normal weekly hours of work which allowed comparison and indications of transition from part time to full time employment. Characteristics of youth employment were operationalised through defining employing industries and within this the type of tasks being performed on a daily basis as well as the size of employing organisations (Department of Labour, 2009).

The more subjective aspects of a positive or negative employment experience were also addressed in the survey, with employer support and guidance operationalised through a question regarding the setting of performance standards either through written terms or verbally. Additionally this provides the first step in procedural fairness for both parties should employment subsequently be terminated due to performance problems. Supporting the establishment of performance standards are the provision of job related training, and feedback from the employer to inform the employee of the need to improve their performance in a particular area or to provide positive feedback on tasks performed well. These points were included as survey questions regarding the provision of training by the employer, the frequency of feedback as well as the manner of feedback ranging from informal verbal comments, through to a more formalised written feedback from the employer to the employee. The reviewed literature (Folger, 1985) suggests that employee perception of fairness of feedback is directly affected by the frequency of feedback provided and the opportunity to provide their employer with their own opinion of how they were performing in the job. Therefore an additional question was included to assess if the employee had the opportunity to tell their employer how they thought they were performing the job, and also how frequently the opportunity to do so arose.

Employment outcomes were an important part of the overall employment experience, and this concept was operationalised by asking if the employment relationship had been terminated by the employer, if so what the reason was for this. Connecting back to legislative requirements in regard to employment termination (Employment Relations Act 2000 and the Holidays Act 1981), information was also sought on the timing of employment termination which was especially relevant if the 
employee had been engaged on a trial period, and the final payments made to the employee to examine if legislative requirements regarding holiday pay in particular had been met.

The latter part of the survey was designed to examine respondent's views of their work experiences and this was initially addressed through asking what they had enjoyed about the job, and what factors had provided more of a challenge or a negative experience. This concept was further operationalised by asking a series of questions designed to test optimism and resilience about the respondent's future prospects in the areas of employment, income and education and this had been established in the reviewed literature as an important indicator of the working experience (Fenton, 2006; Hodkinson, 1996).

The second research question examined the usage and experience of trial periods. The first variable established was the frequency of trial periods for this group of young people and this was operationalised by asking respondents if their employment agreement had put them on a trial period. Following on from this, respondents level of knowledge of trial periods was assessed by asking them to describe in their own words what they understood a trial to be. This question was designed to test previous research into trial periods (Department of Labour, 2012) which examined employer awareness of trial period requirements. In addition, this question was expanded on to ask the respondent's source of information in regard to trial periods.

Further to these questions on trial periods, cues could also be taken from legislative requirements contained in the Employment Relations Act 2000. This data and other relevant information was captured through questions developed in the earlier part of the survey and provided all the additional information needed to analyse the usage and experiences of trial periods.

\section{Phase 1 Self Administered Survey}

The survey was prepared by the researcher for young people to complete and this was designed to gather specific data to answer the research questions (Appendix $A$ ). The survey questions asked for demographic data and data on work history, 
experiences, environmental factors and views of the employment experience as outlined above. A total of 43 questions were asked and answers could range from tick boxes to written information. A self administered survey option was selected which had the following advantages: surveys could be distributed to a large number of people resulting in increased chances of a satisfactory response rate; interviewer bias was eliminated; anonymity was assured and respondents could fill in the survey in their own time. The survey was available to participants on line and in hard copy. Distribution of the survey was either via an agency representative during training sessions or meetings with young people, via a mail out to an agency address list, or directly from the researcher to the participant during an agency run training session or visit. Survey data was compiled through survey software and text responses were analysed and sorted into themes by the researcher

\section{Phase 2 Semi Structured Stakeholder Interviews}

Interview questions (provided in Appendix B) were prepared by the researcher to gather perspectives relevant to the research questions from stakeholders. Interview questions explored challenges for young people, the usage of trial periods and successful youth employment initiatives. Semi-structured interviews were conducted with identified stakeholders. The interviews were recorded and then transcribed. Transcribed interviews were then analysed and themes were identified.

\section{Validity and Reliability}

Non-probability sampling has the potential for bias, and in this situation those willing to participate may share negative or positive experiences. The application of quantitative methods, as well as qualitative will help to mitigate this limitation.

The validity of the Phase 1 Survey was increased by establishing a pilot group of 10 young people to complete it and provide comments on its contents. Feedback provided by the pilot group was that the language used was very academic and needed to be amended to increase ease of understanding, that the question order should change to make progression through the survey more streamlined, and that changing a number of questions from open-ended text responses to tick-box answers would ensure the survey was easier to complete. This feedback was taken into account, as a result questions were modified in terms of language and survey 
layout was amended to provide a more logical order to the questions. Survey reliability was also increased by amending the survey to provide more tick box answers, rather than text responses, and this meant data could be interpreted more consistently throughout.

The validity of the Phase 2 Interview was also increased by piloting interview questions to ensure they were targeted enough to provide rich data. As a result of the pilot the interview questions were amended. However, as the interviews were semi-structured, quality information to be gathered was in the extra comments and opinions the interviewees expressed. Structure was not forced into the interview. Simple introductory questions were used and interviewees could determine areas for elaboration dependent on their areas of expertise and their individual perspectives.

\subsection{Data Collection}

Using a questionnaire for data collection was the selected method for Phase 1 of the research as it was seen to be the most effective way of gathering large amounts of quantitative data in a timely manner over a specific geographic area. However, this method of data collection bought with it shortcomings, these were a low response rate, due to literacy issues with completing the survey as respondents had more limited education, and lower literacy levels than anticipated. Face to face administration of the survey was preferred as this would allow the purpose of the research to be well explained, more assistance to be provided with the interpretation of survey questions and rapport to be reached with respondents (Cavana, 2001; O'Leary, 2010).

Phase 1 Survey data collection took place during 2012 and methods of gathering this data changed during the course of that year. Initially the researcher planned to gain access to eligible participants via agencies, employers and training organisations and to collect a number of valid surveys within a short period of time. Recruitment of participants for phase 1 of the research was through advertising on notice boards at a variety of locations in the two geographical areas selected, including youth transition agencies, youth training facilities, and community areas where youth may gather. Self-selection of participants was planned to ensure participation was 
voluntary, and that a random sample is achieved. Participants were able to fill in a hard copy of the questionnaire which was available at the selected locations. Completed questionnaires were to be placed in a secure post box for collection by the researcher. However, this approach was not as straight forward as predicted. Although most agencies approached to facilitate data collection were extremely supportive and understood the need for the research, the targeted participants were difficult to identify and were not interested in filling in a survey. Successful data collection at that stage came about through two channels, either an agency representative distributing the survey while running a seminar to a group of young people, or where the researcher was invited to attend a training session or seminar with the purpose of explaining the research and distributing surveys. Those organisations running courses were reluctant to devote long periods of time to explaining and administering the survey, therefore blank copies of the survey were left with organisers and completed surveys were collected several days later. Distribution of surveys via employers was not successful as they seemed uncomfortable in regard to the disclosure of terms of employment. A large organisation engaged in the provision of employment support to young people provided a mail out list of 129 young people who had attended their training recently and who met the participation criteria. A total of three valid responses were received as a result of this mail out. The survey was also made available online to groups of participants via a youth support agency as it was anticipated this would increase participation, however less than 10 surveys were completed online. During data collection it was noticeable that survey participants had difficulties writing text responses, were slow to complete surveys, sought support from the researcher (when present) over correct spelling and lacked awareness of employment terms and legislation. Literacy levels and confidence in written expression were seen to be a barrier to survey completion.

Data collection proved very difficult with this sample and on exhausting links to survey participants via agencies or organisations an alternative strategy was developed. Taking a cue from the literature reviewed on youth research where the gatekeeper or researcher could be a barrier to collecting research (Simmons, 2007) the researcher adapted the approach to survey distribution and arranged for this to be done by several people of similar demographics to the respondents. While 
agencies were comfortable with these people distributing surveys within their organisations more progress was made via informal approaches from them to other young people in the locations of youth transition and education providers.

This meant that the sampling approach of the research was consistent as the young people surveyed were accessing the services of the nearby agency or educational organisation; however they were approached in an informal manner by one of their peers. This approach proved to be more successful and $55 \%$ of surveys were collected in this manner. Overall data collection was spread over a 12 month period due to difficulties accessing participants and subsequent changes in approach.

Phase 2 Stakeholder interview data was gathered in a more straight forward manner in the latter part of 2012. The selected method for Phase 2 of the research used semi-structured surveys in order to gather a wide range of qualitative data. Key stakeholders to be interviewed as part of this process were identified with the objective of including the views of key influencers, and providing a broad view of trial periods and the associated issues of youth employment. The criteria for identifying key stakeholders were to have a connection with youth employment and be in a position of influence or engagement. Based on the New Zealand literature the business viewpoint was essential, as was that of the union viewpoint as the major opponent of the introduction of trial periods. Including these two key stakeholders in the interview process allowed the researcher to gain a wider view of their promotion and opposition to trial periods, well beyond the information available in media statements and publications and additionally these stakeholders could provide a New Zealand wide view.

A focus on the specific areas surveyed (Porirua and Lower Hutt) was also required to provide a local voice to compare against quantitative data collected. Combining the need for local views with those from youth employment focused stakeholders meant a stakeholder dealing with youth transition from school to further education or employment in Lower Hutt was identified, as well as a secondary school level career transition specialist from the Porirua area. The final stakeholder was identified as they led a community initiative in another geographical area with some similarities to the geographical areas surveyed in this research. The purpose of this was to 
consider a successful and comprehensive youth employment scheme and gain views from that perspective. Identified stakeholders were formally invited to take part in the research, and were very supportive and quick to agree to be interviewed. An explanation of the research and participant information was provided prior to interviewing and all stakeholders were agreeable to the conditions of the research and were provided with interview transcripts as they were prepared.

\subsection{Data Analysis}

1 Phase 1: Self Administered Survey

Three methods of quantitative data analysis were used for survey data: chi-square tests, independent samples t-tests and binary logistic regression.

The survey was established in Qualtrics (Version 2009) as this provided a survey format that could be made available anonymously on line and also provided online reporting and data export functionality into SPSS to enable a higher level of data analysis. All survey data was entered into Qualtrics, which then provided simple data analysis on each of the 43 questions to understand response numbers, ranges, means and standard deviations. Statistical analysis using Statistical Package of the Social Sciences (IBM SPSS Version 20) was then conducted and chi square tests applied to variables to compare observed data with expected data. There were five key variables selected for analysis as it was anticipated these would provide a useful basis for differentiation. The key variables used were respondent age, respondent gender, respondent ethnicity, the highest level of qualification held by the respondent and the normal weekly hours the respondent worked. Hours of work were categorized into full time (30 or more hours per week) and part time (up to 29 hours per week).

Data analysis was reported in the form of percentage, mean, standard deviations and then chi square tests. Graphs were also used to illustrate key points. Of the 43 questions in the survey, four required a text answer, statistical analysis was not appropriate and these text responses were analysed separately by coding responses 
and organising into a number of themes and categories. SPSS was then used to carry out binary logistic regression analysis on the two main dependent variables, which were:

- Did your employment agreement put you on a trial period? And

- In this job was your employment terminated by the employer?

These dependent variables were selected as they were the core questions to the research, establishing how often and in what circumstances trial periods were used, and revealing the success of the employment engagement through analysing the frequency of employment termination and the circumstances surrounding that.

Logistic regression is used to model the dichotomous outcome variables of trial periods and employment termination. This is a useful method to identify the factors that influence whether a trial period is used in employment, and whether employment ends in termination. The outcome dependent variables were binary $(0 / 1)$; trial period or no trial period, and employment termination or no employment termination. The predictor variables of interest were respondent age, gender, hours of work, presence of a written agreement, feedback on performance from the employer, presence of performance standards, hourly rate, industry employed in and organisation size. A forward selection addition of variables was carried out in each regression and this involved holding constant the additional variables added to the model with the objective of arriving at the model with the highest significance.

SPSS output then identifies the coefficients, their standard errors, degrees of freedom and significance levels. The coefficient exponent is then calculated to show the change in log odds of the outcome for a one unit increase in the predictor variable. For example, for every one unit increase in a variable, the odds of being employed on trial period increases by the amount of the odds ratio. Analysis of trial period regression estimates are contained in Appendix $\mathrm{D}$, and analysis of employment termination regression estimates are contained in Appendix E.

To provide additional analysis on trial periods independent sample t-tests were run as this enabled the means of two groups of cases (those on trial periods and those not on trial periods) to be compared on a range of variables to establish significance levels on differences. 
Statistical analysis was not possible on those who were working on trial periods and had their employment terminated as the sample size was too small (of the 21 respondents working on a trial period only 1 had their employment terminated), likewise further statistical analysis was not possible using interaction terms of gender and ethnicity as the sample size was too small to allow this.

\section{Phase 2: Semi-structured Stakeholder Interviews}

Qualitative data from stakeholder interviews was transcribed and initially analysed on the basis of cue questions used in the interviews, these questions are contained in Appendix C. The data was then further analysed through a process of recursive abstraction to identify core themes in the data. This was a process of summarising data, and then further summarising that data until a concise summary of each theme resulted. (Jackson, 2010)

The process of recursive abstraction was well suited to the data as the number of interviews was small and the researcher had conducted all interviews personally. This process allowed independent summarising of theme areas before using the data for further analysis (Crowther \& Lancaster, 2012).

Quotations were selected from interviews to illustrate themes and findings and then interview data was compared with survey data to determine where findings were supportive or contrary to quantitative data.

The following chapter introduces key findings from the research through the use of descriptive statistics and by incorporating qualitative data to provide comprehensive data analysis. 


\section{CHAPTER 4: $\quad$ FINDINGS}

\subsection{Introduction}

This chapter outlines the key findings of the research. In particular it describes the usage of trial periods in the employment of young people, the work experiences of young people and an indication of the employment issues facing young people in the labour market. To achieve this, descriptive statistics are provided firstly to describe the sample, to then analyse the occurrence, characteristics and outcomes of 90 day trial periods, and to further explore educational characteristics, the general nature of employment, more specific terms of employment and employment outcomes. This largely quantitative data from young people is incorporated with qualitative data from stakeholder interviews to provide more depth to analysis in examining the extent and effect of trial periods on young employees 15 to 19 years, and the challenges and experiences this group faced in their initial labour market entry. Qualitative data was gathered through interviews carried out with a range of stakeholders in youth outcomes including an employer/business representative, an employee/union representative, a youth transition agency, a school based career transition representative and the representative of a community led youth employment initiative.

\subsection{Sample}

This section outlines characteristics of the survey sample which contains responses obtained from 100 participants. Table 4.1 contains descriptive statistics from the sample and shows that in this sample the current employment status of respondents was evenly spread between those who remain in their final year(s) at school and are employed in some part time form (27\%), those who are employed on a full time basis (25\%), those who consider themselves to be unemployed (24\%) and those currently participating in a training course $(24 \%)$.

Table 4.1 also shows that in terms of the highest qualification achieved there were relatively even numbers of respondents who had no qualification (28\%), those who had achieved NCEA Level 1 (29\%) and those who had achieved NCEA Level 2 
(31\%). A smaller number of respondents had achieved a qualification at NCEA Level 3 or above (12\%). This sample differs from the general population of young people in the area as fewer young people reported they held no qualification (28\%) compared to Census data (2006) which shows an average of $34 \%$ of young people in the areas surveyed held no qualification.

In the survey sample the majority of respondents were aged 19 years $(31 \%)$ or 18 years (28\%). Other age groups were represented in smaller portions with 16 and 17 year olds having fairly similar representation (16\% and $15 \%$ respectively). Those aged 15 years made up the smallest portion of respondents (10\%) and the average age of participants was 17.7 years. While the sample provides a good example of the population, the exact age of respondents was not identified and this could add to measurement errors.

There was an almost even gender representation in the data with $51 \%$ male respondents and $49 \%$ female respondents. In terms of ethnicity, New Zealand Europeans made up the largest portion of respondents in the survey data $(57 \%)$ followed by Maori (20\%) and those of Pacific Island ethnicity at a total of $11 \%$ (Samoan, Cook Island Maori, Tongan and Niuean categories combined). Other ethnicities totaled $12 \%$, with most of those responses identifying as Asian. This ethnic split is broadly representative of the geographical areas covered in the survey as detailed in Chapter 3 for NZ Europeans and for Maori, however this sample contains less Pacific Island respondents and more Asian/Other respondents than were represented in Census 2006 data. 


\begin{tabular}{|c|c|c|c|}
\hline \multicolumn{4}{|l|}{ Descriptive Statistics } \\
\hline Variable & Variable Definition & Mean & Standard Error \\
\hline \multirow[t]{4}{*}{ Current status } & At school & .28 & .045 \\
\hline & Unemployed & .24 & .043 \\
\hline & Employed & .25 & .044 \\
\hline & In training & .24 & .043 \\
\hline \multirow[t]{4}{*}{ Highest qualification } & No qualification & .28 & .045 \\
\hline & NCEA Level 1 & .29 & .046 \\
\hline & NCEA Level 1 & .31 & .046 \\
\hline & NCEA Level 3 & .12 & .033 \\
\hline \multirow{5}{*}{ Age } & 15 years old & .10 & .030 \\
\hline & 16 years old & .16 & .037 \\
\hline & 17 years old & .15 & .036 \\
\hline & 18 years old & .28 & .045 \\
\hline & 19 years old & .34 & .050 \\
\hline \multirow[t]{2}{*}{ Gender } & Male & .51 & .050 \\
\hline & Female & .49 & .050 \\
\hline \multirow[t]{5}{*}{ Ethnicity } & NZ European & .56 & .050 \\
\hline & Maori & .21 & .041 \\
\hline & Pacific Island & .11 & .031 \\
\hline & Asian & .06 & .024 \\
\hline & Other & .06 & .024 \\
\hline \multirow[t]{6}{*}{ Industry } & Manufacturing & .05 & .022 \\
\hline & Retail & .26 & .044 \\
\hline & Hospitality & .29 & .046 \\
\hline & Construction & .04 & .020 \\
\hline & Government & .03 & .017 \\
\hline & Other & .31 & .046 \\
\hline On trial period & Yes & .21 & .041 \\
\hline \multirow[t]{2}{*}{ Hours of work } & Part time (>30/week) & .71 & .046 \\
\hline & Full time $(30$ +/week $)$ & .29 & .046 \\
\hline \multicolumn{2}{|c|}{ Employment terminated } & .30 & .046 \\
\hline
\end{tabular}


Simple chi-square testing was carried out to indicate the variables of significance. Results of this testing are contained in Table 4.2 and referred to in this Chapter.

\begin{tabular}{|c|c|c|c|}
\hline Reference & Chi-Square Test & Variable 1 & Variable 2 \\
\hline 1 & $\mathrm{X}^{2}(24, \mathrm{~N}=71)=54.63, p<0.00$ & Year left school & Hours of work \\
\hline 2 & $\mathrm{X}^{2}(24, \mathrm{~N}=71)=54.3, p<0.05$ & Year left school & Stage left school \\
\hline 3 & $X^{2}(24, N=96)=42.3, p<0.01$ & Number of jobs & Hours of work \\
\hline 4 & $X^{2}(12, N=99)=21.33, p<0.04$ & Written agreement & Hours of work \\
\hline 5 & $\mathrm{X}^{2}(12, \mathrm{~N}=100)=26.57, \mathrm{p}<0.009$ & Type of agreement & Hours of work \\
\hline 6 & $X^{2}(4, N=99)=8.63, p<0.07$ & Terms explanation & Hours of work \\
\hline 7 & $X^{2}(8, N=100)=15.7, p<0.04$ & Agreement signed & Age \\
\hline 8 & $X^{2}(8, N=100)=16.7, p<0.03$ & Agreement signed & Hours of work \\
\hline 9 & $\mathrm{X}^{2}(12, \mathrm{~N}=100)=36.42, p<0.000$ & Hourly rate & Hours of work \\
\hline 10 & $X^{2}(16, N=100)=29.5, p<0.02$ & Hours of work & Age \\
\hline 11 & $\mathrm{X}^{2}(4, \mathrm{~N}=99)=14.8, p<0.05$ & Hours of work & Gender \\
\hline 12 & $X^{2}(8, N=99)=19.76, p<0.01$ & Performance standards & Hours of work \\
\hline 13 & $X^{2}(20, N=100)=39.62, p<0.006$ & Positive feedback & Hours of work \\
\hline 14 & $\mathrm{X}^{2}(3, N=99)=8.88, p<0.03$ & Termination & Gender \\
\hline 15 & $\mathrm{X}^{2}(12, \mathrm{~N}=99)=22.75, p<0.03$ & Employment expectations & s Hours of work \\
\hline 16 & $X^{2}(16, N=99)=36.34, p<0.003$ & Income expectations & Hours of work \\
\hline 17 & $\mathrm{X}^{2}(8, N=99)=11.4, p<0.10$ & Trial periods & Age \\
\hline 18 & $X^{2}(2, N=99)=3.4, p<0.10$ & Trial periods & Gender \\
\hline 19 & $X^{2}(2, N=98)=13.63, p<0.001$ & Trial periods & Terms explanation \\
\hline 20 & $X^{2}(4, N=99)=23.72, p<0.00$ & Trial period & Agreement signed \\
\hline 21 & $X^{2}(4, N=99)=12.21, p<0.01$ & Trial periods & Negotiated terms \\
\hline 22 & $X^{2}(6, N=99)=19.27, p<0.004$ & Trial periods & Hourly rate \\
\hline 23 & $\mathrm{X}^{2}(8, \mathrm{~N}=99)=16.85, p<0.03$ & Trial periods & Hours of work \\
\hline 24 & $\mathrm{X}^{2}(4, \mathrm{~N}=99)=14.52, p<0.006$ & Trial periods & $\begin{array}{l}\text { Performance } \\
\text { standards }\end{array}$ \\
\hline
\end{tabular}




\subsection{Trial Periods}

As stated from the outset of this chapter, the central focus of the research relates to the usage and experience of trial periods in the employment of young people. Within this analysis an important point is that while $47 \%$ of respondents could state they were not on a trial period and $21 \%$ of respondents could state that they were employed on a trial period, there was another large category of $32 \%$ who did not know if they were employed on a trial period or not. This group was typical of the sample in displaying a lack of awareness of their employment terms and although they may have been employed on a trial period for the purpose of this analysis they could not be included as a positive response.

Three levels of statistical analysis were used in regard to the trial periods data. Initially simple chi-square tests (Table 4.2) were carried out to indicate the relationships between variables of significance. Secondly independent samples ttests were carried out to compare data of respondents on trial periods and those not on trial periods. Further analysis was carried out on trial periods using regression analysis. Table 4.3 contains regression estimates, identifying significance levels between trial periods and key variables. Regression analysis was carried out in five steps, beginning with core demographic variables in Regression A, adding employer characteristics in Regression B, adding process and performance management variables in Regression $\mathrm{C}$, adding variables relating to employment terms in Regression D and finally attempting to isolate key variables in Regression $\mathrm{E}$.

The age of respondents was the first variable to be analysed and this was found to have a significant relationship with trial periods through independent samples t-tests and through regression analysis. An independent samples t-test was conducted to compare age for those on trial periods and those not on trial periods. There was a significant difference in the ages of respondents on trial periods $(M=18.19$, $S D=1.030)$ and those respondents not on trial periods $(M=17.37, S D=1.370) ; t$ $(40.887)=-3.020, p=0.004$. These results suggest that age has a significant link with trial periods. Specifically, the results suggest that when respondents are older they are more likely to be on a trial period. Regression analysis also indicated significance for age (Table 4.3) in Regression B only $(p<0.042)$ suggesting that age 
has a significant relationship with organisation size and industry which also showed significance in Regression B. The coefficient for the age variable indicates that the likelihood of being on a trial period increases by 1.9 for each year increase in age, and this calculation is included in Appendix D.

The gender of respondents showed a significant relationship with trial periods in regression analysis (Table 4.3) and this was consistent over each of the regressions. Males were found to be more likely to be employed on trial periods, with the most significant finding in Regression D, which indicated that males were 14 times more likely than females to be employed on a trial period (Appendix D).

A significant relationship was seen between trial periods and the industry respondents were employed in. An independent samples t-test was conducted to compare industry sector for respondents on trial periods and those respondents not on trial periods. There was a significant difference in industries where respondents on trial periods worked $(M=0, S D=0)$ compared to respondents not on trial periods $(M=0.06, S D=0.245) ; t(78)=2.296, p=0.024$. These results suggest that industry sector does have a significant relationship with on trial periods. Specifically, the results suggest that trial periods are used significantly more in the construction industry than in other industries. Regression analysis results also showed industry significance (Table 4.3) for the construction industry over all other industries. This was significant in Regressions $\mathrm{B}, \mathrm{C}$ and $\mathrm{E}$ of regression analysis with the likelihood of being on a trial period increasing by up to 43 times in construction than for other industries (Appendix D).

The size of organisations also showed a significant relationship with trial periods however this was not consistent through all methods of analysis. Regression analysis did show a consistently significant relationship between organisation size and trial periods where it was tested in Regressions B, C, D and E. This showed that the likelihood of being on a trial period increased as organisation size increased, this was an increase of one for each unit increase in organisation size.

While the usage of trial periods is not widespread for 15 to 19 year olds, it is clear that there is a high usage of trial periods for 18 to 19 year old males within the 
construction industry in particular. For this group it seems that trial periods have created employment opportunities in a rapidly growing industry. The trend for more males to be employed on trial periods can be attributed to the construction industry, which employs more males than females. Employment in the construction industry presents these young people with the opportunity to gain further qualifications and maybe learn a trade, and the trend for this employment to be within large organisations also provides an advantage as more resource and structure will be present to support the transition to work and ongoing learning. It is possible that these employment opportunities would have existed regardless of the introduction of 90 day trial periods, however it is beyond the scope of this research to establish that. Within the scope of this research this analysis shows a very positive usage rate of trial periods for one group of young people, and this suggests that demand side interventions have made a positive difference for this group. However, for the remainder of this sample group there is no apparent advantage or employment opportunities created by trial periods.

There are significant findings in terms of trial periods and the process and terms of employment. Respondents on trial periods were more likely to have their terms of employment explained to them by the employer (Table 4.2, 19), and an independent samples t-test was conducted to compare the frequency of the employer explaining terms of employment to respondents on trial periods compared to those respondents not on trial periods. There was a significant difference in the frequency of the employer explaining terms of employment to respondents on trial periods ( $M=1.14$, $\mathrm{SD}=0.359)$ compared to those respondents not on trial periods $(\mathrm{M}=1.59, \mathrm{SD}=0.495)$; t $(42.864)=4.643, p=0.00$. These results suggest that there is a significant relationship between explanation of terms of employment and trial periods. Specifically, the results suggest that respondents on trial periods are more likely to have their terms of employment explained to them. Subsequently there was also a significant relationship between being on a trial period and the respondent signing their employment agreement (Table 4.2, 20). An independent samples t-test was conducted to compare the frequency of the employee signing their employment agreement of respondents on trial periods and those respondents not on trial periods. There was a significant difference in the frequency of signing an employment agreement of respondents on trial periods $(M=1.05, S D=0.218)$ and 
those respondents not on trial periods $(M=1.8, S D=0.822) ; \quad t 97.983)=7.206$, $p=0.00$. These results suggest that there is a relationship between signing the employment agreement and trial periods. Specifically, the results suggest that respondents on trial periods are more likely to sign their employment agreement.

Respondents on trial periods were less likely to have negotiated changes to their employment agreement, and this is a significant relationship (Table 4.2, 21). An independent samples t-test was conducted to compare the frequency of negotiation of employment terms by employees who are on trial periods and employees not on trial periods. There was a significant difference in the frequency of negotiation of terms of respondents on trial periods $(M=0.24, S D=0.436)$ and those respondents not on trial periods $(M=0.48, S D=0.503) ; \quad t(35.472)=2.193, p=0.035$. These results suggest that there is a significant relationship between negotiation and trial periods. Specifically, the results suggest that respondents on trial periods are less likely to negotiate terms, as they are often presented with a 'take it or leave it' employment agreement.

Respondents who were employed on trial periods were paid a higher hourly rate than respondents not on trial periods and this was a significant relationship in chisquare testing (Table 4.2, 22). This shows that respondents on trial periods were mostly paid between $\$ 13$ and $\$ 15$ per hour, and are much more likely to be paid over $\$ 15$ per hour than respondents not on trial periods. An independent samples t-test was conducted to compare hourly rates of pay for respondents on trial periods and those respondents not on trial periods. There was a significant difference in the hourly rates of respondents on trial periods $(M=3.19, S D=0.68)$ and those respondents not on trial periods $(M=2.33, S D=0.97) ; \quad t(44.218)=4.677, p=0.00$. These results suggest that there is a significant relationship between hourly rate and trial periods. Specifically, the results suggest that respondents working on a trial period are more likely to be paid at a higher hourly rate. Further analysis confirms this in Regression D with a significant result indicating that the likelihood of being on a trial period increases by over 11 times for each dollar increase in hourly rate (Appendix D). 
Respondents who were employed on trial periods were more likely to work full time hours (30 to $40+$ per week) than respondents not on trial periods and this is a significant result in chi-square testing (Table 4.2, 23). An independent sample t-test was conducted to compare weekly hours worked for those on trial periods and those not on trial periods. There was a significant difference in the hours worked of respondents on trial periods $(\mathrm{M}=2.62, \mathrm{SD}=0.498)$ and those respondents not on trial periods $(\mathrm{M}=0.2, \mathrm{SD}=0.404) ; \mathrm{t}(27.424)=-3.538, p=0.001$. These results suggest that there is a significant relationship between weekly hour's worked and trial periods. Specifically, the results suggest that respondents working on a trial period are more likely to work full time (30 hours per week or more). Regression analysis showed a link between hours worked and trial periods in the two regressions where it was tested (Table 4.3, Regressions $D$ and E) and this indicates that the likelihood of being on a trial period increases by up to 25 times for full time employees (Appendix D).

Respondents on trial periods are more likely to have had performance standards set out for them by their employer than respondents who were not on trial periods, and this was also a significant result in chi-square testing (Table 4.2, 24). An independent samples t-test was conducted to compare the frequency of having set performance standards for respondents on trial periods and those respondents not on trial periods. There was a significant difference in the frequency of performance standards set for respondents on trial periods $(M=0.43, S D=0.507)$ and those respondents not on trial periods $(\mathrm{M}=0.16, \mathrm{SD}=0.373) ; \mathrm{t}(26.034)=-2.231, p=0.035$. These results suggest that there is a significant relationship between setting performance standards and trial periods. Specifically, the results suggest that respondents on trial periods are more likely to have performance standards set for them by the employer. Regression analysis also showed a significant relationship between trial periods and having performance standards set (Table 4.3, Regression C), which indicates that respondents on trial periods are six times more likely to have performance standards set for them than respondents not on trial periods (Appendix D).

This data shows that when trial periods were used they were implemented using fair processes by employers. Respondents on trial periods were treated well by the 
employer, with the exception of a lack of opportunity to negotiate employment terms. Using mostly fair employment processes cannot be solely attributed to trial periods though, as they are more likely to be a factor of being employed by a large organisation with established employment processes and adequate human resources to ensure legal obligations are met.

Interestingly there was no significant relationship found at any level of analysis between a respondent being on a trial period and having an increased likelihood of having employment terminated. The Council of Trade Unions anticipated that employers would use trial period provisions as a way to take on fixed term employees (Rosenberg, 2010) and that a high proportion of those on trial periods would be dismissed. They also anticipated that employers would use trial periods rather than developing and using sound employment practices to recruit new staff (NZ CTU, 2008). However this research shows that these anticipated outcomes have not eventuated for young people in particular.

This research shows that most $(55 \%)$ respondents had only a partial or general understanding of the concept of a trial period, with little knowledge of the legal requirements surrounding them. Within this group many could state only that a trial period was "a time to see if you are suitable for the job" or "time where you work to prove yourself before you get selected". A small portion (15\%) were able to demonstrate a fuller understanding of the legal requirements of a trial period, including the 90 day time period, as evidenced in their comments " 90 days and if I don't perform they fire me" and "Your employer has the right to deny you work after three months if your work is not up to standard". A further $11 \%$ of those surveyed had no knowledge what a trial period was, and a further $11 \%$ were aware that a trial period was linked to a period of time, but they were unaware of the correct time period. For example, one respondent commented that a trial period is "A period you have to work before they make a choice on you, they can fire you in 60 days no problems". Another suggested that it was "Where you work for a few days to see how you go at the job", and "A set number of jobs within the company". The remainder of respondents $(8 \%)$ thought that a trial period was an unpaid period of work, for example "See how you go with no pay, if you are good they will hire you" and 'to see if you have the required skills to work at this job (without pay)". 
As these comments highlight there is a lack of awareness of the purpose and requirements of trial periods among the respondents. A low level of awareness of personal employment rights means young people are entering employment relationships with reduced bargaining power. There is a clear need for more employment related education to be provided to young people before they enter into employment agreements.

\section{Table 4.3:}

\section{Logistic Regression Estimates for Trial Periods}

Dependent variable: Likelihood of being employed on a trial period

\begin{tabular}{|c|c|c|c|c|c|c|c|c|c|c|}
\hline \multirow[t]{2}{*}{ Demographics } & \multicolumn{2}{|c|}{ Regression A } & \multicolumn{2}{|c|}{ Regression B } & \multicolumn{2}{|c|}{$\underline{\text { Regression } \mathrm{C}}$} & \multicolumn{2}{|c|}{ Regression D } & \multicolumn{2}{|c|}{ Regression $\mathrm{E}$} \\
\hline & B & $\mathrm{p}$ & B & $\mathrm{p}$ & B & $\mathrm{p}$ & B & $\mathrm{p}$ & B & $\mathrm{p}$ \\
\hline Age & 0.492 & 0.073 & 0.663 & 0.042 & 0.680 & 0.075 & 0.889 & 0.091 & 0.504 & 0.153 \\
\hline Gender & -1.280 & 0.031 & -1.723 & 0.027 & -1.779 & 0.037 & -3.383 & 0.007 & -2.656 & 0.006 \\
\hline \multicolumn{11}{|l|}{$\underline{\text { Industry }}$} \\
\hline Manufacturing & & & -20.51 & 0.999 & -20.74 & 0.999 & -20.52 & 0.999 & -21.301 & 0.999 \\
\hline Retail & & & 1.068 & 0.216 & 1.054 & 0.280 & 1.373 & 0.278 & 1.315 & 0.182 \\
\hline Hospitality & & & -0.136 & 0.888 & -0.382 & 0.734 & 0.717 & 0.629 & 0.662 & 0.533 \\
\hline Construction & & & 2.608 & 0.050 & 3.765 & 0.024 & 3.601 & 0.215 & 3.395 & 0.045 \\
\hline Communications & & & 1.588 & 0.296 & 1.631 & 0.352 & 2.413 & 0.339 & 2.104 & 0.261 \\
\hline \multicolumn{11}{|l|}{ Management } \\
\hline Organisation size & & & 0.005 & 0.052 & 0.006 & 0.056 & 0.009 & 0.034 & 0.007 & 0.030 \\
\hline Written agreement & & & & & 1.453 & 0.115 & -0.863 & 0.478 & & \\
\hline Performance stanc & ards & & & & 1.819 & 0.045 & 1.970 & 0.127 & 0.446 & 0.567 \\
\hline Feedback & & & & & -0.033 & 0.816 & -0.230 & 0.247 & & \\
\hline Hourly rate & & & & & & & 2.423 & 0.015 & 0.716 & 0.172 \\
\hline Hours & & & & & & & 3.221 & 0.011 & 2.560 & 0.004 \\
\hline Nagelkerke R Squ & & 0.235 & & 0.391 & & 0.513 & & 0.707 & 0.5 & \\
\hline
\end{tabular}


In summary, the survey data shows that trial periods are not widely used for young people $(21 \%$ of respondents overall), they are used widely for young people who are working full time, with over $81 \%(\mathrm{~N}=13$ out of 16$)$ of respondents employed on a full time basis reporting they were employed on a trial period. When trial periods were used some factors appear to be significant determinants, including a formal written employment agreement and an explanation of employment terms by the employer. The employee is then more likely to seek sign the agreement and to enjoy defined performance standards, full time hours of work and a higher hourly rate. Overall, the survey data shows that, where trial periods are used by employers it is in a structured way which meets employment obligations. However, this only applies to one distinct group of employees. Where trial periods are used they are contrary to union anticipated issues that written employment agreements would not be provided, and that there is minimal monitoring of performance levels during the trial period.

Qualitative data gathered from key stakeholders shows the wide range of views over the principle of trial periods. The case for trial periods was predictably put most strongly by the business stakeholder who emphasised that the goal of the 90 day trial periods was to provide employers with flexibility in order to increase work opportunities for young people (as well as other groups), as the business stakeholder explained:

One of the things about the 90 day trial period is work readiness. You're taking on a raw person with no skills, background, whatever else and usually the average employer taking on a young person will say that the first three months are a waste of time because they are not even in tune with the idea of turning up to work on time, focusing on the fact that they put their personal life aside for a few hours a day. That stuff takes time to gel.

Therefore, it was explained that trial periods can mitigate that initial cost to the employer by providing a reasonably straight forward and no risk means of employment termination should that be necessary, as explained by the business stakeholder:

Let's call it an investment package; it's the cost of an employer taking on an untried, untested, unproven worker with the prospect that once in it's very difficult to get them out. With the growing body of law and complexity around, you know one step in the process is wrong and you get the whole lot wrong 
and you are penalised for it. That became not just a physical barrier, it became a mental barrier to employers and the first sacrifice was that you don't take people on you don't have a really good feel for.

Despite the logic of this point of view this research showed that trial periods were not widely used for 15 to 19 year olds and other stakeholders interviewed anticipated this finding. They generally felt that the labour market is so tight that employers have plenty of choice, and young people are not being provided with work opportunities as employers see them as low skilled, untested and time consuming in terms of training and resolving performance issues that may arise. Stakeholders felt that this was such a significant barrier that it could not be resolved by loosening EPL in the form of a 90 day trial period. An additional reason for the low uptake of trial periods could be union intervention in preventing large employers from using trial periods. Prior to the introduction of trial periods employee representatives came out strongly in opposition as they claim that New Zealand is already rated as an easy place to do business, where it is relatively easy to hire and fire (Doing Business, 2011). As an alternative and more effective way to improve employment levels unions promoted increased focus and investment on increasing the skills of vulnerable employees. Following the introduction of trial periods unions have remained critical and have not found evidence for trial periods increasing the employment rates of vulnerable employees (CTU, 2010).

The union stakeholder expressed a philosophical objection to trial periods due to the removal of natural justice and that the right of appeal should employment be terminated. This has led to the union strategy of restricting the use of trial periods where this is possible. As the union stakeholder commented:

Creating a higher minimum standard in those collective agreements was the strategy of unions so that businesses that were organised were sort of encouraged and I guess pressured to steer clear of 90 day trial periods.

Stakeholders in youth transition and business felt that the consequences of this strategy were that trial periods would therefore tend to be used by smaller, nonunionised employers running businesses such as cafes and shops. However, stakeholders could also identify barriers to small employers taking on young people on trial periods. Further to this, the cost to a small business of training someone with 
few skills represents a high cost as productive time, and therefore income, is lost while potentially investing on someone else. Overall it was seen that small employers especially are carrying such high levels of risk in their businesses already that they will not take on more risk with a low skilled and untried employee.

Asked why they thought there was a low use of trial periods for young people the youth transition service stakeholder commented that employers were working with a high level of risk in running a business during a recession, and employing an untested young person only increased their risks.

The stakeholders interviewed anticipated the low rate of usage of trial periods overall. While there are some areas of high usage, most young people have not experienced any advantage in the labour market as a result of trial periods predominantly because they are employed on a part time or casual basis in order to balance ongoing education with employment.

\subsection{Characteristics of Employment}

This section outlines the broad characteristics of the employment of young people in the sample in their current or most recent employment. Overall there is relatively little turnover in employment, and employment opportunities are generally clustered in the retail and hospitality sectors with low level tasks being carried out by most respondents.

The average length of time that respondents have been employed was reasonably lengthy considering the age of respondents. The average length of time in their current or most recent job was just over one year $(M=12.13)$, however there was a large standard deviation $(S D=14.5)$, and accordingly a sizeable range exists with a minimum of two days employment in a single job through to a maximum of 84 months employment in a single job.

The sample as a whole had held a small number of jobs $(M=2.36)$, however a wide range was seen from one job through to a maximum of 11 jobs. Logically the 
number of jobs held is linked to age. Respondents aged 18 and 19 years have held a higher number of jobs than those aged 15, 16 and 17 years and clearly this was due to the length of time since leaving school and therefore increased exposure to the labour market. Analysis of the number of jobs held and hours worked showed a significant link (Table 4.2,3) and this indicates that the more jobs a respondent has held the more likely they are to be in full time employment. This supports the view that part time employment is used as a stepping stone to full time employment (Topel, 2009). This again highlights the concerning recessionary trend of diminishing part time opportunities for young people, and the long term effect on a successful transition to employment.

The industries in which respondents were employed were dominated by hospitality $(29 \%)$ and retail $(26 \%)$. Smaller numbers were employed in manufacturing $(5 \%)$, construction (4\%), communications (1\%) and local government (3\%). Interestingly a significant number of respondents (31\%) indicated they were employed in other industries and this category was comprised of the service sector (cleaning, home and property care, child and aged care). While all age groups showed strong employment in the retail and hospitality industries, employment in manufacturing was confined to 18 and 19 year olds, employment in the construction industry was confined to 18 year olds, and employment in government or local government featured only for 19 year olds. These findings are broadly consistent with Census 2006 data showing that youth in the Wellington region are mainly employed in retail trade, and accommodation, cafes and restaurants. However in this sample there is a significantly higher representation of young people employed in hospitality, and a slightly lower representation of young people employed in retail (Department of Labour, 2008; Department of Labour, 2010).

Tasks carried out by respondents in their employment showed the degree of skill utilised and responsibility given. The majority of tasks carried out fell into the customer service category such as waitressing, reception, taking orders and serving. In descending order; cleaning duties at a low level were reasonably frequently reported, followed by general stock handling tasks, food and beverage handling tasks, and laboring/agricultural work made up a smaller portion of tasks carried out. A small portion of respondents reported involvement in tasks that required a higher 
level of skill, and higher levels of responsibility given. These tasks fell into areas of cash handling, care, teaching and higher level office administration. However, the majority of day to day tasks carried out by respondents fell into low skill and low responsibility areas as outlined in the literature (Caritas, 2003; Department of Labour 2010; Gasson, 2003).

Although these low level tasks are useful in the early stages of employment, the clustering of young people in retail and hospitality may mean they remain in low level roles long term due to the lack of formal learning opportunities and career paths in these industries. Promoting and facilitating employment opportunities into other industries would benefit young people as well as providing future skilled employees for those industries.

Most respondents were employed in small to medium sized organisations. The largest number, $43 \%$, were employed in organisations with between one and 10 staff members. A significant portion of $23 \%$ were employed in organisations with between 11 and 20 staff, and organisations with 21 to 50 staff employed $16 \%$ of respondents, while only $4-5 \%$ were employed in organisations with more than 51 employees. Within this research there is a trend for younger people to be employed in smaller organisations. Although small employers are providing employment opportunities for young people they tend to have less robust employment and performance processes than larger employers, and can offer less to the employee in terms of up skilling, ongoing education and career opportunities. The lack of time and resource available means these areas are not a focus for small employers and this means young people can miss out. Positive examples were described by stakeholders where these small employers were able to provide unit standard based training to young employees.

Qualitative information gained from stakeholder interviews provided a business perspective that young people are unrealistic about the entry level jobs they seek and will avoid jobs that involve cleaning or other low skill tasks. This perspective was not supported by the data gathered from young people as the majority carried out low level tasks within their employment. Overwhelmingly stakeholders commented that employers, especially large ones, need to be incentivised to take on 
a certain percentage of young people into their employment as part of future proofing their organisations, as well as meeting their social obligations to improve the outcomes of young people. This is an interesting view, contrasted by the fact that in this sample most young people were employed by small organisations who have fewer resources to train and support new entrants to the labourforce. However Wellington data (Department of Labour, 2008) shows that most young people in the region are employed by large employers, therefore this trend could be due to geographical differences with fewer large employers in the areas surveyed. The incentivising of employment of young people, directed towards large employers is an interesting concept worthy of further investigation. However, in areas where there are fewer large employers there could be similar incentives for small employers with a focus on encouraging formal training opportunities.

In summary, the frequency of job changes are lower than the literature suggests (Holzer, 1994; Topel, 1992) and this could be to the respondents disadvantage as job changes bring with them increased skills and higher pay rates. Those in the sample do work mostly in retail and hospitality as the literature suggests (Department of Labour, 2008).

\subsection{Terms of Employment}

This section looks more closely at the individual terms of employment of the respondents. There is a trend for increased formalisation of the employment process, and for improved terms of employment to be linked to older respondents, those with a higher level of qualification and those working full time hours. Overall there is a low level of awareness among respondents of their employment terms and rights.

The Employment Relations Act 2000 (as amended) requires that all employment agreements are in writing. Of the respondents, $58 \%$ were given a written employment agreement. Analysis of the provision of a written agreement and hours showed a significant result, (Table 4.2,4) and this indicated that those working more hours per week were more likely to receive a written employment agreement. For 
example $83 \%(\mathrm{~N}=24 / 29)$ of respondents working 30 or more hours per week received a written agreement, and only 49\% ( $\mathrm{N}=34 / 70)$ of those working one to 29 hours per week received a written agreement. These findings are supported by literature in Caritas (2003) and Gasson (2003), which found younger part-time employees were less likely to receive an employment agreement in writing.

An explanation of the terms of employment by the employer was provided to $51 \%$ of respondents, with the remainder reporting no discussion had occurred. It was seen to be more likely a respondent had their terms of employment explained to them by their employer if they were a full time employee (Table 4.2, 6).

Signing of an employment agreement is significant as it indicates a formal offer and acceptance of the terms contained, and is therefore an indicator of the level of formality included in the employment process. Most respondents (70\%) reported that they had signed their employment agreement, and those aged 18 and 19 years were much more likely to have done so, with a significant result shown in testing (Table 4.2, 7). Analysis of signing an agreement and the number of weekly hours worked shows a significant result (Table 4.2, 8). Indicating the more hours worked per week results in an increased likelihood of the employee signing their employment agreement. For example, $83 \%(\mathrm{~N}=24 / 29)$ of respondents working 30 or more hours per week signed their agreement, whereas only $45 \%(\mathrm{~N}=32 / 71)$ of those working one to 29 hours per week signed their agreement.

The data shows that respondents working full time hours experience a more comprehensive employment process with legal obligations regarding employment agreements being met. However those working part time or casual hours (mostly younger employees) are not experiencing these basic processes. This is a vulnerable group as they lack skills and experience, and the lack of formal employment process means they remain vulnerable as they have no formal employment agreement. This is a difficult situation to remedy as policing employment agreements for young people may mean employers are reluctant to employ them and their employment opportunities are often limited. A possible approach is to ensure young people have knowledge of their employment rights at an early stage. 
The negotiation of changes to their terms of employment by respondents was not widely seen and only $8 \%$ of respondents reported that they had engaged in some form of negotiation. Where respondents did negotiate changes these were largely requests for more hours of work or more shifts. A total of $49 \%$ of respondents did not negotiate for changes to terms of employment as they did not feel that changes were needed, and a further $43 \%$ of respondents reported that they did not negotiate for changes to terms of employment as they felt the employment agreement was offered to them on a "take it or leave it" basis; therefore there was no opportunity to negotiate over terms.

Employees are given the right to seek independent advice on their terms of employment under the Employment Relations Act 2000. Only 7\% of the respondents chose to exercise this right. Where independent advice was sought it was from family members only.

This lack of assertion in the employment relationship demonstrates the imbalance of bargaining power young people experience in their early experiences in the labour market. Again, an increased awareness of employment rights within their secondary education may begin to balance the power in employment.

Analysis of hourly rates of pay shows that most respondents (41\%) reported an hourly rate of between $\$ 13$ and $\$ 15$, and $24 \%$ reported a lower hourly rate of between $\$ 10.40$ and $\$ 13$. At the lower end of payments, $20 \%$ of respondents reported a pay rate of less than $\$ 10.40$ per hour, and the smallest proportion of respondents, $15 \%$, reported a rate of over $\$ 15$ per hour. As hourly rates are connected with age by way of legislative minimums, further meaning can be added to the survey data by analysing hourly rates for different age groups.

Analysis of pay rates and the number of hours worked per week showed a link (Table 4.2, 9) indicating that the higher the number of hours worked per week the higher the hourly rate paid. For example, of those working 30 or more hours per week, $79 \%$ were paid $\$ 13$ per hour or more $(\mathrm{N}=23 / 29)$. In contrast of those working from one to 29 hours per week, only $46 \%$ were paid $\$ 13$ or more per hour. 
Analysis of normal weekly hours of work showed that the largest proportion of respondents were employed for only one to nine hours work in each week $(31 \%)$, and following this was another large group of respondents who were employed for between 10 and 19 hours per week (27\%). Seventeen percent of respondents were employed to work between 30 and 39 hours per week, $12 \%$ of respondents were working 40 or more hours per week, and the smallest proportion, $13 \%$, worked between 20 and 29 hours per week.

It was shown that higher weekly working hours, ranging from 30 to more than 40 hours per week, are more likely to be worked by respondents in the upper age bracket of 19 years (50\% and 59\% respectively). Weekly hours of 20 to 29 per week are dominated by 18 year olds (54\%), with 19 year olds also featuring strongly $(31 \%)$. At 10 to 19 hours per week the same trend is seen, with 18 year olds accounting for $30 \%$ of this group, 19 year olds at $26 \%$ and with 16 year olds becoming more represented with $22 \%$. The category of one to nine hours worked per week sees a stronger response from 15 year olds, but with other age groups represented as well. The overall trend seen in this data is that the older respondents were working more hours per week and this is significant, (Table 4.2, 10). There were gender differences in working hours, with males being more likely to work between 30 and 40 or more hours in each week and females being more likely to work between one and nine hours per week and this is a significant result (Table 4.2, $11)$.

This data shows overall that the more hours worked the higher the rewards, and this is consistent with the trend that full time employees enjoy better employment processes and terms of employment. Employers see full time employees as more integral to their business and therefore they will invest more time in their development and will reward them accordingly.

Most respondents had the support of family and friends to find employment (56\%) however $31 \%$ indicated they had no support at all. Of the remainder, $9 \%$ indicated that a government agency had provided job finding assistance, and for the last $3 \%$ of respondents agencies specialising in youth transition provided support. Other 
education organisations provided support to $1 \%$ of respondents. Qualitative data emphasised the importance of family and friends in gaining employment opportunities, but those same networks can also be the source of barriers to employment.

It was seen by the careers advisory stakeholder that family circumstances can also hold a young person back from exploring employment options by limiting their employment aspirations, as commented:

Students are quite narrow about their career prospects and are just influenced by what their family do and don't look any wider than that.

The business stakeholder also identified family as a potentially strong negative influence on employment outcomes due to a lack of knowledge of employment choices available and a lack of aspiration for employment as commented:

There are whole populations of people for whom work has never been a real prospect or hasn't been an easy thing to do. So there are whole communities of people whose aspirations to work aren't that high. The worst end of it is multigenerational beneficiary type environments, but there are still communities who are not so dependent on benefits but for whom the community aspirations are not high. You are looking at families who are probably doing two or three jobs often at the low skill end to make ends meet. And that is all their kids see. The kids are going to school but they are coming home and they are managing a family so that the parents can go out and earn money. They are not being exposed to opportunities that might otherwise grow them and their families for the future. They've been locked into a lifestyle roster that is self limiting.

It is clear that family connections do play a key role in the transition from education to employment. The positive side of this was highlighted by the youth transition stakeholder who provided examples of family networks delivering employment opportunities for young people, and in particular removing them from negative situations to provide them with meaningful employment as well as ongoing protection and support, as commented on several situations where a young person was recruited into employment by family:

He's had to give up dope to work in forestry, and he has skilled up. 
He's moved away from Dad, again he's had to give up dope, he is working full time on a farm.

He had a farming opportunity, he got kicked off for a little while, and he had to do some work to get the job back. But it's that employer that is going to have a bit of give and take. These kids are going to be fine. And now that they are turning 18, the difference is they have got skills and purpose, they have to pass a drug test, they have got money, more responsibility and they'll be good.

The support of family and friends in gaining, and keeping, initial employment is a key advantage to young people and they should be encouraged to use these networks to their advantage. Where family and friend networks cannot provide this support there is an opportunity for careers support within schools to increase their focus on exposing young people to different careers by engaging with business to address this deficit.

\subsection{Education}

This research highlighted an overall trend amongst young people to remain in school for longer than young people have in the past. Differences emerged in the stage young people chose to leave school, the reasons they left and their qualification level on leaving the school system.

Of the total sample, just over a quarter remained at school when they were surveyed. Separate analyses have been conducted on the subsample of school leavers. Most respondents were recent school leavers, with $41 \%$ of the sample having left in 2011 and $24 \%$ having left in 2010. These numbers are predictable given the data sampling method, which was aimed at recent school leavers. The majority of respondents (55\%) who have finished school left between 2009 and 2011.

Analysis of the year of leaving school and weekly hours worked shows a significant relationship (Table 4.2, 1). Respondents who left school in 2007 and 2008 are more likely to be working full time hours, and those who left school more recently (2009, 
2010 and 2011) are more likely to work part time than full time. Those who left school most recently (2010 and 2011) are working the least hours of between 1 and 19 hours per week. This transition over time from part time to full time employment could reflect the need to balance further study with employment and the use of part time employment as a transition to full time employment (Topel, 1992). The trend for reduced part time employment in Lower Hutt and Porirua between 2006 and 2013 (Tables 3.1 and 3.2) is particularly significant as this indicates a reduction in early employment opportunities for young people, especially those in Porirua, as this city has experienced a significant drop in part time employment. Without this first essential step into employment, the transition from education to employment is made more difficult as part time roles increase understanding of work obligations, career opportunities and confidence. A lack of exposure to part time work means this transition may be stalled and have negative effects on future employment (Gregg, 2005). Increasing the number of part time employment opportunities for young people should be a priority at government and/or region/city level in order to avoid more long lasting negative employment effects, such as long term unemployment and ongoing low skill-low pay employment.

In analysing the year respondents left school and the stage of schooling reached, it is clear that the number of respondents who left school on the completion of Year 13 increased over the years covered in the survey. Accordingly numbers leaving school on completion of Year 12 have reduced over the years surveyed, those leaving school on completion of Year 11 are reasonably consistent over time, and those leaving on completion of Year 10 have reduced significantly over time, from $33 \%$ in 2007 to $7 \%$ in 2011. The relation between these variables was significant, (Table $4.2,2)$ as the more recently respondents had left school then the more likely they were to have stayed on to complete their secondary education at Year 13. Completion rates of secondary school to Year 13 have increased over the last five years and the literature supports this finding with increasing numbers of young people leaving school with higher level qualifications, and therefore remaining in the education system for longer to achieve this (State of Education in New Zealand, 2008). This can be attributed partly to a change in education policy during 2007 , which put tighter controls on early leaving exemptions for students, with those who wished to leave school early being encouraged to remain in the education system 
(State of Education in New Zealand, 2008). However, economic conditions have also encouraged students to remain at school for longer with it being more likely that in a recession situation job opportunities diminish especially for those with few skills and minimal work experience. Therefore, remaining in secondary education for longer is preferable to being unemployed. Whether this trend proved advantageous or not was the focus of comments from stakeholders interviewed. Those from business and youth transition support areas felt that young people were too rushed through the school system with a heavy focus on credits to be gained, rather than having time to explore their strengths and opportunities. It was generally felt that schools could work harder to recognise and develop skills in their students, and that although not all students will excel academically, they will have other skills that could be channeled into appropriate work choices. The career transitions stakeholder and the youth transitions stakeholder supported this by commenting that some students stay at school too long, and for some there is little to gain by staying to complete year 13 as not all students are suited to a university level education. As the youth transition stakeholder commented:

I think we sold young people a real myth in telling them that they needed to stay in school until Year 13. When we did that then we abolished apprenticeships, so we had all these kids stuck in school till year 13 who would have been capable of getting into work.

For these young people, stakeholders felt it would be advantageous to leave school earlier in order to gain work based training and employment, however there are currently few opportunities in the labour market for students who fit into this profile. Research results did demonstrate that an early exit from secondary education can prove advantageous, and this was seen with respondents of Pacific Island ethnic origin in particular. In data analysis this group of respondents showed earlier school leaving stages, however they went on to achieve NCEA Level 2 qualifications possibly through other education providers and were receiving higher hourly rates and more full time work in comparison to other ethnic groups. However, it is probable this is a short term advantage only and in the long term this group could fall behind others who chose to remain in education longer. This was not able to be tested in the data collected. 
The level of qualification achieved in schooling was also identified as having an effect on outcomes as those with higher levels of education are more likely to be employed (Ministry of Education, 2006). In this sample most respondents had achieved NCEA Level 2 as their highest qualification (30\%), closely followed by respondents who had achieved NCEA Level 1 as their highest qualification (28\%). A large number of respondents (25\%) indicated they had not achieved any qualification, and in contrast, $14 \%$ of respondents indicated they had achieved a qualification higher than NCEA Level 2 and this tended to be course or trade related.

In the qualitative data, interesting comments were provided by the youth transition stakeholder that the education system's focus on all young people achieving Level 2 NCEA is not without its flaws. It was explained that while it may seem the overall education level of young people was increasing, there are different values attached to different courses as far as the labour market was concerned. This situation may mean some young people will struggle to gain employment due to the creation of different values within the same qualification, as the Youth Transition stakeholder explained:

You can stay in school and get a very academic NCEA Level 2 in English, Statistics, Chemistry and Physics - an academic Level 2 which is a lot of hard work. Or you can come out of school and you can get a NCEA Level 2 attached to a course and it will be in computing or CV preparation based around the National Certificate in Employment Skills. But when you present that certificate it says NCEA Level 2 and so the baseline is not consistent.

The strong focus on credits to gain qualifications was also commented on by the careers transition stakeholder in negative terms:

The kids are quite hurried through school and we are so busy doing the syllabus and all the requirements and all the compliance things, we don't get a chance to be exploratory and have a look and have a go. It's all so tied up with outcomes and some of those outcomes aren't what the kids need at the moment. They are in need of experience rather than just getting credits. And the kids won't do anything unless it's got credits. They are only starting to be driven by anything else when it's time to leave school and they realise they haven't seen or heard all the things they need to. 
However, more positively the business stakeholder observed a much higher potential in young people than they were currently achieving, and through a greater connection with business during their education, believed that young people could be inspired and motivated beyond their modest ambitions:

The innate ability of many kids is far higher than the sorts of things they are exposed to. But we have a school system that is more about delivering curriculum than it is about developing choices. Business wants a far greater connection to education so that kids are being developed with a real life kind of awareness of the business of work and the opportunities there are.

However, the business stakeholder expressed frustration with the education system and the low literacy levels young people emerge with, as well as the barriers to business engaging more effectively with education to deliver work ready young people to employers. The barriers identified were the layers of bureaucracy and inertia in the education system, including teacher unions and policy makers. It was also noted that career support for young people in schools is under-resourced and variable in its delivery, and resourced correctly would be a valuable tool to identify strengths in young people and guide them into employment, as commented:

There is an awful lot more work out there than people think and again some of these kids don't know where to look. There needs to be some sort of filter or support to give them a sense of self awareness and some aim.

In summary, the education data shows that in this sample, respondents who have left school most recently are more likely to be working part time, and respondents are remaining at school for longer than they have in the past, therefore continue to a later stage in their education. Qualification levels achieved by respondents showed that $25 \%$ of those who left school had achieved no qualification. Stakeholders provided contrasting views of young people remaining in education for longer; that some are more suited to leaving school earlier to pursue employment or alternative education channels and that others, although they remain to complete year 13, are still rushed through the syllabus with no time to prepare for employment. Despite young people remaining in school longer, there are still large numbers leaving with no qualifications, which is a barrier to securing employment. It is evident there is an opportunity for schools to encourage young people to gain qualifications in whatever 
form suits them best, and to provide more early education to ensure young people are work ready in terms of knowledge about employment rights and career options.

\subsection{Transition from education to employment}

The transition of young people from education into employment has emerged as a significant theme in this research. Key themes identified were: variable career advice available through schools; a lack of transition support into employment; and a lack of meaningful access pathways into employment. Stakeholders were united in finding young people to be poorly prepared for making career decisions, lacking in skills, confidence and direction. Transition processes in the past were more linear and structured with apprenticeships and training programs available, albeit within a narrower occupational field (Higgens, 2002). Currently support for youth entering employment is available in apprenticeships, the Gateway programme and youth transition services, with sporadic careers advice provided at school. These methods of support seem insufficient for young people in terms of overall numbers, there is not enough support to cover all young people making the transition from education to employment and added to this young people face more diverse and individualistic career pathways (Higgens, 2002), with an increased exposure to unemployment and more mobile careers (Rea, 2009).

The literature, and the stakeholders interviewed are unified in finding young people do best in early employment where they have support in sampling different occupations and navigating early employment experiences (Hodkinson, 1996), either from family or agencies (Ball, 2000). The earliest opportunities to access this support are through career advice in schools, which both the literature (Boven, 2011) and all stakeholders identified as lacking.

The stakeholder providing careers advice in schools expressed frustration with a lack of resource to assist young people to transition well into work, with there being few intermediate steps between school and employment, as commented: 
It would be nice for them to have maybe a year or six months of mentoring when they have left school to support them through all the difficulties. If we could do a real life skills programme without the kids saying "are there credits at the end" then we could prepare them better. But because everything is so credit and results driven we can't afford that luxury.

Although this stakeholder did identify some positive steps taken by local employers, retailers in particular, who have enabled young people to combine work experience with completing unit standards at the same time. This was a significant advantage for the young people as this could increase their confidence in the workplace and make finding future employment easier. The careers advisory stakeholder also found one of the current youth transition programmes to be a good example of what could be a more widespread initiative and describes the advantages of the programme:

It gives them a very nurtured first step into the world of work. We find the jobs and we take them to the first interview. So they've had their hand held. They are all proud and they can go off and go to work now because they have had that experience and been mentored while they did it. Gateway gives them the chance to try a job and see what they enjoy doing, it gives them a reference to use to get more work and that is valuable.

From a union stakeholder point of view making a successful transition from school to employment is the biggest challenge young people face, due to the lack of a comprehensive youth transition service. Services tend to be targeted towards 16 and 17 year olds, while 18 and 19 year olds are missing out on specialist assistance they could benefit greatly from. Additionally the lack of careers advice in schools means that links are not well established between local employers and trainers and young people.

Transitions into employment for young people can tend to be fragmented as seen in the research with casual, part time and temporary employment common place (Dupuis, 2006; Marks, 2006). This research shows that young people are using part time work successfully as a transition to full time employment and whether this is a deliberate strategy or an outcome of combining ongoing education with employment, it is a successful means of gaining full time employment. Those in full time employment have better outcomes than those in part time work as full time 
employees are more likely to have higher earnings, higher levels of satisfaction and hold higher levels of skills (Marks, 2006).

Youth transition is a key step in ensuring positive employment outcomes, and this research shows there are many opportunities to improve youth transitions from school to employment in particular. The resource allocated to career advice within schools is too low to provide effective individual support for large numbers of young people and should be an area to consider extra resource to make a significant impact on transition outcomes. Although positive initiatives for introducing young people to employment were mentioned, these could be more widespread to ensure young people have increased exposure to employment opportunities. This would require stronger links between schools and business, which would be advantageous to young people initially and to business, with a longer term view of developing more young people. The youth transition support provided to young people is aimed at particular groups, such as those not in employment or education (NEETs) or young parents. There are many young people who could benefit from early transition support before falling into these categories and youth transition support could be more effective if it was more widely available.

\subsection{Performance Management}

This section examines the performance management framework provided for young employees by the employer. The literature reviewed suggests that a performance management process should set clear performance expectations for the employee, include regular feedback about the level of performance (positive or negative), provide an opportunity for an employee to comment on their own performance and ensure the employee is provided with training to ensure they can reach the required performance standards (Folger, 1985).

However, most respondents in the sample had no discussion or written agreement covering how or when performance would be reviewed (57\%), with another large group of respondents $(21 \%)$ not knowing if these arrangements were discussed or 
written into their agreement. Respondents who indicated that there had been a discussion or something in writing about how and when their performance would be reviewed made up only $22 \%$ of responses. Analysis of hours worked showed a link to having performance standards set out (Table 4.2, 12), this indicated that the more hours worked per week the more likely there is to have been a discussion or setting out of performance standards in some manner. For example, 31\% ( $N=9 / 29)$ of respondents working 30 or more hours per week had established performance standards, and only $19 \%(\mathrm{~N}=13 / 70)$ of those working one to 29 hours per week had established performance standards.

Less than half of respondents received negative feedback from their employer (45\%), and where the employer identified an area of performance that was not to the desired standard it was most frequently in the area of timekeeping and attendance (15\%), followed closely by technical skills (14\%). Seen at fairly similar levels were personal presentation (4\%), work relationships with co-workers or customers $(5 \%)$, and other areas such as; sleeping on the job, lack of concentration, working too slowly and failing to follow workplace guidelines. These occurrences amounted to $7 \%$ of responses.

A greater proportion of respondents (66\%) received positive feedback from their employer. Where the employer identified a positive area of performance it was mostly in the area of technical skills (25\%), and a further $16 \%$ of respondents received positive comments on their work relationships (either with colleagues or customers). Positive feedback was given to $8 \%$ of respondents regarding their personal presentation, and a further 7\% reported they had received comments praising them for being hardworking, quick to learn and able to work well on their own. Analysis of positive feedback and hours worked showed a significant relationship (Table 4.2, 13), indicating that part timers (those who work one to 29 hours per week) receive less positive feedback than those who work 30 hours plus per week. And those more full time employees receive a large amount of positive feedback on their technical skills $(48 \%, N=14 / 29)$, followed by work relationships $(21 \%, N=6 / 29)$. 
In summary, this section shows that performance management for these young people was not particularly formal and performance standards were not always established. Once again, more comprehensive performance management processes are seen with full time employees. This is unfortunate for part time and casual employees as they would benefit from feedback on their performance. An increase in awareness of employment rights could result in a more confident employee able to ask for feedback from their employer.

\subsection{Employment Termination}

In this section the termination of respondents' employment is examined to identify factors involved and to provide a basis for discussion on trial periods in further sections. Two levels of statistical analysis were used in regard to the employment termination data. Initially, simple chi-square tests were carried out to indicate the variables of significance. Secondly, analysis was carried out on employment termination using regression analysis. Table 4.4 contains regression results, identifying significance levels between employment termination and key variables. Regression analysis was carried out in five steps, beginning with core demographic variables in Regression A, adding employer characteristics in Regression B, adding process and performance management variables in Regression $\mathrm{C}$, adding variables relating to employment terms in Regression $D$ and finally attempting to isolate key variables in Regression E.

Termination of employment was experienced by $30 \%$ of respondents. Regression analysis of age showed a significant relationship with termination of employment in Regression A and Regression D, with the likelihood of having employment terminated increasing by between 1.57 and 1.66 for each year of age (Appendix E).

Respondents' gender did show a significant relationship with employment termination in chi-square testing (Table 4.2, 14) with more males than females having their employment terminated. Gender also showed a consistently significant relationship with employment termination in regression (Table 4.4) with the likelihood 
of having employment terminated being between 3.1 and 4.8 times more likely for males than for females (Appendix E).

This data demonstrates that older respondents were more likely to be employed full time and on a more formal basis, therefore if there was a performance issue a formal termination process was required. Younger respondents were employed on a part time/casual basis with more fluid employment terms. Therefore, if there was a performance issue, the employer would be less likely to use a formal termination process and more likely to not roster that young person on again. Once again these part time or casual employees are more vulnerable in employment, with termination rates probably hidden within less formal employment arrangements.

The industry where respondents were employed had a significant relationship with employment termination. Regression analysis (Table 4.4) showed industry significance in Regressions C and D, with the likelihood of employment being terminated increasing by between 26.81 and 27.68 for the manufacturing industry compared to other industries (Appendix E).

This industry bias for termination also accounts for the gender bias in termination, as males are more likely to be employed within the manufacturing industry. It is likely that high termination rates in manufacturing come about from more strictly enforced performance standards in terms of health and safety, time keeping and attendance.

Whether or not performance standards were set by the employer showed a significant relationship with employment termination in Regression $E$ only, with a small effect of a 0.2 decrease in the likelihood of employment being terminated if performance standards were set (Appendix E). This finding suggests that, all else being equal, if employees are made aware of the performance standards they are required to meet, they are less likely to behave in a way that would warrant termination of their employment.

Reasons for the termination of employment were largely due to a lack of work $(50 \%)$, with $27 \%$ of respondents either not asking or not being told the reasons for the termination of their employment. Those who preferred not to reveal the reasons for 
termination of employment made up $13 \%$ of responses and those whose employment was terminated for performance reasons made up only $10 \%$ of responses.

In summary, termination of employment was reasonably frequent for those young people surveyed, more frequent for males and usually for reasons of a lack of work rather than performance problems.

Table 4.4:

Logistic Regression Estimates for Termination of Employment

Dependent variable: Likelihood of having employment terminated

\begin{tabular}{|c|c|c|c|c|c|c|c|c|c|c|}
\hline \multirow{2}{*}{ Demographics } & \multicolumn{2}{|c|}{$\underline{\text { Regression A }}$} & \multicolumn{2}{|c|}{$\underline{\text { Regression B }}$} & \multicolumn{2}{|c|}{$\underline{\text { Regression C }}$} & \multicolumn{2}{|c|}{$\underline{\text { Regression D }}$} & \multicolumn{2}{|c|}{$\underline{\text { Regression E }}$} \\
\hline & $\mathrm{B}$ & $p$ & $\mathrm{~B}$ & $\mathrm{p}$ & $\mathrm{B}$ & $\mathrm{p}$ & B & $\mathrm{p}$ & B & $\mathrm{p}$ \\
\hline Age & 0.455 & 0.044 & 0.441 & 0.075 & 0.435 & 0.106 & 0.464 & 0.091 & 0.507 & 0.023 \\
\hline Gender & 1.169 & 0.029 & 1.349 & 0.028 & 1.378 & 0.033 & 1.570 & 0.022 & 1.134 & 0.036 \\
\hline \multicolumn{11}{|l|}{ Industry } \\
\hline Manufacturing & & & 2.561 & 0.087 & 3.289 & 0.040 & 3.321 & 0.049 & 2.485 & 0.061 \\
\hline Retail & & & 0.244 & 0.755 & 0.481 & 0.568 & 0.294 & 0.733 & 0.472 & 0.496 \\
\hline Hospitality & & & 0.393 & 0.579 & 0.256 & 0.735 & -0.28 & 0.972 & -0.175 & 0.790 \\
\hline Construction & & & 1.064 & 0.411 & 0.672 & 0.608 & 0.864 & 0.534 & 0.460 & 0.684 \\
\hline Communications & & & -0.721 & 0.659 & -0.671 & 0.728 & -0.602 & 0.758 & -0.588 & 0.674 \\
\hline \multicolumn{11}{|l|}{ Management } \\
\hline Organisation size & & & -0.001 & 0.760 & -0.002 & 0.578 & -0.002 & 0.544 & & \\
\hline Written agreement & & & & & 0.508 & 0.457 & 0.961 & 0.250 & & \\
\hline Performance standards & & & & & -1.873 & 0.071 & -1.760 & 0.095 & -1.598 & 0.043 \\
\hline Feedback & & & & & 0.168 & 0.153 & 0.193 & 0.115 & & \\
\hline Hourly rate & & & & & & & -0.259 & 0.574 & & \\
\hline Hours & & & & & & & -0.907 & 0.309 & & \\
\hline Nagelkerke R Square & & 0.309 & & 384 & & .440 & & .457 & 0.3 & \\
\hline
\end{tabular}




\subsection{Working Experiences}

This section outlines the respondents' own views of their working experience, the feedback they received and their expectations for the future in three key areas of employment, income and education.

Respondents' views of the feedback they received from their employer were largely that it was fair $(70 \%)$, however a small proportion (5\%) felt that the feedback they were given was unfair, and $26 \%$ reported that no feedback had been given. No significant differences on the basis of age, gender, ethnicity or qualifications were found in how respondents perceived feedback from their employer.

In cases where employer feedback was perceived to be fair respondents indicated that they appreciated the feedback regardless of it being positive or identifying areas for improvement. As one respondent noted "... it was good to be told what I was doing wrong or right". Other comments from respondents indicated a respect for their employer, as another respondent noted, "he was calm and fair" and "he's straight up". Few negative comments relating to employer feedback emerged, although one respondent did comment that "I helped to do everything and in return got nothing".

These findings show that feedback from the employer regarding performance is an important factor in the employment relationship, and especially so to young people who lack skills and confidence. Employers should be more aware of the importance of providing feedback.

When asked which aspects of their job they enjoyed most, many identified the opportunity to interact with new people, either customers or co-workers. Some commented that they enjoyed working with their clients (mainly young children or the elderly) and others referred more specifically to colleagues and working as part of a team with responses such as, "love the people I work with and the customers". The next most frequent positive aspect of employment was the pay, as one respondent commented, "the income compared to the benefit", followed by general comments about the work environment such as, "enjoyed myself a lot" and "it was a good fun 
environment to work in". Gaining new skills and experience came through in the comments, although not strongly, comments from respondents were "learning how to work, managing time", and "that it gave me experience in the industry". A minor theme emerged of the benefits of work in providing exercise and the opportunity to be active. A sense of purpose and feeling of being needed was another minor theme, and the last positive theme identified was in regard to flexible hours of work.

These findings show that young people are generally positive and happy in their employment. This is contrary to the perspective seen in the business stakeholder interview that young people are not interested in working and are too selective about the type of work they are willing to do. These young people seem to enjoy working with others, appreciate and accept feedback on their performance and are grateful for their pay. It would be useful for business stakeholders to be informed of the positive attitudes young people display towards employment.

When asked which aspects of their job they did not enjoy, fewer comments were provided. The greatest number of negative comments fell into the area of work tasks such as "I don't like how unsafe it is" and "Work in all weather (even thunderstorms)". Another significant area was in regard to negative views of co-workers, customers or employers, with respondents providing comments such as "Older staff...differences in opinions" and "Rude customers". Stronger comments were provided in regard to employers such as "...manager is unfair, treated badly by him..." and "unfriendly boss, felt unappreciated and overworked". Hours of work also appeared as a negative work issue, in particular, not enough hours, and frustration with the casual or anti-social nature of hours of work. More minor issues emerged of difficulties with transport to and from work, lack of training opportunities and low rates of pay.

These comments are concerning, especially those who highlighted concerns with the safety of their working conditions. Detailed data was not collected on this issue, however literature shows that younger employees in particular are at risk of injuries and exploitation as a result of unsafe working conditions and a lack of training and supervision in safety and health (Caritas, 2003; Department of Labour, 2010). This suggests that young people could be made more aware of the health and safety 
responsibilities of employers and the rights of employees, with the hope that this would increase assertiveness in raising these issues with their employer.

When respondents were asked about expectations for their future most were positive about their future employment prospects $(71 \%), 24 \%$ of respondents gave neutral responses, with only $4 \%$ of respondents feeling negatively about their future employment. Analysis of hours worked showed a significant result (Table 4.2,15), and this indicates that the full time respondents are more strongly positive regarding their future employment prospects.

In terms of expectations for their future incomes, most respondents reported positive responses (63\%) and neutral responses were $30 \%$ with only $6 \%$ who felt negatively about their future income. Analysis on the basis of hours shows a significant result (Table $4.2,16$ ) indicating that those working full time hours are more likely to be positive about their future income prospects than part time employees.

Responses for expectations about future education prospects were mostly positive $(65 \%)$ and neutral responses were $29 \%$ with only $5 \%$ who felt negatively about their future education.

The literature found that even in the face of a tight labour market and difficulties finding and retaining employment, there was strong evidence of resilience among youth sampled. Displaying optimism and adaptability was a key finding (Hodkinson, 1996), as well as a strong commitment to their own training and development (Higgens, 2002). This research confirmed this finding, with the survey sample reporting very positive feelings about their future. Strikingly, even when employment experiences had not been favourable in terms of casual arrangements, low rates of pay and low level tasks, or education experiences had not been highly successful in terms of qualifications gained, respondents still reported positive expectations about their future employment, education and income prospects. The respondents also strongly reported positive feelings about their work, mainly in regard to the people (customer and co-worker) contact they had, and this factor came through as more important than the rate of pay and other terms. This finding is in contrast to the business stakeholder view that young people today have higher expectations than 
previous generations in regard to material wealth, with a much stronger drive for money and a perception of their own value, which is not in keeping with the market. The sample group came across as showing a high level of enjoyment in their jobs and a strong appreciation for any feedback about their performance from their employer. Although there was frustration evident in responses with casual and antisocial of hours of work, this was overshadowed by the expressions of respect and gratefulness they showed for employment opportunities. This is a positive and resilient group of young people, even faced with a difficult labour market for entry opportunities into employment.

In summary, respondents had positive feelings in regard to their work experiences. Feedback received from employers was perceived to be fair and was appreciated, even when it was negative. Respondents shared many positive and respectful comments about their employers, overall the respondents enjoyed their work experiences and the social contacts employment provided were more important than other factors, including pay. Fewer respondents provided negative comments about their employment, and these negative aspects tended to be task related and reflected frustration with colleagues and customers. Expectations for the future in regard to employment, income and education were very positive and young people showed resilience and optimism in the face of a challenging labour market.

\subsection{Skills Gap}

As commented by all stakeholders, young people entering the workforce are perceived to lack the necessary skills to enable them to work effectively immediately, as a result employers perceive them to be a risk and time consuming in terms of training and managing performance issues.

The careers advisor stakeholder observed that the biggest challenge faced by young people in seeking employment was a lack of confidence; those who are confident enough to approach employers in person are seen to be more successful than those who lack confidence and apply for jobs on line or in writing. This lack of confidence also limits the area where employment is sought, with many young people limiting 
themselves to their home geographical area as they are wary of using public transport to travel into larger centres, as commented:

There's a hard core of young people who are street rats, you know going into town and they know Wellington city quite well, and there are others who have never even caught the train to Wellington and I will talk about employment and they say "oh I am not catching the train into town, I'm not going to work in Wellington, I couldn't catch the train with all those people".

This stakeholder identifies a need for extra support and training for young people in "soft skills" to improve confidence and employability. In particular there was a need identified for training in interview preparation, personal grooming, time management, expectations about attendance at work as commented:

I would like to see schools prepare them better so they can feel confidence when they leave school that they know all the little things that come after a year so they won't trip up quite so often -- They need to learn what real jobs involve and that if you are the carpenter you are going to be sweeping the floor and making cups of tea. They have unrealistic expectations and think they are going to be CE on the second day.

The union stakeholder comments supported this view with the idea that school career support needs to be more comprehensive in order to fill soft skill gaps, as commented:

If there was a system which identified the gaps in terms of soft skills particularly for young people then I think employers would have a bit more confidence knowing that they have a work ethic and understand work and their responsibilities.

Along similar lines were comments from the youth transition stakeholder that those things an employer takes for granted, such as organisation skills, time management and politeness, are not there anymore. Young people lack awareness of how to behave in a particular situation, such as a job interview or in a workplace.

Stakeholders identified a gap in support and training for young people to improve their confidence and employability. The provision of work readiness education in schools or by youth transition agencies would generate significant benefits. 


\subsection{Initiatives}

There are a range of different initiatives designed to alleviate a high level of youth unemployment. The need for increased expenditure on youth labour market programmes was signaled by the OECD (2010) to prevent large numbers of young people remaining unemployed or not in training. The introduction of trial periods in New Zealand was just one option to create more employment opportunities for young people, however, there are other examples of youth programme initiatives which have more widespread positive effects.

Within New Zealand the Mayors' Taskforce for Jobs was established in 2000 as a nationwide network of Mayors focusing on youth employment and engagement in local communities. A stakeholder interviewed as part of this research was involved in this initiative and described its success within a particular region. In this region the community has taken on the role of supporting young people into work, mediating issues as they arise, keeping their work related training on track and resolving issues between the employer and employee. By doing this, the community has taken the risk out of employing young people for employers, as the stakeholder commented:

So if something happens the employer doesn't have to grizzle to the wife or go to the pub and tell his mates and just get so angry they eventually fire them, but to tell -- (the community support person).

The driving principle behind this approach is that an aging workforce, a smaller demographic group of young people coming in behind the current working generation, combined with smaller families and increased migration in search of job opportunities, means that action needs to be taken to future proof the community workforce, and as the stakeholder explained:

We are just really encouraging employers to get more creative more urgently around re-engaging with young people and schools to start investing in their next generation of employees, because they won't be there when the job vacancies come up in the future, and we won't have the luxury of lots of young unemployed for much longer. Longer term we have got to be much more mature around re-investing in after school jobs and Gateway placements and re-looking at teen mums and minorities and people with disabilities as future employees. 
This community initiative has been very successful with very small numbers of unemployed youth in the area. Through this supported employment approach the introduction of trial periods has been largely redundant for the area, as explained by the stakeholder:

We found that the 90 day period for us is not being widely used at all and I guess ... we've been doing this for eight years now, long before the 90 day trial period came in so... it wasn't seen as adding anything to what we're doing.

Union stakeholders were opposed to the introduction of trial periods, seeing a bigger issue to be addressed in terms of job creation across the board as beneficial for young people and all other groups in the labour market. They also identified young people's skills as a major issue, with the comment that employers expect a lot of young people when they are new to the workplace. The role of government and employers in closing those skills gaps was the issue to be addressed, as the union stakeholder commented:

There is a lot the state can do to fill skills gaps and get young people to a point where they have a work ethic and work skills, but employers need to play a role too. Employers have an obligation to play a role in building up young people, work to develop them more and realise they will not be perfect employees straight away - but for the future labour market it is best to put time and resource into them.

The union stakeholder also commented that more comprehensive career advice should be available for young people to provide them with more career direction and support through the transition from education to employment and to establish "soft skills" to provide a more work ready employee that an employer can have increased confidence in.

The youth transition stakeholder expressed frustration with the lack of local initiatives to address youth unemployment. It was felt that the City Council should be taking a stronger leadership role, such as developing employment schemes and incentivising the employment of young people. This stakeholder identified a strong need for pastoral care of young people as they entered employment as a way of communicating realistic expectations to the employer in regard to skills and abilities of the young person, and the need to allow for mistakes and provide second chances 
where possible. The stakeholder felt these were more effective initiatives than trial periods, and would also welcome large employers in the area taking a more strategic view of workforce planning by taking on young people for short term work experience or for training opportunities. There was frustration that local large employers, most noticeably in infrastructure industries, were not future proofing their workforce and had not forecast skills shortages. This needed to be addressed and young people would welcome the opportunity. If provided with tailored or supported employment, young people would become skilled employees. It was suggested that large employers should have a youth employment goal in their strategic plans and to work towards achieving that goal over a number of years. Without more proactive initiatives young people with high potential will be lost to Australia, contributing to a looming skill shortage in New Zealand.

The business stakeholder also expressed frustration that there is a lack of a coherent government strategy to train and support young people into employment, as a result there is great variety in the efforts being made in this area. Ideally business should group together and catalyse across sectors to encourage action around this issue. Stronger connections between business and education could help to expose young people to different vocations and show them practical uses for the skills they are learning at school, therefore making learning more meaningful to them. Identifying each child's strengths and channeling these towards further education and employment would be ideal, and would make the education system more relevant to business. Re-energising the willingness of business to invest in apprenticeships and other training programmes would work to manage future skill shortages for New Zealand.

Of all stakeholders interviewed none felt that trial periods had made a significant difference to the employment opportunities for young people. There was a feeling that although trial periods were not being misused, it was unlikely they were providing many employment opportunities for young people. Instead, common themes were identified of young people needing more career advice at an early stage, that there was a strong need for support in gaining employment and in the early stages of employment, that business needed to forecast future skills shortages, 
and with a coherent government strategy for youth employment these issues could be addressed.

\subsection{Summary of Chapter}

This Chapter presented the findings of the research, initially through descriptive analysis of the variables included in the dataset, followed by testing to determine the significance between variables and informed by qualitative data gathered from stakeholder interviews. Trial periods were not widely used, but where they existed there was a formal approach to employment arrangements from both employers and employees. Respondents were found to be remaining in education longer, presumably as labour market conditions are currently not favorable. When in employment, trends are for longer periods of employment, low frequency in employment changes and employment largely within the retail and hospitality sectors. Improved terms of employment for respondents were found to be linked to higher qualification levels, increased age and working full time rather than part time. The work performance of respondents was not managed formally by employers and showed variable standards. Employment termination was experienced frequently by respondents, and this was largely due to a lack of work rather than performance problems. Overall respondents felt their employment experiences were positive, and they demonstrated resilience and optimism in regard to their future prospects. 


\section{Chapter 5: Analysis and Conclusions}

\subsection{Usage and experience of trial periods}

Trial periods were introduced in New Zealand with the objective of creating workforce flexibility for employers, and creating employment opportunities for vulnerable groups such as young people. This was intended as a relaxation of employment protection legislation (EPL) to provide employers with increased workforce flexibility (Skedinger, 2010) and to reduce duality in the labour market by giving vulnerable groups more opportunities to enter the workforce. This flexicurity approach to the labour market can strike a balance between employee security and business flexibility in a non-competing way (Wilthagen, 2004).

Empirical evidence of the effect of increased EPL shows a resulting reduction in employment flows and a reduction in the establishment of new businesses (Autor, 2007), and increases duality in the labour market, making a rigid labour market where it is difficult for vulnerable groups to gain employment (Cazes, 2003; Skedinger, 2010). Therefore the removal of EPL should have the reverse effect of increasing employment flows, increasing new businesses and increasing employment for vulnerable groups. Funk (2003) proposes the creation of many new jobs as a result of lifting employment protections for small employers, and Bentolila (2012) outlined the loosening of employment protection legislation in an effort to lift employment rates. However a caution exists of removing too much EPL, with a negative effect on vulnerable groups through the increased use of unpredictable and antisocial hours, combined with low rates of pay (Masterman-Smith, 2007).

Compared to other OECD countries New Zealand has relatively loose EPL (Appendix A), however the effect of further loosening dismissal laws for 90 day trial periods was expected to deliver results of higher employment rates for those groups with a weak connection with the labour market. Young people made up a large part of this group and were expected to have increased employment opportunities as a result. 
However this research has shown that the usage of trial periods is not widespread for 15 to 19 year olds, with the exception of high rates of usage for 18 to 19 year old males within the construction industry in particular.

It appears that loosening of EPL has had some success in terms of usage, and it is probable that this was due to the combination of trial periods and an increase in demand for construction employees at the same time. For other industries there has been no apparent effect and it seems that loosening of EPL has the most effect where it can leverage from other positive employment trends and is not a powerful intervention on its own.

The effects of EPL can be made more or less effective with the concurrent use of active labour market policies (OECD, 2004). Active labour market policies (ALMP) facilitate the transition from unemployment to employment through the use of a range of interventions such as job search assistance, vocational training, job creation schemes, employment subsidies and job placement schemes. These policies are designed to improve the employability of those who have a weak link to the labour market. It is proposed (Bentolila, 2012) that EPL and ALMP work in tandem, and a weakness in ALMP can render loosening ELP futile.

A combination of EPL and ALMP are used in New Zealand, with 90 day trial periods introduced to increase business flexibility and the employment of vulnerable groups, and ALMP used to aid the transition of young people from school into employment or further education. It was therefore expected that trial periods and ALMPs would combine to create increased employment opportunities for young people however this research shows that for 15 to 19 year olds this has not occurred. Qualitative evidence from stakeholder interviews exposes gaps in education to employment transition support for young people, resulting in school leavers ill-equipped for employment. This weakness in young people's transition support and workreadiness means that trial periods have not been fully utilised by employers as they still see young people as a risky employment option.

Despite the low usage of trial periods, this research shows that when they were, employers utilized fair processes with written employment agreements, signing of 
agreements and an explanation of the terms of employment. This differs to the low rates of written agreements and signing of agreements seen in the literature (Gasson, 2003) and expected by the CTU (Rosenberg, 2010). Using mostly fair employment processes cannot be solely attributed to trial periods though, as they could be a factor of being employed by a well resourced larger organisation with established employment processes and adequate human resources to ensure legal obligations are met.

An exception to the fair processes used by employers was the lack of opportunity to negotiate the inclusion of a trial period in the employment agreement, as well as the lack of opportunity to negotiate on any other employment terms, and this was anticipated by the CTU (Rosenberg, 2010). The CTU also anticipated that large numbers of employees on trial periods would have their employment terminated, as employers would prefer this to using good employment practices (Rosenberg, 2010). However there was no significant link found at any level of analysis between a respondent being on a trial period and having an increased likelihood of having employment terminated.

There was a lack of awareness of the purpose and requirements of trial periods among the respondents, as seen throughout the literature (Anderson, 2010; Caritas, 2003; Department of Labour, 2010a; Gasson, 2003), and therefore a need for more employment related education to be provided to young people before they enter into employment agreements.

It was seen that trial periods are not being used to benefit young people as employment opportunities are reduced overall, employers see young people as low skilled, untested and time consuming in terms of training and resolving performance issues that may arise and young people are predominantly employed on a part time and casual basis. These were seen as significant barriers that could only be resolved by more active labour market policies to increase the skills and knowledge of these vulnerable employees. While loosening EPL should theoretically result in job creation it has not been proven by this research. 


\subsection{Young people's early labour market experiences}

In New Zealand youth aged 15 to 19 years in New Zealand fare worse than their counterparts in other OECD countries in terms of unemployment rates, they tend to leave school at an earlier age, make a relatively poor transition into employment (Boven, 2011) and have an increased vulnerability in the labour force (OECD, 2010). They are over represented in areas which are low skilled such as sales, service and retail; these are easy occupations to gain entry to as there are generally no educational qualifications or technical skills required, and jobs are often part time or casual which allows work and ongoing education to be balanced. Youth are more likely to work on a part time or casual basis to enable ongoing education (Department of Labour, 2009) and this creates more vulnerability especially in a recession. Youth are also more likely to move overseas in pursuit of employment opportunities, with the number of 15 to 19 year olds recorded as permanent and long-term migrants to Australia in particular steadily increasing each year (Statistics New Zealand, 2013).

The transition from school into the labour market is a challenging time for youth, and is a key step in ensuring positive employment outcomes. Young people in New Zealand make a poor transition compared to their overseas peers (Boven, 2011) in the face of more complex and individualistic pathways than seen in the past (Dupuis, 2006; Fenton, 2006; Higgens, 2002; Zhou, 2009). Qualitative data gathered in this research confirms this with stakeholders in agreement that comprehensive transition support within schools is vital, but lacks consistency in resourcing over New Zealand.

This research shows there are many opportunities to improve youth transitions from school to employment, in particular by increasing allocated resources both within schools and post-school, and improving links between schools and business with a view to producing more work ready young people. There are many young people who could benefit from early transition support before falling into patterns of long term unemployment, and youth transition support could be more effective if it was more widely available. 
The availability of part time employment is an important factor in the transition from education to employment as it can be effectively used as a stepping stone to full time employment as well as a means of increasing skills and confidence in young people (Marks, 2006; Rea, 2009; Topel, 1992). This research shows that part time work is being used in a positive way as a transition step to full time employment as seen in OECD 2010, and with other positive outcomes such as increased academic achievement (Meyer, 2009) and an improved transition from education to employment (Higgens, 2002). The trend for reduced part time employment in Lower Hutt and Porirua between 2006 and 2013 (Tables 3.1 \& 3.2) is therefore a significant disadvantage for young people in these areas. The reviewed literature consistently shows the advantages of early work experience for young people (Education and Employers Taskforce, 2012; Smith, 2004). Those young people with early work experience demonstrate high levels of responsibility, initiative and understanding of work expectations (Smith, 2011; Taylor, 2004). Therefore, increasing the number of part time employment opportunities for young people should be a priority at government or region/city level in order to avoid more long lasting negative employment effects such as long term unemployment and ongoing low skill-low pay employment.

This research shows that young people working full time hours experience a fairer employment process from their employers, with legal obligations regarding employment agreements being met, higher rewards and a comprehensive performance management and feedback process. This outcome is in line with Marks (2006) who outlined the higher rates of pay, levels of satisfaction and increase in responsibility associated with full time employment compared to part time.

Respondents working part time or casual hours (mostly younger employees) are not experiencing these basic processes, with lower rates of pay and less fairness in employment processes. So while part time and casual work can aid transition into employment, it can also take advantage of a vulnerable group of employees. There is a trade off though, as those in part time employment will face more positive future outcomes than those who are unemployed (Gregg, 2005). Beginning to increase the bargaining power and assertiveness of young people in employment could be 
achieved through an increased awareness of their employment, with particular regard for safety and health knowledge to be improved.

This research demonstrates that if employees are made aware of the performance standards they are required to meet, they are less likely to behave in a way that would warrant termination of their employment. Therefore feedback from the employer regarding performance is an important factor in the employment relationship, and especially so to young people who lack skills and confidence. Employers should be more aware of the importance of providing feedback.

As commented by all stakeholders, young people entering the workforce are perceived to lack the necessary skills to enable them to work effectively immediately, as a result employers perceive them to be a risk and time consuming in terms of training and managing performance issues (Rudiger, 2013). While young people may not be aware of this it does present strongly through this research as a lack of confidence and knowledge about employment rights and responsibilities. More comprehensive transition support would alleviate this, as would employers recognising there is a business case to invest in young people as they think more strategically about future workforce planning (Rudiger, 2012).

Common themes were identified of young people being vulnerable in part time and casual employment, needing more career advice at an early stage, requiring support in gaining and retaining employment and that business needs to forecast future skills shortages. With a comprehensive government or local government strategy for youth employment these issues could be addressed.

\subsection{Researching Young People}

This research identified the difficulties in researching young people effectively, and the need to employ an adaptive sampling strategy. The initial stage of data gathering relied on access to young people through organisations and agencies, and therefore depended on the organisations' gatekeeper (usually a teacher or youth worker) placing a high priority on survey completion and explaining the purpose of 
the research well enough to encourage responses. This approach was partially successful, however the negative aspects of this approach outlined in literature (Tisdall, 2009) were highlighted with poor response rates due to survey completion being fitted in amongst competing priorities and a lack of explanation of the research purpose. A change in approach was taken in order to generate a greater response, and using young people to gather survey data proved more successful, in line with evidence provided in Bennett (2003) and Jardine (2012) that this approach would be less threatening and less formal.

Additionally the targeted demographic of young people aged 15 to 19 years who were likely to have left school early, held low level qualifications and were accessing training or support in the Porirua or Hutt Valley area were a fragmented group who were not particularly interested, or able to participate in the survey due to low literacy levels. During data collection it was noticeable that survey participants needed reassurance on their understanding of the questions, showed difficulties in completing text responses, were slow to complete surveys, sought support from the researcher (when present) over correct spelling and showed very little awareness of their employment rights and relevant legislation. Literacy levels and confidence in written expression were seen to be a barrier to survey completion. These observations made during the data collection phase provide further evidence to support the view that young people would benefit from employers who can provide support, training and feedback to counter low literacy and confidence levels.

The views of those young people are important in understanding the issues they face, and further research into effective methods of capturing information from young people would be useful.

\subsection{Limitations}

As detailed in Chapter 3 of the thesis, it was difficult to achieve a large sample for the self administered survey. With only 100 completed surveys it was possible to draw conclusions, however a larger sample would have made these conclusions more robust. An alternative approach to surveying would have been a fully online 
option utilising social media and it is anticipated this approach would have generated a larger number of survey responses. However, this approach would have the effect of changing the group surveyed, and would have accessed those who are regular online users rather than the targeted population. The reason for this is that not all households in New Zealand have access to the internet, and a self selection bias may have occurred where those who choose to participate in the research would be different in systematic ways from those who do not choose to take part. In this case it may have meant that those responding to the survey were those who were confident using an online option, those who possessed higher levels of literacy, and had either a very positive or a very negative experience to report.

\subsection{Areas for Further Research}

This research has contributed to an increased understanding of youth experiences in the labour market and the use of trial periods. It also identifies gaps in our knowledge where further research is needed.

The employment of young people is at a very low level and the ongoing implications of periods of unemployment and a lack of work skills are significant for this demographic. Further research into successfully incentivising the employment and ongoing development of young people by both small and large employers would be an area worthy of further investigation, with national and international best practice being analysed, evaluated and trialed within New Zealand. The value of this research would be increased if it focused on areas of current and anticipated skills shortages within the New Zealand labour market.

Further research, with a larger sample, into the usage of trial periods for young people would be advantageous. A larger and more widespread sample for future research could provide more understanding of the how and where trial periods are used.

Research into the usage of trial periods for other vulnerable groups, such as those returning to the workforce after periods of unemployment, different ethnic groups and 
other vulnerable groups would be useful to assess if trial periods had delivered additional employment opportunities for them.

Throughout this research it became clear through observation, quantitative data and stakeholder views that young people have a low level of understanding of their employment terms and rights. Further research into effective methods of increasing young people's understanding of their rights in the employment relationship would be beneficial, including identifying the most effective channels and stages for this education to be carried out.

Young people's work ethic and confidence was identified as an important issue impacting on their work readiness. Commonly termed as "soft skills", these are behavioral competencies that complement technical skills required for any job. Further research into how to ready young people for the workplace by increasing their skills in communicating effectively with co-workers and customers, time management, presentation, confidence and practical skills such as negotiating public transport would be useful.

\subsection{Conclusions}

This research began as an investigation into young people's early work experiences, and the usage and experience of trial periods. In researching this issue it became apparent that although the approach of relaxing employment protection legislations to increase labour market flexibility and give employers less risky employment options via 90 day trial periods should increase employment, the opportunities they create for young people in particular are limited. Youth unemployment is a large and complex issue with systematic causes and a small legislative change of trial periods do not seem to have had enough impact to significantly increase employment opportunities for young people.

To improve employment opportunities for young people a more successful approach could be through an active labour market policy approach with the objective of 
facilitating the transition from school to employment to improve the employability of those who have a weak link to the labour market. A skill mismatch is evident between these young people and the needs of employers. Rightly or wrongly employers perceive employing a young person with few qualifications and little work experience as risky and time consuming in terms of training and managing performance issues. Correspondingly, potential employees lack confidence, exposure to a wide range of work and work skills, resulting in a situation where young people are employed on low hourly rates, performing low levels tasks in the workplace and being engaged on casual hours of work. This demonstrates a lack of value and could be improved by increasing potential employee's value through ensuring they are work ready and therefore a lower risk for employers. This could be achieved through reviewing and developing comprehensive career advice for schools and youth transition support for those moving from school to employment, as well as facilitating business, education and youth transition providers joint and government funded approaches to developing young people to up skill in order to future proof New Zealand's skill base.

Stakeholders agreed on many issues relating to the experiences of young people in employment in this research. These areas would ideally form the starting point of a comprehensive government strategy for youth employment with the buy in of these key stakeholders. 


\section{APPENDIX A: $\quad$ Strictness of Employment Protection Overall}

\begin{tabular}{|c|c|}
\hline Country & Score \\
\hline Australia & 1.38 \\
\hline Austria & 2.41 \\
\hline Belgium & 2.61 \\
\hline Canada & 1.02 \\
\hline Chile & 1.93 \\
\hline Czech Republic & 2.32 \\
\hline Denmark & 1.91 \\
\hline Finland & 2.29 \\
\hline France & 3 \\
\hline Germany & 2.63 \\
\hline Greece & 2.97 \\
\hline Hungary & 2.11 \\
\hline Iceland & 2.11 \\
\hline Ireland & 1.39 \\
\hline Israel & 1.88 \\
\hline Italy & 2.58 \\
\hline Japan & 1.73 \\
\hline Korea & 2.13 \\
\hline Luxembourg & 3.39 \\
\hline Mexico & 3.23 \\
\hline Netherlands & 2.23 \\
\hline New Zealand & 1.16 \\
\hline Norway & 2.65 \\
\hline Poland & 2.41 \\
\hline Portugal & 3.05 \\
\hline Slovak Republic & 2.13 \\
\hline Slovenia & 2.76 \\
\hline Spain & 3.11 \\
\hline Sweden & 2.06 \\
\hline Switzerland & 1.77 \\
\hline Turkey & 3.46 \\
\hline United Kingdom & 1.09 \\
\hline United States & 0.85 \\
\hline Brazil & 2.27 \\
\hline China & 2.8 \\
\hline Estonia & 2.39 \\
\hline India & 2.63 \\
\hline Indonesia & 3.02 \\
\hline Russian Federation & 1.8 \\
\hline South Africa & 1.35 \\
\hline OECD countries & 2.24 \\
\hline
\end{tabular}

Source: OECD.stat 2008 


\section{APPENDIX B: $\quad$ Self Administered Questionnaire}

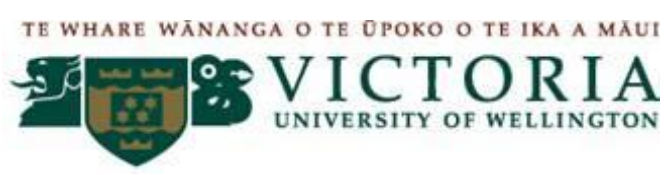

Thank you for choosing to participate in this research. The survey will take 10 to 15 minutes to finish and will be kept completely anonymous.

\section{Personal Characteristics}

1 What is your current status? (Tick those that apply to you)

$\begin{array}{ll}\square & \text { At school } \\ \square & \text { Employed } \\ \square \quad \text { Unemployed } \\ \square \quad \text { In a training course }\end{array}$

2 If you have left school when was your last year?

\section{4}

3 If you have left school what year were you in when you finished?

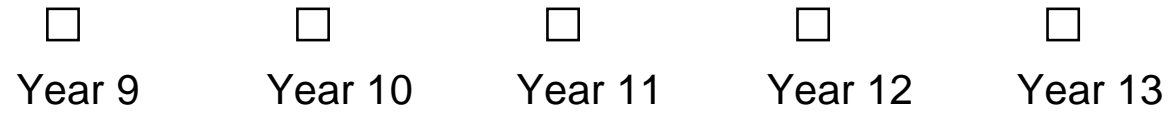

$4 \quad$ If you have left school, what was your main reason for leaving?

$\square \quad$ I wanted to get a job

$\square \quad$ To earn my own money

$\square \quad$ To do job training that was not available at school

$\square \quad$ I didn't like school

$\square \quad$ I was not doing very well at school

$\square \quad$ The school didn't offer the courses I wanted

$\square \quad$ Teachers thought I should 
Financial reasons

Other reasons (please give details) 
5 What is the highest qualification you have?

No qualification

NCEA Level 1

NCEA Level 2

NCEA Level 3

NCEA Level 4

Other (please

give details)

6 What age are you?

$\begin{array}{ccccc}\square & \square & \square & \square & \square \\ 15 & 16 & 17 & 18 & 19\end{array}$

$7 \quad$ Are you?
$\square$ Male
$\square$ Female

8 Which ethic group do you most identify with? Select one only.

$\begin{array}{ll}\square \text { NZ European } & \square \text { Maori } \\ \square \text { Samoan } & \square \text { Cook Island Maori } \\ \square \text { Tongan } & \square \text { Niuean } \\ \square \text { Chinese } & \square \text { Indian } \\ \square \text { Asian } & \square \text { Other (please } \\ & \text { specify) }\end{array}$

Employment History - for these questions please think about your current or most recent paid job

9 How long have you been in your current or most recent paid job? (years/months)

10 How many paid jobs have you held in total? (approximate number) 
11 Were you given a written employment agreement?

No

$\square$ Yes, was this? $\Rightarrow$ Before you started work

On the day you started work

After working for a while

12 Was there a union in this workplace?

$\square$ Don't know

No

Yes, were you a union member? $\Rightarrow \quad$ No

Yes

Don't know $\square$

13 What type of employment agreement did you have?

Collective (covering many people)

Individual

$\square$ Don't know

14 Did your employer explain or discuss the agreement with you?
Yes
No

15 Did you sign the employment agreement?

$\square$ Yes

$\square$ No

$\square$ Don't know

16 Did your employment agreement explain that you were on a trial period? 
Yes

No

Don't know

17 What do you think a trial period is? (Explain in your own words) 
18 Where did you find information on trial periods, or other terms of employment?
Family or friends
$\square$ Websites
From school
From other agencies (eg WINZ)
Other
I did not have any information

19 Were you able to negotiate any changes to the employment agreement?

No, it was a take it or leave it deal

No, I didn't need any changes made

Yes, what were the changes you negotiated?

20 Did you receive independent advice on your agreement?

Yes, who provided that?

No

21 What was your hourly rate in this job?

Less than $\$ 10.40$ /hour

$\square \quad$ Between $\$ 10.40$ and $\$ 13 /$ hour

Between $\$ 13$ and $\$ 15 /$ hour

Over $\$ 15 /$ hour

22 What type of industry was this job in? 
Manufacturing

Retail

Hospitality

Construction

Communications

Government or local government

Other, please give details

21 What kind of tasks did you perform in this job? Please list 3 typical tasks. (Eg stacking shelves, cleaning, serving customers)

23 Approximately how many people were employed in this organisation?
$\square \quad 1$ to 10
11 to 20
21 to 50
$\square 1$ to 100
101 to 200
200 to 500

$\square$ More than 500

24 What support did you have to find this job?

$\square$ WINZ $\quad \square$ Youth transition agency
$\square$ Family or friends $\square$ School
$\square$ Polytech $\quad \square$ Other training organisation
$\square$ None $\quad \square$ Other (please give details)

\section{Performance Management}

24 Was there any discussion or anything in writing about how and when your performance would be reviewed?

\section{Yes}


No

Don't know

24 What kind of training did you have in this job?

$\square$ No training $\quad \square \quad$ On the job training

Off the job training (course or classroom training)

$\square$ Other training (please give details) 
25 How often did you get feedback about how you were doing in the job?

$\square$ Never

Less than once a month

About once a month

2-3 times a month

Once a week

2-3 times a week

Daily

$\square$ Several times a day

26 If you were told you needed to improve what area was this in?

Technical skills

Timekeeping/attendance

Presentation

Work relationships (with other workers/ customers)

Other (please give details)

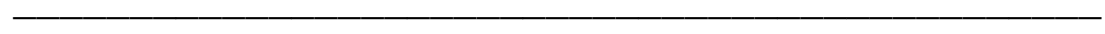

I was not told I needed to improve

27 If you were told you were doing something well what area was this in?

$\square$ Technical skills $\quad \square$ Timekeeping/attendance

$\square$ Presentation $\quad \square$ Work relationships (with other workers/ customers)

Other (please give details) 
$\square$ I was not told I was doing something well

28 How was feedback on your performance given to you?

$\square$ In writing $\quad \square$ Verbally

$\square$ Other (please give details)

No feedback was given 
29 How often did you tell your employer how you thought you were doing?

$\square$ Never

Less than once a month

Once a month

2-3 times a month

Once a week

2-3 times a week

Daily

$\square$ Several times a day

30 How fair do you think your employer's feedback on your work performance was?

Fair Why?

Unfair Why?

\section{Don't know}

No feedback was given

\section{Employment Outcomes}

31 In this job was your employment terminated by the employer? 
No

$\square$ Yes $\Longrightarrow$ Was this under the trial period law? $\square$ Yes

$\square$ No

$\square$ Don't know

32 If your employment was terminated under the trial period law, when did this happen?

Between 1 and 30 days after starting work

Between 31 and 60 days after starting work

Between 61 and 90 days after starting work

More than 90 days after starting work 
33 If your employment was terminated what was the reason for this?

Not enough work

Problems with your performance (please give details)

Other (please give details)

\section{Don't know}

Asked for a reason but was not told

33 If your employment was terminated how fair do you think this was?

Fair (please explain why)

Unfair (please explain why)

Don't know

34 If your employment was terminated, did you receive payment for?

Work you had done

A notice period

Holiday pay

$\square$ Not paid anything

Not sure

35 What did you like most about this job? 
36 What did you not like about this job? 
37 How do you feel about your future employment prospects?
Very positive
Quite positive
$\square$ Neutral
Quite negative $\square$ Very negative

38 How do you feel about your future income prospects?

$\square$ Very positive $\quad \square$ Quite positive $\quad \square$ Neutral
$\square$ Quite negative $\square$ Very negative

39 How do you feel about your future education prospects?
$\square$ Very positive
$\square$ Quite positive
$\square$ Neutral
$\square$ Quite negative $\square$ Very negative

Thank you for filling in this questionnaire. If you would like to add any other comments please do. Otherwise please put your completed questionnaire in the post box provided. If you have any questions about this survey please contact me at finlayanth@myvuw.ac.nz 


\section{APPENDIX C: $\quad$ Stakeholder Interview Questions}

1 What type of work does your organisation do?

2 What is the nature of your role within the organisation?

3 What do you think are the key challenges for youth aged 15 to 19 years in finding employment?

a) In the labour market?

b) In this geographical area in particular?

c) In terms of their skills and abilities?

$4 \quad$ What type of initiatives have you seen work well to help these young people get into work?

$5 \quad$ Are you familiar with the 90 day trial periods and how they work?

6 To what extent have you seen trial periods used in the employment of youth aged 15 to 19 years?

7 If yes,

a) What types of organisations typically use them?

b) Do the young people have knowledge of what this means?

c) Do the young people receive training and support during the trial period?

d) Are the young people generally kept on after the trial period?

8 If no, why do you think this is?

9 How do you think young people aged 15 to 19 years could be supported more? 
APPENDIX D: Analysis of Trial Period Regression Estimates

\begin{tabular}{|c|c|c|c|c|c|}
\hline & $\underline{\mathbf{r}}$ & Significant Variables & Significance & B (log odds ratio) & Exponent (anti log) \\
\hline Step A & 0.149 & Gender & 0.031 & -1.280 & -0.2780373 \\
\hline \multirow[t]{4}{*}{ Step B } & 0.149 & Age & 0.042 & 0.663 & 1.940605427 \\
\hline & & Gender & 0.027 & -1.723 & -0.178529754 \\
\hline & & Industry(construction) & 0.050 & 2.608 & 13.57187993 \\
\hline & & Organisation size & 0.052 & 0.005 & 1.005012521 \\
\hline \multirow[t]{4}{*}{ Step C } & 0.327 & Gender & 0.037 & -1.779 & -0.16880687 \\
\hline & & Industry(construction) & 0.024 & 3.765 & 43.16370586 \\
\hline & & Organisation size & 0.056 & 0.006 & 1.006018036 \\
\hline & & Performance standards & 0.045 & 1.819 & 6.165689676 \\
\hline \multirow[t]{4}{*}{ Step D } & 0.45 & Gender (male) & 0.007 & -3.836 & -0.021579748 \\
\hline & & Organisation size & 0.034 & 0.009 & 1.009040622 \\
\hline & & Hourly rate & 0.015 & 2.423 & 11.27964755 \\
\hline & & Hours & 0.011 & 3.221 & 25.05316082 \\
\hline \multirow[t]{4}{*}{ Step E } & 0.346 & Gender (male) & 0.006 & 2.656 & 14.23921816 \\
\hline & & Industry(construction) & 0.045 & 3.395 & 29.81465347 \\
\hline & & Organisation size & 0.030 & 0.007 & 1.007024557 \\
\hline & & Hours & 0.004 & 2.568 & 13.03971891 \\
\hline
\end{tabular}


APPENDIX E: Analysis of Employment Termination Regression Estimates

\begin{tabular}{|l|c|l|c|c|c|c|}
\hline & $\underline{\mathbf{r}}$ & Significant Variables & Significance & B (log odds ratio) & Exponent (anti log) \\
\hline Step A & 0.218 & Age & 0.044 & 0.455 & 1.576173383 \\
\hline & & Gender & 0.029 & 1.169 & 3.218772256 \\
\hline Step B & 0.27 & Gender & 0.028 & 1.349 & 3.853570033 \\
\hline Step C & 0.309 & Gender & 0.033 & 1.378 & 3.966959769 \\
\hline & & Industry(manufacturing) & 0.04 & 3.289 & 26.81603421 \\
\hline Step D & 0.32 & Gender & 0.022 & 1.57 & 4.806648194 \\
\hline & & Industry(manufacturing) & 0.049 & 3.321 & 27.68802474 \\
\hline Step E & 0.213 & Age & 0.023 & 0.507 & 1.660302808 \\
\hline & & Gender & 0.036 & 1.134 & 3.108063924 \\
\hline & & Industry(manufacturing) & 0.061 & 2.485 & 12.00112025 \\
\hline & & Performance standards & 0.043 & -1.598 & -0.202300715 \\
\hline
\end{tabular}




\section{REFERENCES:}

Akbar, P. (2008). Probationary periods: what's all the fuss? NZ Business, 22(9), 76. Retrieved June 17, 2013 from http://nz.vlex.com/vid/probationary-periodswhat-all-fuss-65446990

Anderson, D.M. (2010). Safe enough? The working experiences of New Zealand children. Unpublished doctoral dissertation, Auckland University of Technology, New Zealand.

Autor, D., Kerr, W., \& Kugler, A. (2007). Do employment protections reduce productivity? Evidence from U.S States. Centre for Economic Studies, Washington DC, CES 07-04.

Ball, S., Maguire, M., \& McRae, S. (2000). Choice, pathways and transition post-16: New Youth, New Economies in the Global City, London: Routledge.

Bazeley, P. (2004). Issues in mixing qualitative and quantitative approaches to research. In R. Buber, J. Gadner, \& L. Richards (Eds.), Applying qualitative methods to marketing management research (pp.141-156). United Kingdom: Palgrave Macmillan.

Belot, M. (2007). Why is employment protection stricter in Europe than in the United States? Economica, 74, 397-423.

Benhayoun, G. (1994). The impact of minimum wages of youth employment in France revisited. International Journal of Manpower, 15, 2-3.

Bennett, A., Cieslik, M., Miles, S. (Eds.). (2003). Researching youth. Houndsmills, Basingstoke, Hampshire: Palgrave MacMillan.

Bentolila, S., Dolado, J., Jimeno, J. (2012). Europe's Labour Markets and the Crisis. The New New Labour Market Reform in Spain: Objectives, Instruments and Shortcomings. Retrieved on July 4, 2013 from http://www.cesifogroup.de/ifoHome/publications/docbase/details.html?docld=18946366

Bertola, G. (2004). A pure theory of job security and labour income risk. CEPR Discussion Paper No. 3430. Retrieved June 17, 2013 from SSRN:http:/ssrn.com/abstract=323385

Blanchflower, D., \& Freeman, R. (2000, May). Youth employment and joblessness in advanced countries. National Bureau of Economic Research Inc, number blan00-1. NBER Books.

Bondi, L., Forbat, L., \& Gallagher, M. (2006). Evaluation of the youth counselling service, Airdrie Local Health Care Co-operative. Retrieved May 10, 2012 from www.geos.ed.ac.uk/homes/eab/youth/report. 
Botero, J., Djankov, S., La Porta, R., Lopez-de-Silanes, F., \& Shleifer, A. (2004). The regulation of labour. Quarterly Journal of Economics, 119(4): 1339-1382.

Boven, R., Harland, C., \& Grace, L. (2011). More ladders, fewer snakes: Two proposals to reduce youth disadvantage. The New Zealand Institute Discussion Paper 2011/1.

Boyd, S., Chalmers, A., \& Seiichi Kumekawa, E. (2001). Beyond school: Final year students experiences of the transition to tertiary study or employment. New Zealand Council for Educational Research.

Brugemann, B. (2007). Employment protection: Tough to scrap or tough to get. The Economic Journal 117 (521), 386-415.

Business NZ (2010). Setting NZ apart - getting more productive and competitive: A plan for action. Retrieved January 20, 2012 from http://www.businessnz.org.nz/file/1702/SETTING\%20NZ\%20APART.pdf.

Caritas. (2003). Protecting children at work: children's work survey 2003. Wellington: Caritas Aotearoa New Zealand.

Cavana, R., Delahaye, B., \& Sekaran U. (2001). Applied business research: Qualitative and quantitative methods. John Wiley \& Sons Ltd, Australia.

Cazes, S., \& Nesporova, A. (2003). Employment Protection Legislation (EPL) and its effects on labour market performance. Proceedings of the international labour office; High-Level Tripartite Conference on Social Dialogue, Malta, Valetta, 28 February -1 March 2003.

Commission of the European Communities (2007). Towards Common Principles of Flexicurity. European Commission, Brussels.

Creswell, J. (1994). Research design; Qualitative and Quantitative Approaches. London: Sage Publications.

Crowther, D., \& Lancaster, G. (2012). Research Methods. London: Routledge.

Deakin, D. (1996) The Youth Labour Market in Britain: The Role of Intervention. Cambridge: Cambridge University Press.

Department of Labour. (2008). Annual in-depth Regional Report (Wellington Region.) Wellington: Department of Labour.

Department of Labour. (2009). Youth in the New Zealand Labour Market: National Monitoring Series. Wellington: Department of Labour.

Department of Labour. (2010). Trial Employment Periods: An Evaluation of the First Year of Operation. Wellington: Department of Labour. 
Department of Labour. (2010a). School Children in Paid Employment: A Summary of Research Findings. Wellington: Department of Labour.

Department of Labour. (2012). Employers' Perspectives - Part One: Trial Periods. Wellington: Department of Labour.

Department of Labour. (2011). 90 day trial period - support and protections.

Retrieved May 8, 2012 from

http://www.dol.govt.nz/workplace/knowledgebase/item/1516.

Dribbusch, H. (2003). Study examines employment effects of statutory protection against dismissal. European Industrial Relations Observatory On-Line, ID: DE0304204F. Retrieved December 5, 2011.

Dupuis, A., \& McLaren, E. (2006). Non standard work and young(er) workers. Labour Market Dynamics Research Programme. Research Report No. $1 / 2006$.

Education and Employers Taskforce (2012). Work Experience: Impact and Delivery - Insights from the Evidence. A report written by Anthony Mann. London: EET.

Elder, V. (2011). 90-day employment rule 'double disadvantage' to youth. Retrieved May 27, 2011 from www.3news.co.nz/defaultStrip.aspx?tabid=213\&articlelD=166381.

European Foundation for the Improvement of Living and Working Conditions (2012). Flexicurity: actions at company level. Retrieved May 25, 2013 from www.eurofound,europe.eu.

Feilzer, M. Y. (2010). Doing mixed methods research pragmatically: Implications for the rediscovery of pragmatism as a research paradigm. Journal of Mixed Methods Research, 4:6-16.

Feldmann, H. (2007). Business regulation and labour market performance around the world. Published online: 27 October 2007. Springer Science+Business Media, LLC 2007. Retrieved April 11, 2011.

Fenton, S., \& Dermott, E. (2006). Fragmented careers? : Winners and losers in young adult labour markets. Work, Employment and Society 20(2): 205.,

Ferry, N. (2006). Factors influencing career choices of adolescents and young adults in rural Pennsylvania. Journal of Extension 44(3).

Folger, R., \& Greenberg, J. (1985). Procedural justice: An interpretive analysis of personnel systems. Research in personnel and human resource management 3: $141-183$. 
Fromm, A., \& Flynn, S. (2012). The youth labour market in New Zealand - A comparison to the pre-recession situation. Paper presented at Labour Employment and Work Conference 2012, Wellington, New Zealand.

Funk, L. (2003). Survey finds that statutory protection against dismissal hurts small firms. Retrieved July 4, 2013 from

http://www.eurofound.europa.eu/eiro/2003/06/feature/de0306108f.htm.

Funk, L. (2008). European Flexicurity Policies: A Critical Assessment. International Journal of Comparative Labour Law and Industrial Relations, Volume 24, Issue 3; 349.

Garibaldi, P., Pacelli, L., \& Borgarello, A. (2003). Employment protection legislation and the size of firms. Institute for the Study of Labour, Discussion Paper No.787, Italy.

Gasson, N.R., Linsell, C., Gasson, J., \& Mundy McPherson,S. (2003). Young people and work. Dunedin: University of Otago, College of Education.

Gregg, P., \& Tominey, E. (2005). The wage scar from male youth unemployment. Labour Economics 12:487-509

Harding, D. (2002). Effect of unfair dismissal laws on small and medium sized businesses. Australian Institute of Applied Economic and Social Research, Report No.2, Melbourne, Australia.

Haughton, G. (1990). Skills shortage and the demographic timebomb: Labour market segmentation and the geography of labour. The Royal Geographical Society,22(4), 339-345.

Hegan, S. (2006). The 90 day probationary period: rhetoric or reality? Otago Management Graduate Review, 4.

Higgens, J. (2002). Young people and transitions policies in NZ. Social Policy Journal of NZ: Issue 18.

Hodkinson, P. (1996) Triumphs and tears: Young people, markets and the transition from school to work. London: The Manchester Metropolitan University Education Series, David Fulton Publishers.

Holzer, H., \& LaLonde, R. (1994). Job change and job stability among less-skilled young workers. University of Wisconsin Institute for Research on Poverty; Discussion Papers 1191-99, Chicago, United States.

Hughes, A., \& Wix, O. (2009, November 26). The job tour: Paula Bennett's 'suck it up advice'. New Zealand Herald. Retrieved February 20, 2011 from www.nzherald.co.nz/employment/news/article.cfm?c_id=11\&objectid=106120 12 
Human Rights Commission. (2010). What next? National conversation about work. New Zealand Human Rights Commission.

Human Rights Commission (2011). Young people at work. New Zealand Human Rights Commission.

Irving, Z., Andre, B \& Lohmann, H. (2010). The working poor in Europe: Employment, poverty and globalisation. Journal of Social Policy 1(39), 170172.

Jackson, S. L. (2010). Research methods: A modular approach, Belmont: Wadsworth.

Jacob, B. (2010). The effect of employment protection on worker effort: Evidence from public schooling. National Bureau of Economic Research, Working Paper No. 15655, Michigan, United States.

Jardine, C. \& James, A. (2012). Youth researching youth: benefits, limitations and ethical considerations within a participatory research process. International Journal of Circumpolar Health, 71: 18415.

Johnson, A. (2012). The growing divide: $A$ state of the nation report from the Salvation Army 2012. Wellington: The Salvation Army Social Policy and Parliamentary Unit.

Kaye-Blake, B. (2011). 90-Day trial periods appear successful. NZ Institute of Economic Research Insight, 25. Wellington, New Zealand.

Kim, M. (1998, March). The working poor: Lousy jobs or lazy workers? Journal of Economic Issues 32, 65-78.

Kugler, A., \& Saint-Paul, G. (2000). Hiring and firing costs, adverse selection and long-term unemployment. Journal of Economic Literature, Discussion Paper No. 134.

Lazear, E. (1990, August). Job Security Provisions and Employment. The Quarterly Journal of Economics, 105(3), 699-726.

Leonardi, M. \& Pica, G. (2007). Employment Protection Legislation and Wages. European Central Bank, Working Paper Series, No. 778.

Loh, E.S. (1994a, April). Employment probation as a sorting mechanism. Industrial and Labour Relations Review 47(3).

Loh, E. S. (1994b, July). The Determinants of Employment Probation Lengths. Industrial Relations 33(3).

Lucas, R., Keegan, S. (2007). Young workers and the national minimum wage. Equal Opportunities International 26(6). 
McDonnell, L., Harris, A \& White, R. (1998). Multiple economies and youth livelihood. Australian Journal of Social Issues, 33 (1): 37-58.

McGrath-Champ, S. Rosewarne, S \& Rittau, Y. (2011). From one skill shortage to the next: The Australian construction industry and geographies of a global labour market. Australian Journal of Industrial Relations. Retrieved April 22, 2013 from http://jir.sagepub.com/content/53/4/467.

Maloney, T. (2004). The effects of in-school and in-tertiary employment on academic achievement and labour market transitions: Evidence from the Christchurch Health and Development Study. Wellington, New Zealand: Department of Labour.

Marks, G., \& McMillan, J. (2001). Early school leavers who are they, why do they leave, and what are the consequences? Paper presented at the 2001 Understanding Youth Pathways Conference, Melbourne, Victoria, Australia.

Marks, G. (2006). The transition to full-time work of young people who do not go to university. Australian Council for Educational Research, Research Report 49. Melbourne, Australia.

Masterman-Smith, H., \& Elton, J. (2007, 7-10 February). Cheap labour: The australian way. Diverging employment relations patterns in Australia and New Zealand? Proceedings of the $21^{\text {st }}$ Conference of AIRAANZ, Volume 1: Refereed Papers, Association of Industrial Relations Academics of Australia and New Zealand, Auckland, New Zealand.

Mertons, D.M. (2003). Mixed methods and the politics of human research: The transformative-emancipatory perspective. In A. Tashakkori \& C. Teddlie (Eds.), Handbook of mixed methods in social and behavioural research (135164). Thousand Oaks, CA: USA.

Meyer, L., McClure, J., Weir, K., Walkey, F \& McKenzie, L. (2009). Motivation and achievement at secondary school: The relationship between NCEA design and student motivation and achievement: $A$ three year followup summary report. Wellington: Jessie Hetherington Centre for Educational Research and the School of Psychology, Victoria University of Wellington.

Miller, S and Rosenbaum, J. (1997). Hiring in a Hobbesian world: Social infrastructure and employers' use of information. Work and Occupations, 24: 498-523.

Ministry of Education. (2008). State of education in New Zealand 2008. New Zealand: Ministry of Education.

Muravyev, A. (2010). Evolution of employment protection legislation in the USSR, CIS and Baltic States, 1985-2009. Institute for the Study of Labour, Discussion Paper No. 5365. St. Petersburgh, Russia. 
Murray, N. (2001). A history of apprenticeship in New Zealand. Unpublished Masters of Social Sciences thesis. Lincoln University, Canterbury, New Zealand.

Nagin, D., Rebitzer, J., Sanders, S., \& Taylor, L. (2002). Monitoring, motivation and management: The determinants of opportunistic behaviour in a field experiment. American Economic Review, American Economic Association, 92(4), 850-873.

Neihoff, B.P., \& Moorman, R.H. (1993). Justice as a mediator of the relationship between methods of monitoring and organisational citizenship behaviour. Academy of Management Journal, 36 (3), 527-556.

New Zealand Council of Trade Unions (2008). CTU Critique: National's Employment Policy. Retrieved June 15, 2012 from www.union.org.nz.

Ochel, W. (2009). New empirical findings on the labour market effects of employment protection. CESifo DICE Report 2/2009.

OECD (2004). Employment protection regulation and labour market performance. Retrieved June 15, 2012 from http://www.oecd.org/els/emp/34846856.pdf.

OECD (2008). Jobs for youth New Zealand. Retrieved June 15, 2012 from http://www.oecd.org/newzealand/jobsforyouthdesemploispourlesjeunesnewze aland.htm.

OECD (2010). Off to a good start? Jobs for youth. Retrieved June 15, 2012 from http://www.oecd.org/els/emp/46717876.

OECD (2013). Harmonised unemployment rates news release. Retrieved June 7, 2013 from http://www.oecd.org/std/labour-stats/HUR 04e13.pdf.

O'Leary, Z. (2010). The essential guide to doing your research project. London: Sage Publications.

Onwuegbuzie, A. (2006, September). Mixed methods data analysis procedures. The Qualitative Report 11(3), 474-498.

Patton, W. \& Smith, E. (2010). Part-time work of high school students: impact on employability, employment outcomes and career development. Australian Journal of Career Development. 19:1 pp. 54-62.

Quintini, G., \& Manfredi, T. (2009), Going separate ways? School-to-work transitions in the United States and Europe. OECD Social, Employment and Migration Working Papers, No. 90, OECD Publishing.

Rea, D., \&Callister, P. (2009). The changing nature of young peoples transitions in NZ. Institute of Policy Studies Working Paper 09/10, School of Government, Victoria University of Wellington, New Zealand. 
Richardson, S. (2009). What is a skill shortage? Australian Bulletin of Labour, 35(1), 326-354. Melbourne, Australia.

Riphahn, R., \& Thalmaier, A. (1999). Behavioural effects of probation periods: An analysis of worker absenteeism. Institute for the Study of Labour, Discussion Paper No. 67. Bonn, Germany.

Rosenberg, B. (2010). 90 day fire at will period - low road policy without evidence. New Zealand Council of Trade Unions. Retrieved February 10, 2012 from http://union.org.nz/policy/economicbulletin115.

Rudiger, K. (2012). The business case for employer investment in young people. Retrieved April 28, 2013 from www.cipd.co.uk/publicpolicy/learning-to work.aspx.

Rudiger, K. (2013). Employers are from Mars, young people are from Venus: Addressing the young people/jobs mismatch. Retrieved April 28, 2013 from www.cipd.co.uk/publicpolicy/learning-to-work.aspx.

Ryan, P. (2001). The school to work transition: a cross national perspective. Journal of Economic Literature, 39(1):34-92.

Scarpetta, S., Sonnet, A. \& Manfredi. T. (2010). Rising youth unemployment during the crisis: How to prevent negative long-term consequences on a generation? OECD Social, Employment and Migration Working Papers, No. 106, OECD Publishing.

Simmons, L. (2007). Research off limits and underground: Street corner methods for finding invisible students. The Urban Review, 39 (3).

Skedinger, P. (2010). Employment protection legislation: Evolution, effects, winners and losers. Research Institute of Industrial Economics, United Kingdom: Edward Elgar Publishing Limited.

Smith, E. \& Green, A. (2003). The development of employability skills in novice workers through employment. Adelaide: NCVER.

Smith, E. \& Green, A. (2005). How workplace experiences while at school affect career pathways. Adelaide: NCVER.

Smith, E. (2011). The changing nature of youth employment in Australia: How can this be understood? In Fashoyin, T. Tiraboschi, M. Manzella, P. \& Rustico, L. (eds). Productivity, Investment in Human Capital and the Challenge of Youth Employment. Newcastle-Upon-Tyne: Cambridge Scholars Publishing.

Snower, D. (1994). The Low-Skill, Bad-Job Trap. International Monetary Fund, Working Paper 94/83. Munich, Germany.

Statistics New Zealand. (2006). 2006 Census Porirua City. Retrieved August 11, 2012 from www.stats.census2006. govt.nz. 
Super, D.E., Savickas, M.L., \& Super, C.M. (1996). The life-span approach to careers. In D. Brown, L. Brooks, \& Associates (Eds.) Career choice and development (121-178). San Francisco: Jossey-Bass.

Tashakkori, A., \& Creswell, J. (2007). Exploring the nature of research questions in mixed methods research. Journal of Mixed Methods Research,1,207.

Taylor, A. (2004). Entering Industry: A Case Study of Links between a School Vocational Program and the Building and Construction Industry. Adelaide: NCVER.

Terrell, S. (2012). Mixed-methods research methodologies. The Qualitative Report, 17, 254-280.

Tisdall, E., Davis, J. \& Gallagher, M. (2009). Researching with children and young people: Research design, methods and analysis. London: SAGE Publications.

Topel, R \& Ward, M. (1992). Job mobility and the careers of young men. The Quarterly Journal of Economics,107(2).

Van Soest \& A. (1994). Youth minimum wage rates: The dutch experience. International Journal of Manpower, $15(2 / 3)$.

Vickerstaff, S. (2003). Apprenticeship in the "golden age": Were youth transitions really smooth and unproblematic back then? BSA Publications Ltd, 17(2), 269-287.

Walker, B., \& Hamilton, R. (2010). The 2010 review of the NZ personal grievance system: Commentary. New Zealand Journal of Employment Relations 34(3):83-91.

Watson, M. (2010). Concerns for skills shortages in the 21 st Century: A review into the construction industry, Australia. The Australian Journal of Construction Economics and Building, 7(1),45-54.

Wilthagen, T., \& Tros, F. (2004), The concept of "flexicurity": A new approach to regulating employment and labour markets, Transfer, 10(2),166-187.

Wyn, J., \& Dwyer, P. (1999). New directions in research on youth in transition. Journal of Youth Studies, 2(1):5-21.

Zhou, Y. (2009/2010). The trend toward non-regular employment among young workers, 1993-2003. The Japanese Economy,36(4), 105. 